\title{
Highways and Byways in the History of High Rate Mechanical Testing
}

\author{
Stephen M. Walley ${ }^{1}[$
}

Received: 18 December 2019 / Accepted: 5 February 2020 / Published online: 24 February 2020

(c) The Author(s) 2020

\begin{abstract}
Up until the Industrial Revolution, the dynamic mechanical properties of materials were only of importance in warfare, particularly after the powder-driven gun was invented. With the invention of the steam engine, the explosion of steam boilers (which is similar to the explosion of cannon) became a concern. When railways began to be built, the lack of knowledge of the dynamic properties of the iron alloys used in rails and railway bridges was understood to be a problem, but no way of measuring them was devised until the end of the nineteenth century. Ingenious mechanical (and later electromechanical) methods of recording signals onto rotating drums or moving smoked glass plates began to be developed from the middle of the nineteenth century onwards. Optical/photographic methods of recording information from dynamic experiments date from the 1890s. The rod-on-anvil technique (later named after Taylor) was developed in France at the beginning of the twentieth century but not mathematically analysed until the 1940s. The Hopkinson pressure bar was invented just before the start of the First World War and found to be useful in improving British artillery shells. It was then forgotten about until the Second World War when a two-bar version was developed for measuring the dynamic properties of soft materials such as explosives and polyethylene. As the story of high rate mechanical testing from about 1950 onwards is quite well known to the high rate testing community, this date is taken as the end point of this article.
\end{abstract}

Keywords Isaac Newton · Ballistics $\cdot$ Taylor impact $\cdot$ Hopkinson bar $\cdot$ Spall $\cdot$ Adiabatic shear band

\section{Note on Imperial Units of Measurement}

Some quotes in this article are taken from British and American sources where Imperial Units of length and weight were used. For those unfamiliar with these units, the (approximate) conversion factors to the metric system are as follows: 1 in. is $25 \mathrm{~mm}$; $1 \mathrm{ft}$. (=12 in.) is $305 \mathrm{~mm} ; 1 \mathrm{lb}$ (abbreviation lb.) is $0.45 \mathrm{~kg}$; 1 (British) ton (=2240 lbs) is $1008 \mathrm{~kg})$.

\section{Historical Introduction}

The following justification for studying the history of technical subjects was given by Pearson [1]:

[History] serves as a guide to the investigator in what has been done, and what ought to be done. In this latter respect the individualism of modern science has not

Stephen M. Walley

smw14ster@gmail.com

1 PCS Fracture and Shock Physics Group, The Cavendish Laboratory, J.J. Thomson Avenue, Cambridge CB3 0HE, UK infrequently led to a great waste of power; the same bit of work has been repeated in different countries at different times...

As it is, the would-be researcher either wastes much time in learning the history of his subject, or else works away regardless of earlier investigations. The latter course has been singularly prevalent with even some first-class British and French mathematicians.

But where to start the narrative? In many respects, this is both arbitrary and also dependent on the background and interests of the writer. But I choose to begin with the dramatic experiments performed on June 9, 1710 by Francis Hauksbee in St Paul's Cathedral, London, England [2]. The rebuilding of the cathedral had recently finished, the previous cathedral on the site having been destroyed in 1666 in the Great Fire of London. The experiments consisted in timing how long it took spheres of different densities to fall 220 London feet ${ }^{1}$ to the floor from a gallery high up in the dome.

Hauksbee reported:

\footnotetext{
$\overline{1}$ The foot had not yet been standardised.
} 
To make these Experiments accurately, I devised the following Apparatus, to account exactly for the time of the Bodies descending. At the Height from which the Balls were to be dropt, I fix'd a contrivance in form of a Trough, in all about 4 Feet long; and the end of it, on which the Balls were laid, was loose, swinging on 2 Pins at the extremity of it. This loose end was supported by a thin Piece of Board, which slid under it through a Groove from the other part of the Board: To this sliding Board was fix'd a String, which related to a small Wire that reach'd to the bottom of the Descent, where it (the Wire) had a Communication with a Contrivance, to give motion to a Pendulum which beat $\frac{1}{2}$ Seconds: Now when this sliding Board (just mention'd) was drawn from under that part of the Trough on which the Balls were placed, the String thereby became so much shorten'd, as to move the Limb of that Contrivance at bottom, which dropt the Pendulum at the same instant of time, as the Balls began to Descend.

The apparatus that Hauksbee had designed was intended to allow a comparison to be made of how much longer it took some relatively light spheres (air-filled glass globes) to fall compared to very dense spheres (glass globes filled with mercury, which was then known as quicksilver). As an aside, Hauksbee laconically commented on the aftermath of his experiments:

...that the Quicksilver Balls made no sensible Impression on the Floor on which they descended (which at that time was covered with Deal Boards) notwithstanding their Weight and Velocity of Descent.

He does not record how long it took to clean up the mercury and whether anyone on the floor of the cathedral was injured by flying shards of glass!

Hauksbee died in 1713 and was replaced as Demonstrator at the Royal Society of London (of which Isaac Newton was then President) by John T. Desaguliers, who almost 9 years later (on April 27, 1719), performed similar experiments from higher up (272 London feet) in the same building. ${ }^{2}$ The main difference was that Desaguliers compared the falltimes of $2 \mathrm{lb}$ lead weights ( $W$ in Fig. 1 ) and carefully made spherical air-filled hogs-bladders $(B$ in the same figure) [3]. Hogs-bladders were the eighteenth century equivalent

\footnotetext{
${ }^{2}$ The galleries that Hauksbee and Desaguliers used must have been what are now known as the Stone and Golden Galleries, although the ratio of their heights (1.75) do not correspond to the ratios of the heights given in their papers in 'London feet'. One possibility might be that in the 1719 experiments, since the Golden Gallery has the smallest diameter of the three galleries, the weights fell through a hole in the centre of the floor under the dome and down to the floor of the crypt.
}

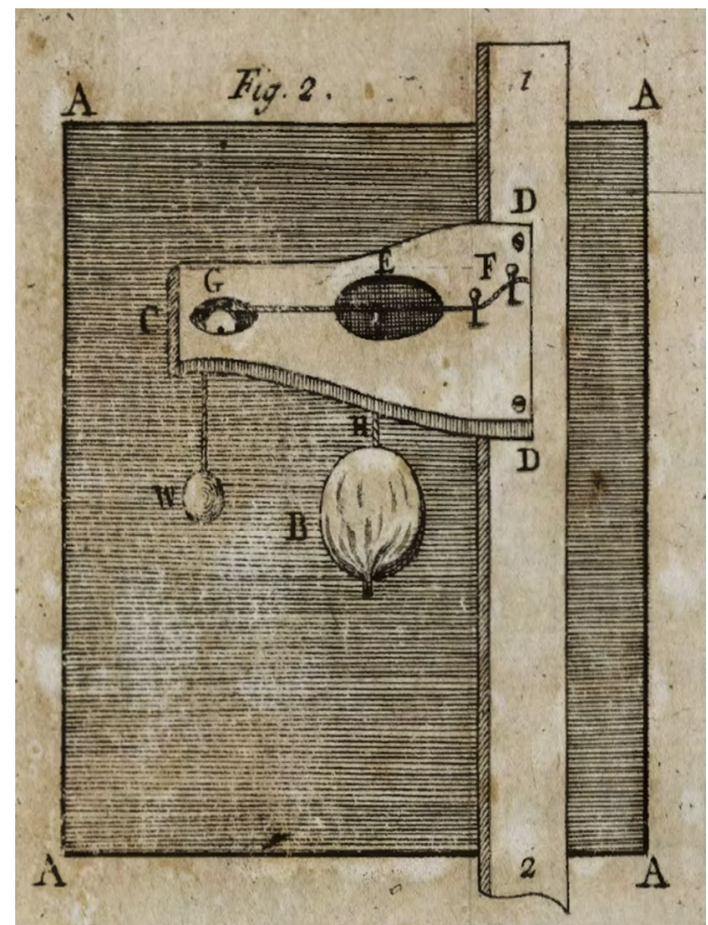

Fig. 1 Experimental arrangement used by Desaguliers in 1719 to ensure that the lead weight, W, began to fall at "exactly the same instant' as the hogs-bladder, B. From [3]

of party balloons. Desaguliers ensured that that the lead weight and the hogs-bladder began to fall at 'exactly the same instant' by using 'scissars' to simultaneously cut both strings that were holding them up (labelled as point $E$ in Fig. 1).

In 1726 in the third and final edition of his Principia, Isaac Newton both reported and analysed in more detail these men's experiments ([4], pp. 351-356, [5] pp. 504-509, [6], pp. 756-761). For example, he calculated that there was no measurable difference between the time Hauksbee's mercury-filled spheres took to fall the 220 London feet to the ground compared with if they had fallen in a vacuum (see also [7], p. 238). Loomis applied Newton's study to the resistance of the atmosphere to the fall of hail through it [8]. Loomis also refers to some similar experiments to Newton's performed in 1802 by Benzenberg in a church tower in Hamburg, but does not say where the results were published.

What was the point of Hauksbee's and Desaguliers' experiments? This was not stated in their papers, but Newton said they were testing Galileo's theory ([6], p. 756). But which theory? Newton did not say. However, in the middle of the nineteenth century, Brougham and Routh ([7], pp. 238-239) reckoned the theory they were testing was that the resistance of a material medium to a projectile moving through it should be proportional to the square of the projectile's velocity. 
Newton had an interest in this problem $[9,10]$. Indeed according to Smith [10], an appropriate title for Book 2 of Principia would be "The motion of bodies in resisting mediums". Smith states that Newton's physical reasoning led him to conclude that the resistance to motion $F_{\text {resist }}$ of a projectile moving through a fluid at velocity $v$ must be the sum of three components (see also [11]):

$F_{\text {resist }}=a+b v+c v^{2}$.

The first term, $a$, is a measure of the strength (tenacity) of the fluid and is independent of $v$. The second term arises from the viscosity (or lubricity), and hence is proportional to $v$. The third (quadratic) term arises from the inertia of the fluid so that the coefficient $c$ varies as $\rho_{\mathrm{m}} A$ where $\rho_{\mathrm{m}}$ is the density of the resisting medium and $A$ is the crosssectional area of the projectile perpendicular to the direction of travel. This then is the background to the spectacular experiments in St Paul's Cathedral as well as the less dramatic experiments that Newton himself conducted on the time taken for spheres of known weight to fall known distances through water ([6], pp. 747-756). Note that Newton was not restricted in his thinking to integer exponents of algebraic variables as the concept of fractional powers had been developed in the previous century [12] and Newton certainly knew about them [13]).

It may come as a surprise to many that Newton concerned himself in Principia with such lowly matters as bodies moving through fluids. For as Cohen and Smith commented in 2002 in the introduction to the Cambridge Companion to Newton ([14], pp. 17-18):

Less widely recognised is the fact that Newton was among the most skilful experimental scientists in history. This is less widely recognised not merely because we tend to celebrate theoreticians, and not experimenters, but also because such a large fraction of Newton's experimental effort is not widely known. His experiments in alchemy and chemistry have yet to be published, the experiments in the Principia are in the rarely read Book 2, and even the experiments that occupy much of the Opticks, which have indeed been widely heralded as examples of experimental science at its best, are rarely seen as the culminations of a much wider range of experiments that complement and support them.

The carefulness of Newton as an experimenter may be gauged from the following quote from what he wrote concerning the 1710 experiments in St Paul's Cathedral ([6], pp. 756-757):

However, the observed times need to be corrected. For balls filled with mercury will (by Galileo's theory) describe 257 London feet in 4 seconds, and 220 feet in only 3 seconds 42 thirds. The wooden platform, when the peg was withdrawn, swung downward more slowly than it should have [i.e. more slowly than in free fall] and as a result impeded the descent of the balls at the start. For the balls were lying upon the platform near its center, and were in fact a little closer to the pivots than to the peg. And hence the times of falling were prolonged by roughly 18 thirds and so need to be corrected by taking away those thirds, especially in the large balls, which because of the magnitude of their diameters remained a little longer upon the platform as it swung downward.

Brougham and Routh also commented on the carefulness of Newton's analysis of these experiments ([7], p. 238).

Montucla, writing later in the eighteenth century (1758), was in no doubt about the importance of Newton's contribution to the field of fluid resistance ([15], p. 432):

C'est à Newton \& Wallis qu'on doit les premieres recherches approfondies sur la résistance des milieux au mouvement. Newton publia le premier ses recherches sur ce sujet, dans ses Principes Mathématiques de la Philosophie Naturelle. Il y emploie presque tout le second Livre, \& il l'y traite avec cette profondeur qui caractérise tous ses écrits. L'ouvrage de Newton excita Wallis, qui avoit considéré de son côté le même sujet, à publier ses réfléxions. Il les communiqua à la Société Royale, \& elles furent inférées dans les Transactions de 1687. La matiere n'est pas autant approfondie dans cet écrit que dans les Principes. Wallis n'embrasse que l'hypothese la plus simple, sçavoir celle de la résistance en raison des vîtesses." ("It is to Newton \& Wallis that we owe the first extensive research into the resistance of media to movement. Newton published the first of his researches on this subject in his Mathematical Principles of Natural Philosophy. This topic takes up nearly all of the second book, and he treats the subject with the depth which characterises all his writings. Newton's work prompted Wallis, who had also made a study of the same subject, to publish his thoughts. He communicated them to the Royal Society, and they were published in the Transactions of 1687 [16]. The topic is not discussed in this paper in as much depth as it is in the Principles. Wallis only considered the simplest hypothesis concerning the resistance due to velocity.)

Note that John Wallis published his paper on air resistance in the January to March 1687 issue of the Philosophical Transactions, and the Principia was first published in July 1687 seeming to imply that Montucla had got his chronology wrong. But in Britain at that time, the first day of the year was March 25 rather than January 1. 1687 was also 
many years before Hauksbee and Desaguliers performed their experiments in St Paul's Cathedral which Newton discussed in the third edition of Principia, which was published in 1726. Montucla continued with a discussion of the studies of other authors' (Leibniz, Huygens, Bernoulli, Varignon) on the effect of air resistance on the motion of projectiles.

Wallis seems to have had the bullet problem in mind, as the introduction to his paper [16] makes clear (note that all but the last eight paragraphs of his paper are numbered):

1. That the Air (and the like of any other Medium) doth considerably give resistance to Bodies moved in it (and doth thereby abate their Celerity and Force:) is generally admitted. And Experience doth attest it: For otherwise, a Cannon Bullet projected Horizontally, should (supposing the Celerity and Force undiminished) strike as hard against a perpendicular Wall, erected at a great distance, as near at hand: which we find it doth not.

2. But at what Rate, or in what Proportion, such resistance is; and (consequently, at what Rate the Celerity and Force is continually diminished) seems not to have been so well examined. Whence it is, that the Motion of a Project (secluding this Consideration) is commonly reputed to describe a Parabolick Line; as arising from an Uniform or equal Celerity in the Line of Projection, and a Celerity uniformly accelerated in the Line of Descent: which two so compounded, do create a Parabola.

3. In order to the computation hereof; I first premise this Lemma (as the most rational that doth occur for my first footing,) that (supposing other things equal) the resistance is proportional to the Celerity. For in a double Celerity, there is to be removed (in the same time) twice as much Air (which is a double Impediment) in a treble, thrice as much; and so in other Proportions.

Although Wallis knew the calculus, he used algebraic geometry to perform his calculations.

Wallis ended his paper with some observations, a selection of which are given here with their original numbering:

46. I am aware of some Objections to be made, whether to some points of the Process, or to some of the Suppositions. But I saw not how to wave it, without making the Computation much more perplexed. And in a matter so nice, and which must depend upon Physical Observations, t'will be hard to attain such accuracy as not to stand in need of some allowances.

47. Somewhat might have been further added to direct the Experiments suggested at [paragraphs] 21 and 31. But that may be done at leisure, after deliberation had, which way to attempt the Experiment.

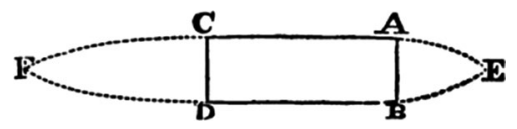

Fig. 2 Newton's method of modifying a cylinder (ABDC) in order to reduce its resistance to motion 'from $\mathrm{F}$ toward $\mathrm{E}$ ' through a fluid. From ([4], pp. 339-340) (see also [5], p. 491 and [6], p. 745)

48. The like is to be said of the different resistance which different Bodies may meet with in the same Medium, according to their different Gravities (extensively or intensively considered) and their different figures and Positions in Motion. Whereof we have hitherto taken no account; but supposed them, as to all these, to be alike and equal.

[Five paragraphs omitted]

As to the question proposed; whether the resistance of the Medium do not always take off such a proportional part of the force moving through it, as is the Specifick Gravity of the Medium to that of the Body moved in it: (for, if so, it will save us the trouble of Observation.)

I think this can by no means be admitted. For there be many other things of consideration herein, beside the Intensive Gravity (or, so some call it, the Specifick Gravity) of the Medium.

A viscous Medium shall more resist, than one more fluid, though of like Intensive Gravity.

And a sharp Arrow shall bore his way more easily through the Medium, than a blunt headed Bolt, though of equal weight, and like intensive Gravity.

And the same Pyramide with the Point, than with the Base forward.

And many other like varieties, intended in my [paragraph] 48.

But this I think may be admitted, namely, That different Mediums, equally liquid (and other circumstances alike,) do in such proportion resist, as is their Intensive Gravity. Because there is, in such Proportion, a heavier object to be removed, by the same Force. Which is one of the things to which [paragraph] 33 refers.

And again: The heavyer Project once in motion (being equally swift, and all other circumstances alike) moves through the same Medium in such proportion more strongly, as is its Intensive Gravity. For now the Force is in such proportion greater, for the removal of the same resistance. And this part of what my [paragraph] 32 insinuates. 


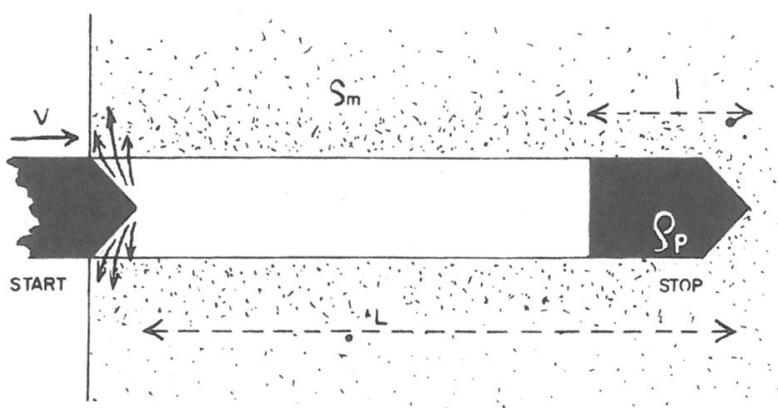

Fig. 3 Schematic diagram by Gamow of Newton's theory of resistance of fluids to projectile motion applied to a solid medium (terminal ballistics). From [28]

But where there is a complication of these considerations one with another, and with many other circumstances whereof each is severally to be considered: there must be respect had to all of them.

The problem that Isaac Newton was considering in his Principia was how far a projectile will travel through a medium that resists its motion and what shape it should be to minimise the resistance (Fig. 2) ([4], pp. 339-340, [5], p. 491, [6], p. 745) and $[17,18]$. The curious asymmetry between the front and back of the drawing presented in Fig. 2 suggests that Newton may have been thinking about ship design (which we know he had an interest in [19]) as much as bullets, although he states explicitly in the third edition of Principia that the object ABDC represented in Fig. 2 is a cylinder. It should be noted that all bullets in Newton's day were spheres ('bullet' is derived from the French word for little ball). It only became possible to manufacture the now-familiar pointed (ogive) projectile during the nineteenth century [20-22]. Whitworth originally developed cylindrical armour-piercing shells in the 1860s in response to the launching of iron-clad naval ships [23]. What we think of as the classic bullet shape (EBDCA in Fig. 2) was suggested in 1858 by Scoffern [24] and then again in 1865 by Holley [25] (p. 536) who acknowledged his debt to Newton. Holley pointed out, however, that Newton had drawn parabolas (EA and EB) rather than ogives, which are circular arcs with a radius of curvature greater than the diameter of the cylinder. The ogive was the shape finally settled upon in the nineteenth century both for shells and rifle bullets [26].

\section{Terminal Ballistics}

Figure 3 is a sketch made by George Gamow many years later (1962) illustrating Newton's analysis applied to the terminal ballistics of a capped projectile [27]. The idea that Gamow picked up from Newton is that the main energy loss

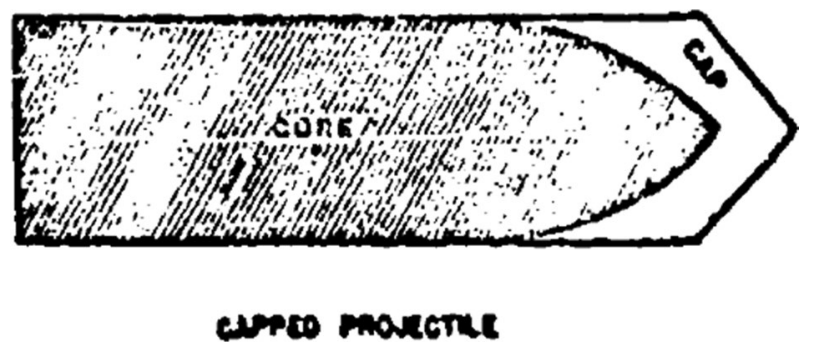

Fig. 4 Sketch by Curtis in 1946 of a capped projectile. Note the similarity to Gamow's drawing of a projectile in Fig. 3. From [27]

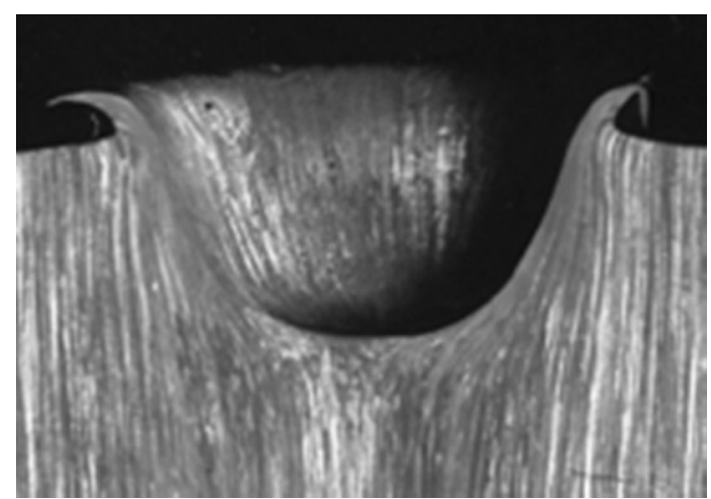

Fig. 5 Crater produced in aluminium by the impact of a $0.25 \mathrm{~g}$ polyethylene projectile travelling at $7 \mathrm{~km} / \mathrm{s}$. A magnification factor of $\times$ 1.4 was given in the original print rather than a scale bar. From [33]. See also [34]

comes arises from pushing the medium aside at a velocity similar to that of the projectile. On this analysis, the projectile will come to rest when it has displaced sideways a mass approximately equal to its own. Thus the ratio of the 'penetration depth' $L$ to the projectile's length $l$ is in inverse ratio to the densities of the medium $(\mathrm{m})$ and projectile $(\mathrm{p})$ i.e.

$\frac{L}{l}=\frac{\rho_{\mathrm{p}}}{\rho_{\mathrm{m}}}$.

One implication of Eq. (2) that Gamow highlighted is that above a "sufficiently high velocity", the penetration depth is independent of impact velocity (or equivalently the drop height for a bomb), something he said the US military found out empirically and which puzzled them until they were told of this analysis by Newton in Book 2 of Principia. Unfortunately Gamow did not give a source for this information and neither Saslow and Lu [17] nor Gaite [18] were able to find any such observations by the military. Since Gamow's drawing of a projectile bears a striking resemblance (see Fig. 4) of a capped projectile in Curtis's summary of American research on armour 


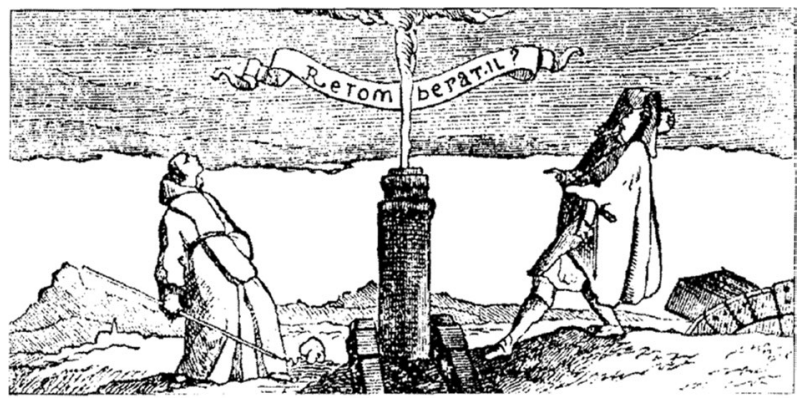

Fig. 6 Will it fall back down again? Drawing taken from the opening page of "Nouvelles Conjectures sur la Pesanteur" by Pierre Varignon, 1690 [41] in which he reported experiments by Mersenne and Petit that had been performed in the 1630s. See also [35]

penetration during World War 2 [27], it is likely that the studies Gamow was thinking of were performed during that conflict.

Gaite pointed out that Gamow did not provide a way of determining what is a "sufficiently high velocity". He derived a more complex formula for the depth of penetration involving a drag coefficient (related to the strength of the resisting medium) and a critical impact velocity. However, Gaite's assessment of Gamow was that: "Gamow's formula is, in fact, a sensible and quick rule for estimating the penetration depth of a fast projectile of generic shape." Note that Newton assumed the resistive medium is fluid. So his analysis is only applicable to hypervelocity impact (Fig. 5), something that was first achieved in the 1940s [29, 30] and which only became important with the launch of the first Earth-orbiting satellites [31, 32].

\section{Velocity Measurement}

The ability to measure the velocity of projectiles is essential if the velocity dependence of the resistance of materials to ballistic impact is to be determined. The most obvious and straightforward method of making this measurement is to fire a cannon upwards and determine how high the cannonball ascends. The first such experiments I know about were reported in 1690 by Pierre Varignon in his book Nouvelles Conjectures sur la Pesanteur (New Conjectures about Heaviness). Figure 6 is a drawing taken from the first page of Varignon's book. It shows two men (Mersenne and Petit) who have just fired a cannonball vertically into the air. The text in French above the gun says "Retombera-t-il?" (Will it fall back down again?). Mersenne and Petit performed these experiments in the 1630s [35]. It should be noted that as a priest in the Roman Catholic church, Mersenne's interest in this problem would probably have been with Aristotle's theory of projectile motion [36-38] and hence presumably with the first part of Thomas Aquinas' famous fivefold proof (based on Aristotle's thought) near the beginning of



Fig. 7 Diagram illustrating how Daniel Bernoulli thought about his internal ballistics calculation for a cannon. This is Fig. 64 from [46, 48]

his Summa Theologiae [39] (which Aquinas wrote in Latin between 1265 and 1274) for the existence of God as the unmoved-mover [38, 40]:

The first and most obvious way is based on change. We see things changing. Now anything changing is being changed by something else... Now we must stop somewhere, otherwise there will be no first cause of the change, and, as a result, no subsequent causes. (Only when acted upon by a first cause do intermediate causes produce a change; if a hand does not move the stick, the stick will not move anything else.) We arrive then at some first cause of change not itself being changed by anything, and this is what everybody understands by God.

There are two main problems with Mersenne's approach: (i) the large shot-to-shot variation in muzzle velocity and (ii) air resistance [42].

\section{Exterior Ballistics}

Concerning air resistance, despite Newton having shown that air resistance follows a $\nu^{2}$ law, people believed for many years afterwards that the resistance of the air to the motion of cannonballs was negligible. This belief started to change during the 1740s when Robins reported the first known measurements of air resistance to the motion of projectiles $[43,44]$. He did this by firing shot through a series of thin screens in order to determine the paths they followed. $\mathrm{He}$ found that the initial resistance of the air to a cannonball fired out of a gun was about 24 times the ball's weight.

In 1812, Simmons wrote the following ([45], pp. 90-91): "...when the resistance of the air is also considered, which is enormously great, and which very much impedes the projectile velocity, the path deviates greatly from the parabola, and the determination of the circumstances of its motion becomes one of the most complex and difficult problems in nature." He also refers (p. 91) to a calculation by Bernoulli that air resistance is sufficient to reduce the height to which a cannonball might ascend from $58,750 \mathrm{ft}$. $(17,920 \mathrm{~m})$ to 


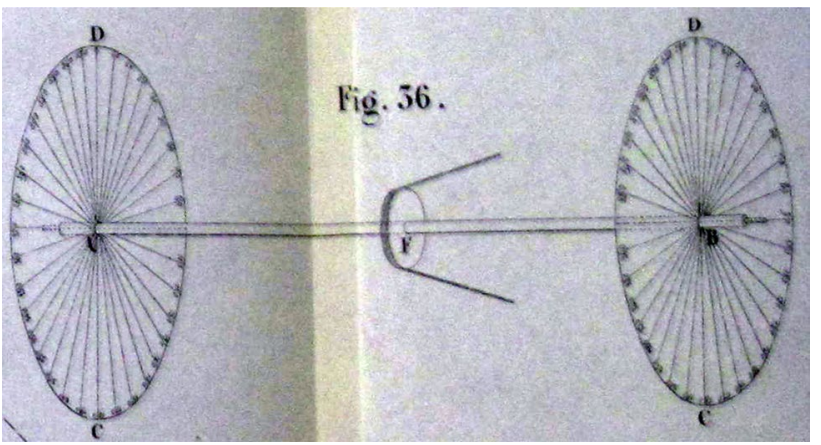

Fig. 8 Drawing of the late eighteenth/early nineteenth century spinning discs method of measuring projectile velocity directly. From [54]

7819 ft. $(2380 \mathrm{~m}){ }^{3}$ Simmons did not say where Bernoulli had published this comparison, but in fact Bernoulli originally published his experiments on cannons in 1729 in the Commentaries of the Academy of Sciences of St Petersburg [47]). Some years later (1738) Daniel Bernoulli presented a more detailed discussion of gunpowder and the internal ballistics of cannons (Fig. 7) in Chap. 10 of his Hydrodynamica [48] (for an English translation, see [49]). In this chapter, Bernoulli discussed a number of factors that will reduce the height of ascent from $58,750 \mathrm{ft}$. for a gun fired vertically in a vacuum. However, as far as I can see he did not record observations made for cannonballs that had actually been fired vertically up into the Earth's atmosphere.

A better, albeit indirect, method of estimating muzzle velocity was devised by Robins, namely the ballistic pendulum $[43,50,51]$. A direct method of measuring projectile velocity was developed in France around the beginning of the nineteenth century that involved firing a shot through two discs a known distance apart and that were also spinning at a known angular velocity on the same axis (Fig. 8) [23, 52-54].

A more accurate method of measuring the velocity of projectiles through the air was devised by Francis Bashforth in the 1860s (Fig. 9) [55-58] and this apparatus was used right up until the start of the twentieth century [59-61]. His aim was to develop a method to measure the velocity dependence of the resistance of the air to a fast moving projectile "without the slightest concern about the cost or weight of the instrument". His design criteria were (italics are original):

(i) The time to be measured by a clock going uniformly;

(ii) The instrument to be capable of measuring the times occupied by a cannon ball in passing over at least nine successive equal spaces;

\footnotetext{
${ }^{3}$ Note that the above conversion to metres assumed Bernoulli used the modern definition of the foot, but he was writing before the foot was standardised and sometimes used Paris feet ([46], p. 265) and sometimes English feet ([46], p. 267).
}

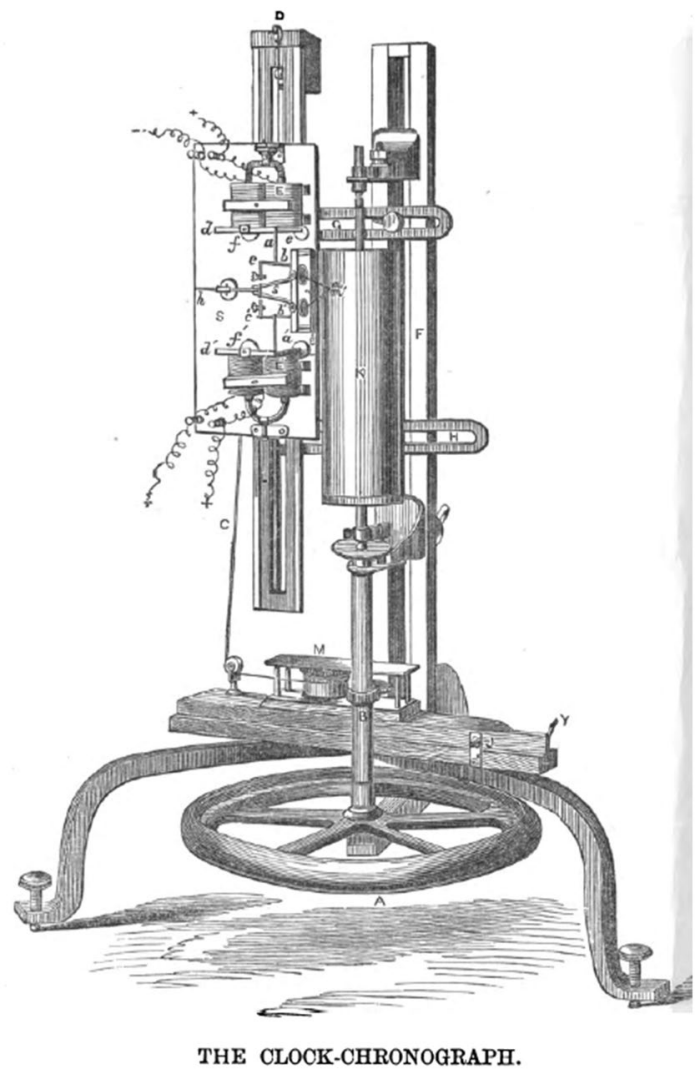

Fig. 9 Drawing of the Bashforth chronograph. From [55]

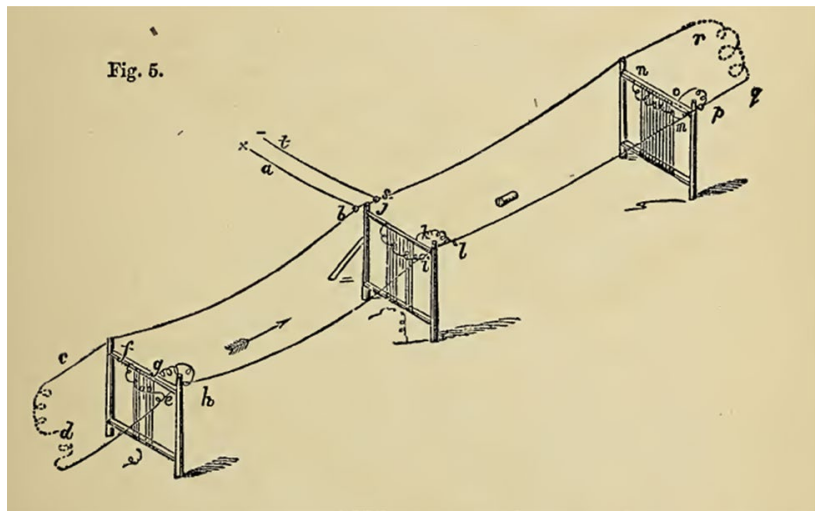

Fig. 10 Schematic diagram from an 1860s electrical method of determining the position (and hence the velocity) of a fast-moving projectile. Three out of the ten screens used are shown. From [55]

(iii) The instrument to be capable of measuring the longest known time of flight of a shot or shell;

(iv) Every beat of the clock to be recorded by the breaking of the same galvanic current, and under precisely the same conditions; 


\begin{tabular}{|c|c|c|c|c|}
\hline $\begin{array}{l}\text { Distance } \\
\text { from gun. } \\
\text { ft. }\end{array}$ & Screen. & $\begin{array}{c}\text { Average } \\
\text { Time. }\end{array}$ & $\Delta_{1}$ & $\Delta_{2}$ \\
\hline 120 & 1 & 0.00000 & & \\
\hline 240 & 2 & $\cdot 10489$ & $\begin{array}{r}+10489 \\
+70617\end{array}$ & +128 \\
\hline 360 & 3 & $\cdot 21106$ & +10617 & +122 \\
\hline 480 & 4 & $\cdot 31845$ & $\begin{array}{r}+10739 \\
+10860\end{array}$ & +121 \\
\hline 600 & $\tilde{5}$ & $\cdot 42705$ & +10860 & +119 \\
\hline 720 & 6 & $\cdot 53684$ & $\begin{array}{r}+10979 \\
+\end{array}$ & +117 \\
\hline 840 & 7 & $\cdot 64780$ & +11096 & +112 \\
\hline 960 & 8 & $\cdot 75988$ & +11208 & +113 \\
\hline 1080 & 9 & .87309 & +11321 & +201 \\
\hline 1200 & 10 & •98831 & & \\
\hline
\end{tabular}

Fig. 11 Times and errors (and errors in the errors) in the timings for a projectile passing through 10 screens shown schematically in Fig. 10. From [55]

(v) The time of passing each screen to be recorded by the momentary interruption of a second galvanic current, and under precisely the same conditions;

(vi) Provision to be made for keeping the strings or wires of the screens in a uniform state of tension, notwithstanding the force of the wind and the blast accompanying the ball.

The time the projectile reached a sequence of locations was determined electrically as shown schematically in Fig. 10. Figure 11 is an example of a table of timing data from Bashforth's first (1866) paper [55] for a projectile passing through 10 of the screens shown schematically in Fig. 10. Note (as discussed earlier) Bashforth is an example of a nineteenth century investigator who quotes his results to far more significant figures than can be justified by the accuracy of the technique he used.

From these results Bashforth was able to distinguish between the various formulas that had been previously proposed for the resistance $\rho$ of the air to projectile motion, namely:

Newton: $\rho=b v^{2}$,

Hutton: $\rho=a v+b v^{2}$,

Didion: $\rho=b v^{2}+c v^{3}$,

Mayevski: $\rho=b v^{2}+d v^{4}$,

where $a, b, c$, and $d$ are constants. The preface to and third chapter of his 1873 book [62] give an excellent historical survey of exterior ballistics research up to that date. In addition, his results showed that "the resistance of the air varied approximately as the cube of the velocity for the particular velocities obtained in these experiments" [58] (p. 43). He also compared some experiments on cylindrical projectiles that varied "in the forms of their heads" [58] (p. 30). He gave more details of these experiments in his Royal Society paper of 1868 [56] and his first book (published in 1870) [57].

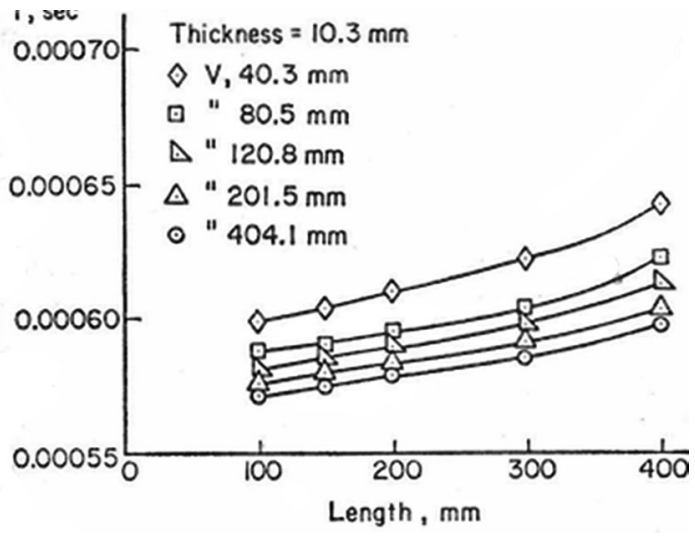

Fig. 12 Variation of contact time with cylinder length and plate thickness. Data from [65], plotted by [66]

Towards the end of his 1866 paper [55] Bashforth set out what would be necessary to determine the law of penetration of iron plates:

The law of penetration of iron plates by hardened steel shot is another purely mathematical question. When a particular form of head of shot has been decided upon, and when a satisfactory method of hardening the shot has been discovered, it will be an easy matter to determine the laws which govern the perforation of iron plates. The quantities to be connected are the velocity, the weight, and the diameter of the shot, and the thickness of the iron plates. It is probable that a series of experiments conducted with plates of tolerably good iron of a uniform quality would be sufficient to afford all necessary information. A few comparative experiments might be made with plates of different qualities of iron but of equal thicknesses.

\section{Interior Ballistics}

The first known electrical measurements on the travel time of a bullet in a gun (to $100 \mu$ s accuracy) were performed by Pouillet in the 1840s [23, 63]. Schneebeli later used Pouillet's technique to investigate the contact times of metal spheres on metal rods and spheres [64]. He found the contact times were proportional to $1 / E^{0.5}$ where $E$ is Young's modulus. In 1973, Bell published some plots of data originally obtained by Hamburger in 1866 [65] for contact times for cylindrical projectiles impacting iron plates of various thicknesses (Fig. 12).

In order to make progress in interior and terminal ballistics, it was necessary to have some method of measuring and recording electrical or mechanical impulses. As far as I have been able to determine, the first such recordings were made by medical researchers in the middle of the nineteenth 


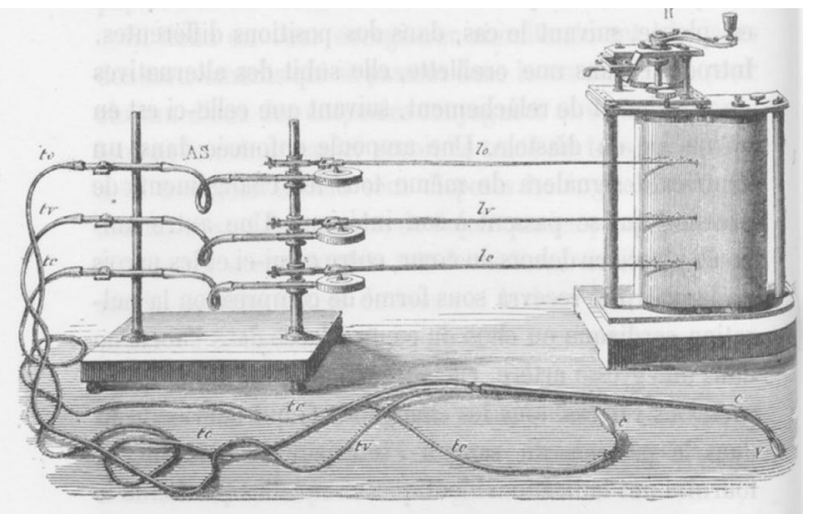

Fig. 13 Engraving of a three-channel cardiograph in use by the early 1860s. From [67]

century [67]. By 1863 it was possible for Marey to publish a book (Physiologie Médicale de la Circulation du Sang) containing more than 200 figures showing heartbeat traces obtained using the apparatus shown schematically in Fig. 13. The signals were transmitted pneumatically to a set of long levers that terminated in pens that recorded the traces on a vertical rotating cylinder. Examples of traces so obtained are shown in Fig. 14. Timing traces (Fig. 15) could be generated using the device shown in Fig. 16. Marey also performed a few experiments to demonstrate the difference between pulses that had been artificially generated pneumatically and hydraulically (Fig. 17).

Donders subsequently investigated the response of a cardiograph to square waves generated electrically (trace ' $\mathrm{s}$ ' in Fig. 18). He reported:

En fermant et ouvrant le circuit suivant un rhythme déterminé, la tige à traçoir, dont il vient d'être ques-



Fig. 15 Timing pulses generated using the device shown in Fig. 16. From [67]

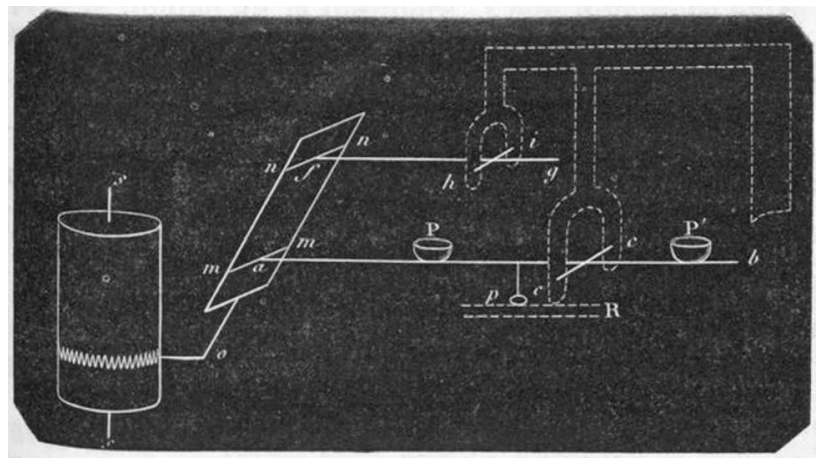

Fig. 16 Vierordt's design of sphygmograph for timing purposes. From [67]

tion, est attirée et abandonée par l'électro-aimant d'une manière également rhythmique, et ce mouvement, qui ce communique au stéthoscope, est de nouveau noté concurrement avec celui du cardiographe. En operant ainsi nous obtenons le graphique suivant [figure 18]: Dans cette figure, $s$ est le movement du traçoir, $c$ celui du cardiographe. Là où la ligne $s$ descend, la tige est attirée et presse sur la membrane du stéthoscope; là où
Fig. 14 Recording of heartbeats made in the early 1860 s. From [67]

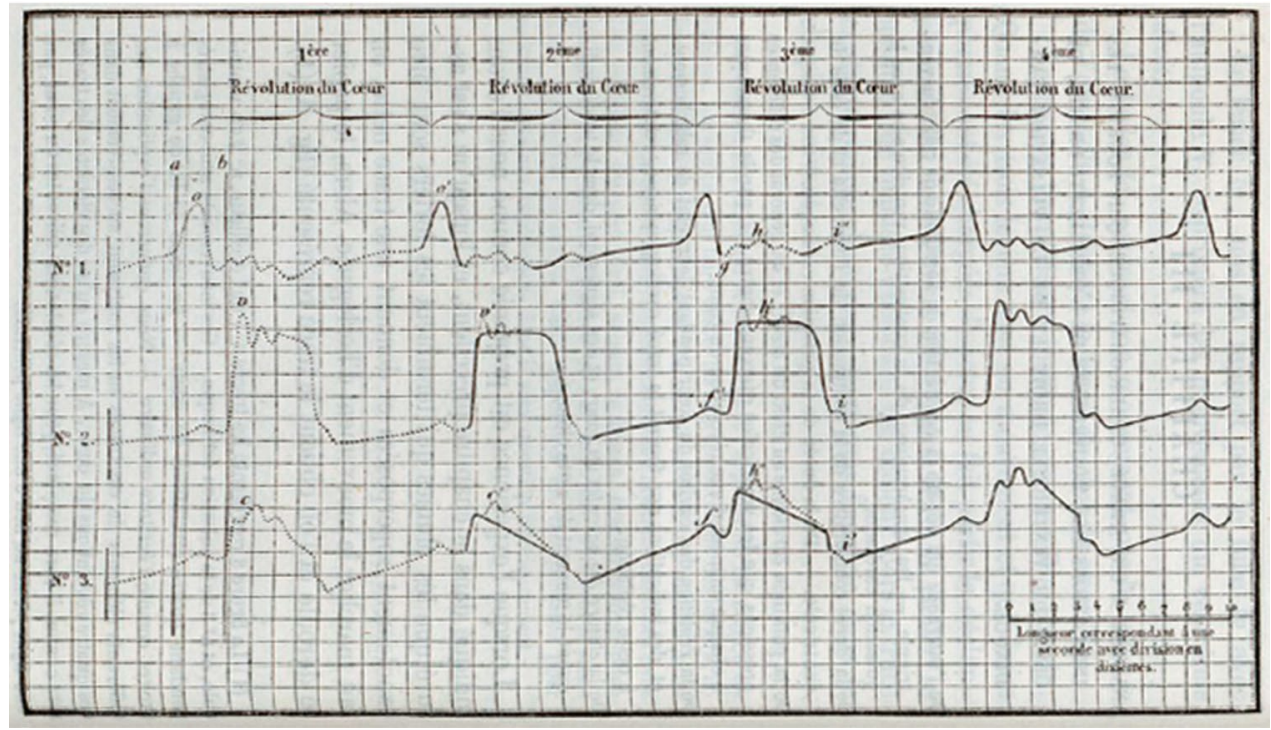




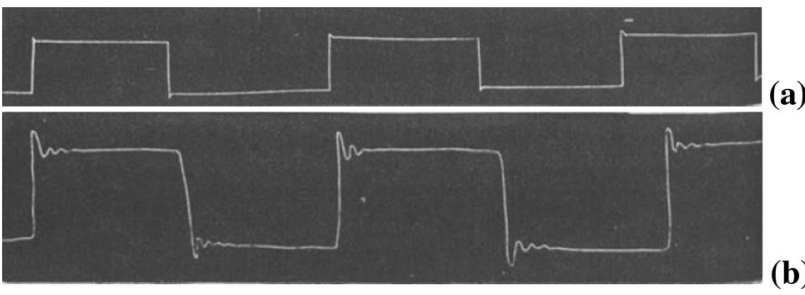

Fig. 17 Recordings showing the difference between pulses recorded in the early 1860s that had been generated artificially in $\mathbf{a}$ air and $\mathbf{b}$ water. From [67]

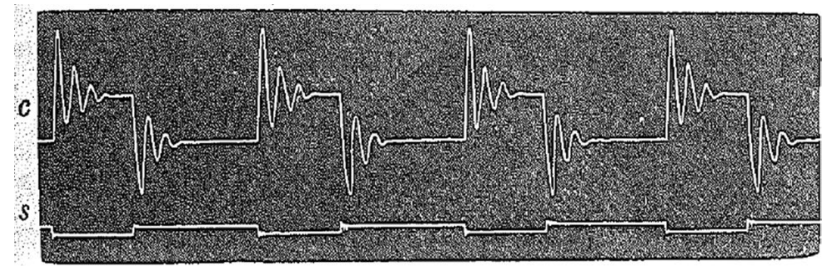

Fig. 18 Traces obtained using a pulsed electromagnet mechanically connected to the same recording system as shown in Fig. 13. From [68]

$s$ se relève, la tige est repoussée et la pression cesse. Au lieu de suivre les mouvements brusques du traçoir, et de décrire, comme lui, dans les intervalles une ligne horizontale, nous voyons que $c$, au moment de la pression du traçoir, monte beaucoup trop haut et execute encore quelques vibrations avant d'arriver au repos, - et que de même, au moment où la tige se relève, $c$ descend trop bas et se met de nouveau en vibration. La période entire est ici de $\frac{1}{70}$ de minute. Ce résultat montre que le cardiographe ne convient par pour enregistrer des chocs brusques.

(By closing and opening the circuit according to a preset rhythm, the drawing rod, which we have just discussed, is pulled and pushed rhythmically by the electromagnet, and this movement, being also communicated to the stethoscope, is recorded simultaneously with the cardiograph trace [figure 18].

In this figure, $s$ is the input signal and $c$ the response of the cardiograph. The descending line in $s$ occurs when the stem is attracted and presses on the stethoscope's membrane. When $s$ rises, the stem is being pushed back and hence the pressure drops. However, instead of following the sudden movements of the input signal, and hence outputting horizontal lines, we see that trace $c$, at the moment the pressure rises, overshoots and then performs some oscillations before coming to rest. A similar thing happens when $s$ falls. The entire period is $\frac{1}{70}$ part of a minute. This result shows that cardiographs are not suitable for recording sudden shocks.)

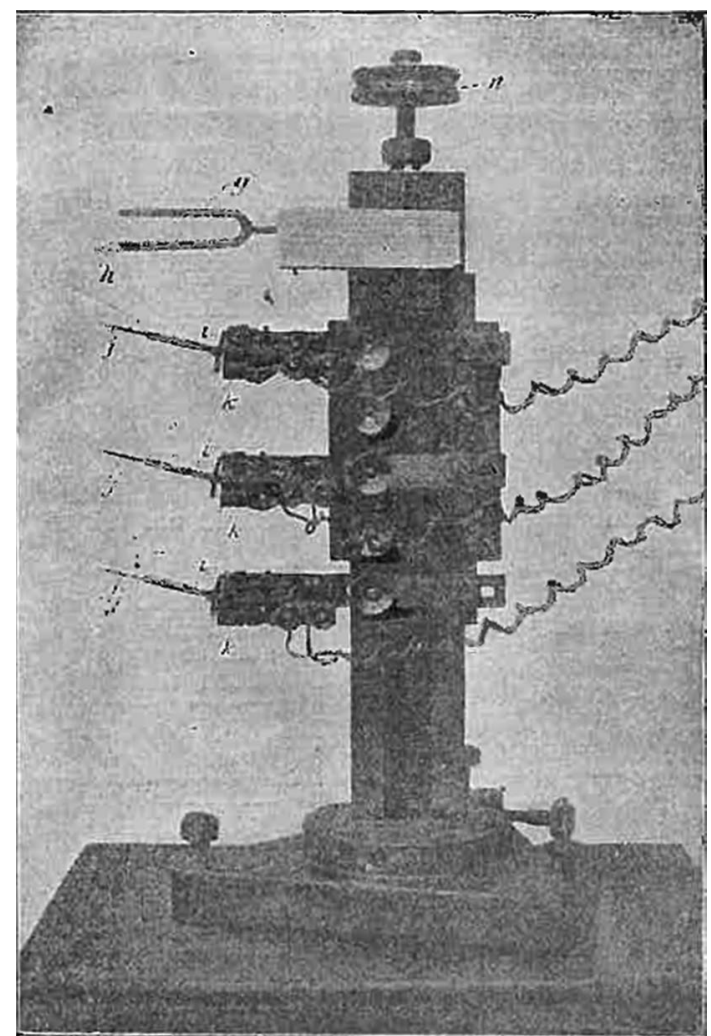

Fig. 19 Photograph of Smith's chronograph for measuring the velocity of a rifle bullet both inside and outside the barrel. From [69]
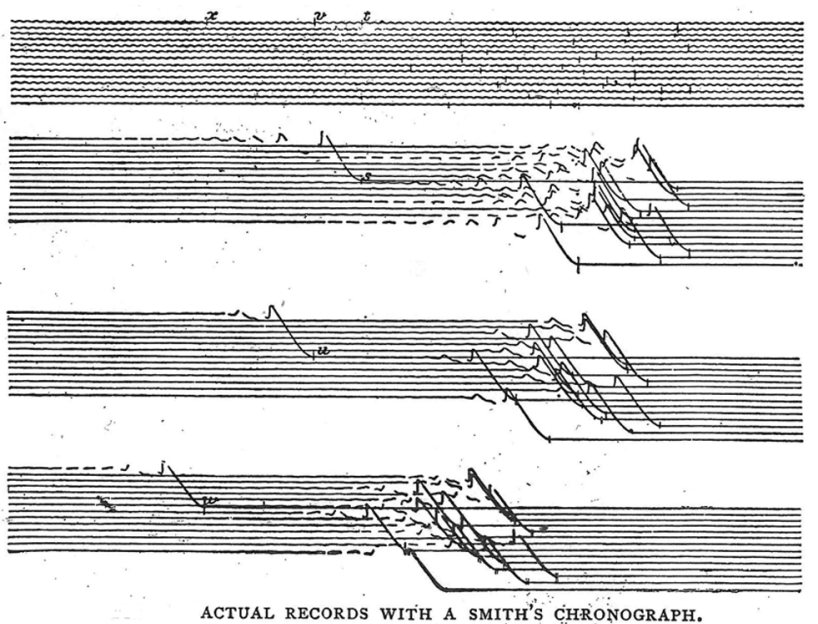

Fig. 20 Data obtained using the apparatus shown in Fig. 19. From [69]

By the end of the nineteenth century, it was possible to make measurements of the velocity of rifle bullets both as they travelled up a barrel and for the first few metres of their travel using a dropweight, a tuning-fork, some wires, and a piece of smoked glass (Figs. 19, 20) [69]. The frequency of 
Fig. 21 Published table of results of measuring velocity of sound in American woods (1879). This table gives some idea of the lack of understanding at the time of the concept of measurement accuracy, a problem still current among students of the sciences to this day. From [78]
Velocity of sound in American woods: measured by the Graphic Hethod.

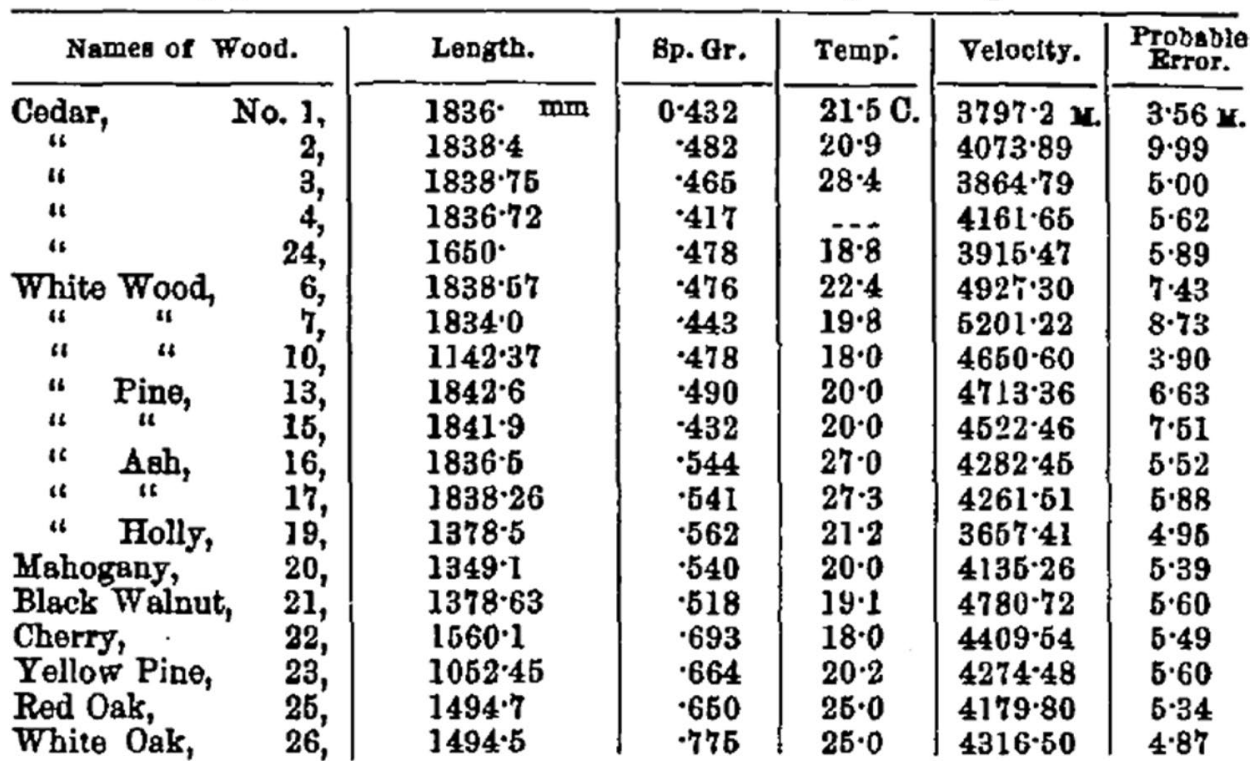

the tuning-fork used was $10 \mathrm{kHz}$, giving a time resolution of $0.1 \mathrm{~ms}$. These are probably the most sophisticated measurements of interior and exterior ballistics that were possible before the development of the cathode ray oscilloscope in the 1930s.

\section{Mid-nineteenth Century Terminal Ballistics Experiments}

So now the velocity with which a shot was fired could be measured, it became possible to investigate the velocity dependence of the resistance of various types of target to ballistic impact. Until the middle of the nineteenth century, the main materials of interest in this regard were earth, stone and wood [70]. I recently published a fuller version of what follows in a book chapter whose theme was the beginnings of the use of iron and steel in heavy armour [23].

The first systematic studies of ballistic penetration of solids were reported by Moore in 1810 for wood [71], by Piobert in the 1820s-1830s (again for wood) [72], and by Isidore Didion in 1834-1835 for earth, masonry and wood [70]. There had been earlier isolated unsystematic reports of experiments performed in 1651 at Woolwich, England on oak butts [73] and by Robins in 1742 and 1747 of some experiments he had performed on the ballistic resistance of wood [43, 74]. Simmons [45] later credited Robins with confirming the idea arising from Newton's study of fluids that the depth of penetration of wood scales with the square of the velocity of impact. Note that the only experiments on penetration that Simmons mentioned when writing in 1812 were those by Robins on wood [45].

Robins made the following important observation concerning the ballistic penetration of wood by cannonballs: "It is Matter of Experiment, that a Bullet, which can but just pass through a Piece of Timber, and loses almost all its Motion thereby, has a much better Chance of rending and fracturing it, than if is passed through it with a much greater velocity" [74].

In 1848 Didion published the following formula for the penetration $E$ of wood impacted at a velocity $V$ by a spherical projectile [70]:

$E=\frac{2 R D}{3 g \beta} 2.3026 \log \left(1+\frac{\beta}{\alpha}\right) V^{2}$,

where $R$ is the radius of the projectile, $D$ its density, $g$ its weight, and $\alpha$ and $\beta$ are 'quantities that depend on the nature of the medium' which he defined by the following equation:

$\rho=\pi R^{2}\left(\alpha+\beta v^{2}\right)$

where $\rho$ is the resistance of the medium and $v$ is the velocity at any given instant.

The numerical factor in front of the logarithm function in Eq. (3) highlights an issue with the nineteenth century literature that is very striking: the lack of understanding of measurement error and limits of precision (see Figs. 21, 22). This is despite the fact that the first discussion on this topic is believed to be by Pierre-Simon Laplace in the Introduction to the second edition of his book Théorie Analytique des Probabilités published in 1814 [75-77]. Laplace wrote: 
Fig. 22 Results of hydraulic (oil) measurement of the blast produced by the firing of various cannons and muskets. These measurements were performed in the 1850s. From [79]

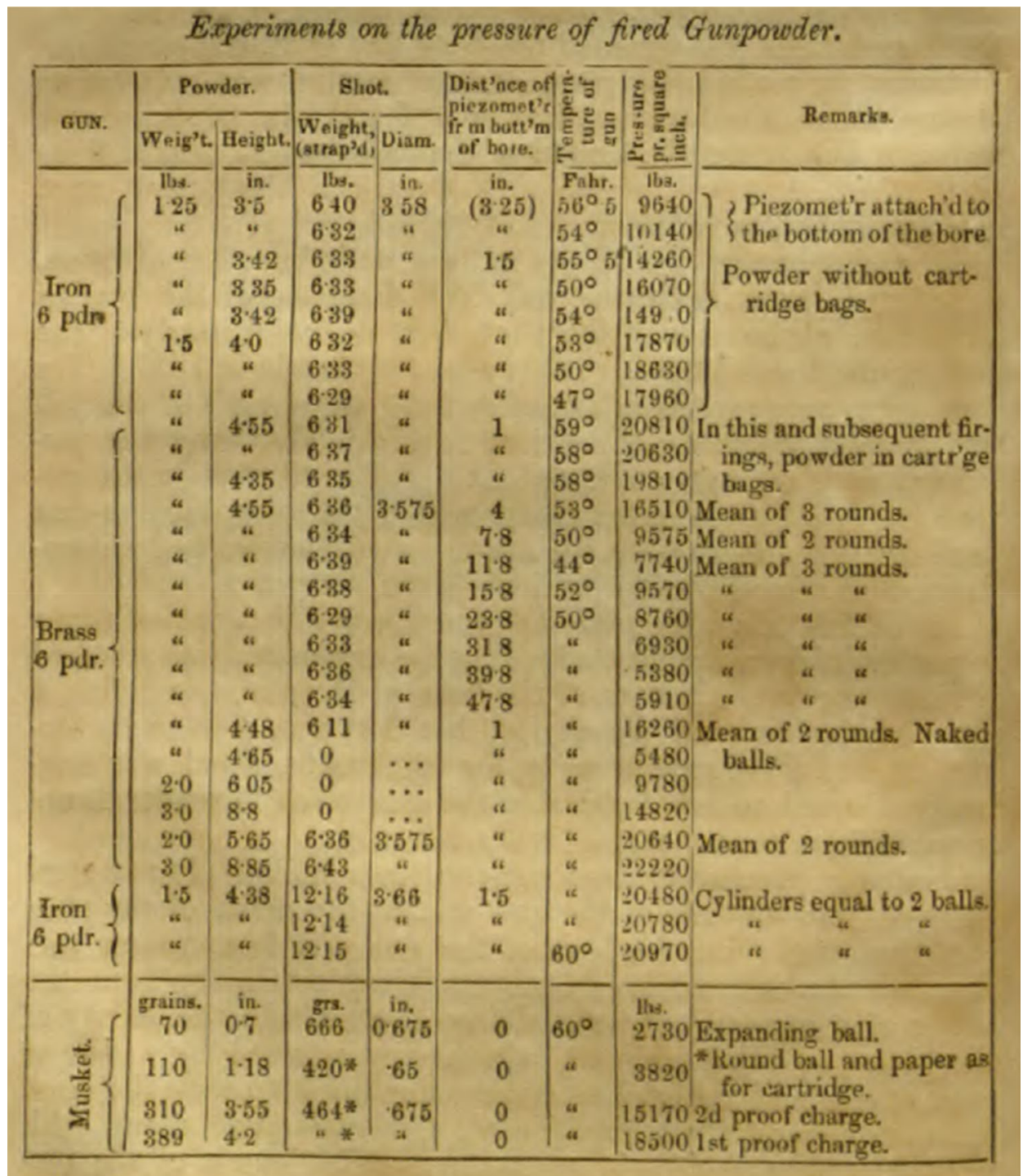

Les observations et les expériences les plus précises sont toujours sujettes à des erreurs qui influent sur la valeur des élémens que l'on veut en déduire. Pour faire disparaître ces erreurs, autant qu'il est possible, en les détruisant les unes par les autres; on multiplie les observations done le résultat moyen est d'autant plus exact, que leur nombre est plus considérable. Mais quelle est la manière la plus avantageuse de former ce résultat moyen? De quelle erreur ce résultat est-il encore susceptible? C'est ce que l'analyse des probabilités peur seule faire connaître; et voici ce qu'elle nous apprend. (The most precise observations and experiments are always subject to errors which affect the value of the numbers which we wish to obtain from them. To make these errors disappear, as far as is possible, through setting them off one against another, we increase the number of observations, since a greater number of observations produces an average result that is more exact. But what is the most advantageous way of reaching this average result? What error is it still susceptible to? Only probability analysis can tell us.).

Despite much that was subsequently published about measurement accuracy in the nineteenth century e.g. [80-85], it remains both a topic for discussion and also confusion for students of the sciences to the present day [86-88].

It is also striking that graphs of one variable against another were not often published in the mechanics literature of the nineteenth century. Rather the data that were obtained were usually presented as indigestible tables of data that must have been a right pain for the printers of the day to typeset using solid movable type. This is despite the fact that the graph was invented in the fourteenth century by Giovani di Casali and Nicolo Oresme [89] (there is one earlier 
plot known from the tenth or eleventh century showing the inclination of the planets as a function of time [90], but this way of presenting information appears to have been a oneoff and did not influence the way numerical information was presented in the following centuries). Several people have suggested reasons why the graphical way of presenting numerical information was not widely used until the middle of the nineteenth century [91-93]. The problem of presenting data in tabular form was well-expressed by Playfair in 1801 [94] (p. xiv):

Information that is imperfectly acquired is generally as imperfectly retained; and a man who has carefully investigated a printed table finds, when done, that he has only a very faint and partial idea of what he has read; and that like a figure imprinted on sand it is soon totally erased and defaced.

The separation of density and weight in Eq. (3) allowed comparisons to be made between shells and solid shot of the same diameter, a matter that soon became important in the middle of the nineteenth century when the transition was made from all-wood to iron-clad wooden ships and eventually all-steel ships [23]. Didion's book is remarkable for two other things: (i) his thorough survey of previous analyses of round and oblong projectile motion in vacuum and air and (ii) his observations on the effect of moisture content on the penetration resistance of earth.

Prosser reported in 1840 [95] a proposal by Costigin in 1810 to armour forts using iron. Prosser also wrote that Paixhans had performed some small-scale experiments on this matter in France as early as 1809 that yielded mixed results. Positively, the projectiles broke up on striking iron plates. Negatively, the fragments of iron that were formed were highly likely to be dangerous to the defenders. The cast iron target plates also shattered. Thus the funding agency that paid for the study concluded that "the use of cast iron...to revet the cheeks of embrasures...is far from offering the advantages imagined by some persons..."

Holley asserted in 1865 [25] (p. 623 and following) that the first authenticated experiments of the effect of artillery upon metal armour were conducted in the US during the war with the British Empire in 1812. Holley also wrote that a few years later (1827), experiments were performed at Woolwich, England on masonry covered by iron.

In 1856, Dahlgren summarised the difference in effect between solid shot and gunpowder-filled shells on wood in his book Shells and Shell-Guns:

There is no similarity in the action which shot and shells are designed to exert on timber. The shot is to pierce and separate the wood by the force of penetration alone, crushing and rending the fibres, tearing asunder the several parts bolted together, and driving

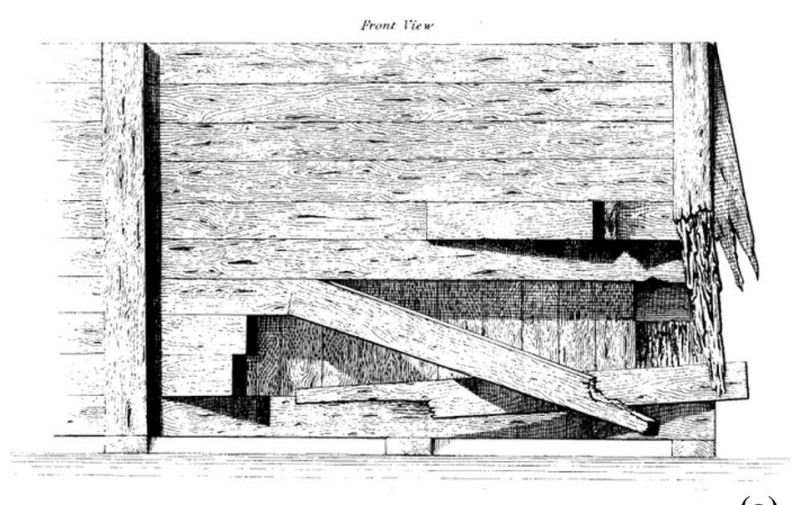

(a)

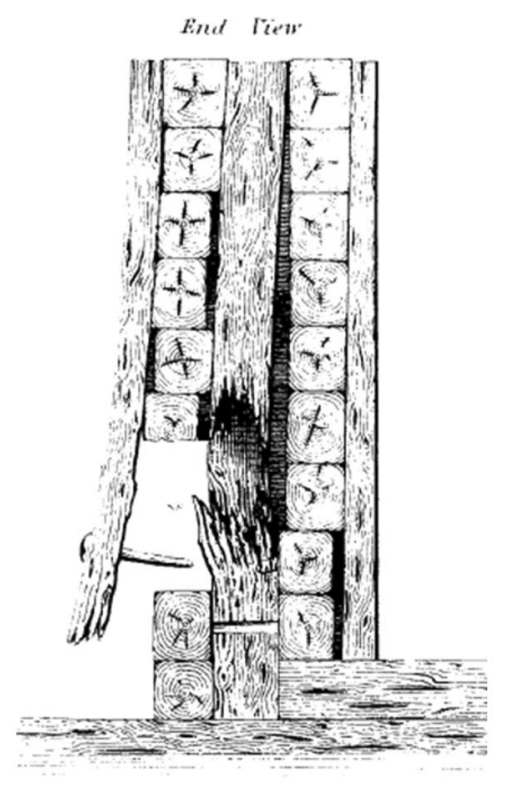

(b)

Fig. 23 Effects of the explosion of a heavy shell that was fired at an oak target. a Front view and b end view. From [96]

off splinters large and small with great violence from the further surface. The shell is intended to explode while lodged in the mass of the ship, disuniting its structure, and driving out more or less of the material in fragments [96].

Drawings from his book that demonstrate the effects of an exploding shell on a wooden target are presented in Fig. 23.

That there was much that investigators of the 1850s knew they did not understand about ballistic impact (what we might term 'known unknowns') may be seen from the following quote from Dahlgren's book:

...the probable effects of artillery on ships, require no little patience and ingenuity to resolve, even when the practice is conducted experimentally, and therefore with power to determine many of the conditions under which 
it shall occur: but in action, these are not only beyond control, but most frequently beyond conjecture, and the results are liable to the whole possible combination of effects, due to unequal force and to unequal resistance [97].

He also noted that there were differences between "the results of practice upon ships and upon the solid wood of targets".

\section{The Dawning of the Idea that the Dynamic and Quasistatic Properties of Materials Differ}

In 1856, Professor Joseph Henry wrote as follows about the unsatisfactory state of materials testing, particularly of stone [98]:

\begin{abstract}
Although the art of building has been practised from the earliest times, and constant demands have been made, in every age, for the means of determining the best materials, yet the process of ascertaining the strength and durability of stone appears to have received but little definite scientific attention, and the commission, who have never before made this subject a special object of study, have been surprised with unforeseen difficulties at every step of their process, and have come to the conclusion that the processes usually employed for solving these questions are still in a very unsatisfactory state.
\end{abstract}

The commission that Henry refers to, and which he was a member of, had been appointed by the President of the US to examine the quality of the various marbles that had been offered to the Government of the US for the extension of the US Capitol.

Henry concludes his paper with a discussion of a possible reason for the difference in the amount of extension possible in steel and lead. His ideas were speculative, but prescient, as the following quote shows:

According to the views I have presented, the difference in tenacity in steel and lead does not consist in the attractive cohesion of the atoms, but in the capability of slipping upon each other.

He then summarised a presentation he had made (but not published) at a meeting of the American Association for the Advancement of Science that had been held in Cleveland, Ohio:

From this it would appear that metals should never be elongated by mere stretching, but in all cases by the process of wire-drawing, or rolling. A wire or bar must always be weakened by a force which perma- nently increases its length without at the same time compressing it.

Another effect of the lateral motion of the atoms of a soft heavy body, when acted upon by a percussive force with a hammer of small dimensions in comparison with the mass of metal (for example, if a large shaft of iron be hammered with an ordinary sledge) is a tendency to expand the surface so as to make it separate from the middle portions. The interior of the mass by its own inertia becomes as it were an anvil, between which and the hammer the exterior portions are stretched longitudinally and transversely. I here exhibit to the Association a piece of iron originally from a square bar $4 \mathrm{ft}$. long, which has been so hammered as to produce a perforation of the whole length entirely through the axis. The bar could be seen through, as if it were the tube of a telescope.

This fact appears to me to be of great importance in a practical point of view, and may be connected with many of the lamentable accidents which have occurred in the breaking of axles of locomotive engines. These, in all cases, ought to be formed by rolling, and not with the hammer.

The whole subject of the molecular constitution of matter offers a rich field for investigation, and isolated facts, which are familiar to almost every one when attentively studied, will be made to yield results alike interesting to abstract science and practical art.

\section{The Beginnings of the (Quasistatic) Mechanical Testing of Materials}

So what was known about the strength of materials before Joseph Henry wrote and when and why did mechanical testing of materials start? The most thorough relatively modern survey of this topic is The Experimental Foundations of Solid Mechanics, written by James F. Bell in 1973 as a memorial to his son who died in 1969 in the Vietnam War [99]. Bell's book is mostly about low rate testing from the seventeenth century onwards, but he also surveys the development of high rate tests. A list of the milestones in materials testing is also given in the Appendix to Tóth et al.'s 2002 book chapter on the history of the Charpy impact fracture test [100].

The people who built large buildings before the seventeenth century must have had some understanding (even if only qualitative) of the mechanical properties of the materials they were working with (stone, wood, brick). However, the first investigation that we know of into the effect of the relative length, breadth and width of a (wooden) beam on its breaking strength was written up by Galileo [101] (Fig. 24). 


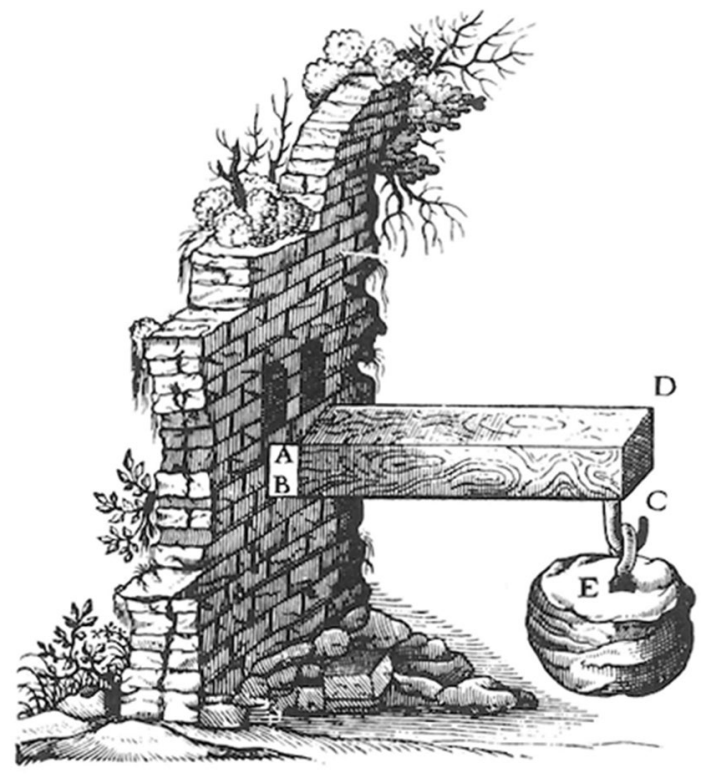

Fig. 24 Galileo's 1638 experiment on the breaking of a beam by an end load. From [101]; see also [102-104]

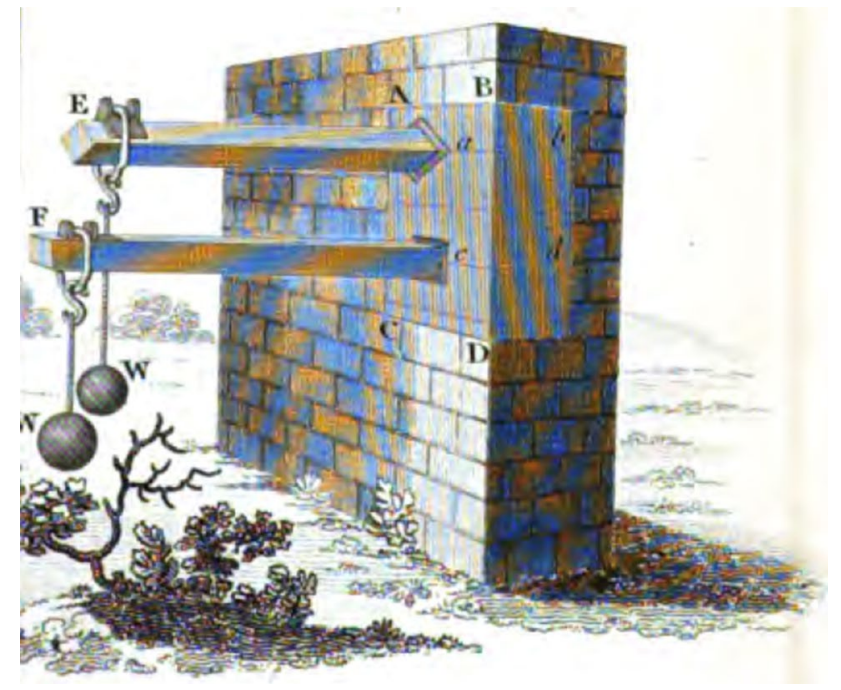

Fig. 25 Barlow's 1867 drawing of the dead-loading of square section beams in two different orientations. The influence of Galileo's 1638 drawing can be clearly seen. From [106]

In 1817, Peter Barlow (of the Royal Military Academy, Woolwich, England) wrote a book about his measurements of the strength of timber and iron [105]. This book went through several editions, a new edition revised by his two sons being published in 1867 [106]. Due to the high regard with which Galileo was held, even as late as 1867 the Barlows included a similar amount of extraneous artistic detail in the drawing of the dead loading of beams in two different orientations (Fig. 25).
Fig. 26 Tensile fracture test devised by Mariotte in 1680

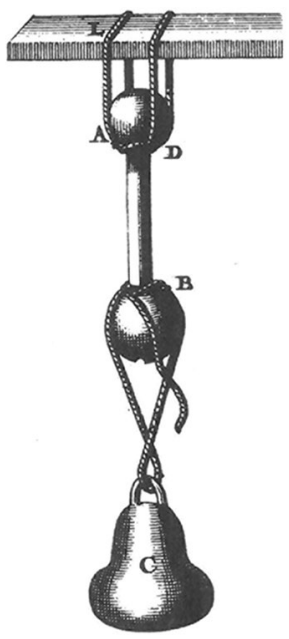

After Galileo, a number of researchers developed methods of investigating the strength of materials in a number of different modes of loading. The first recorded tensile fracture test that Bell discovered was performed by Mariotte in 1680 (Fig. 26). By 1729, devices for loading specimens in compression and flexure had been devised by Pieter van Musschenbroek (Fig. 27). In the 1770s and 1780s, CharlesAugustin Coulomb performed a number of studies of the effect of loading materials in compression (Fig. 28), tension and shear (Fig. 29), and torsion (Fig. 30). He also published the first analysis of the distribution of the tensile and compressive forces through the vertical thickness of an endloaded beam (Fig. 31). Most of these studies involved simply measuring the forces but Coulomb measured the torsional deflection in wires in 1784 (Fig. 30) and by 1824 Tredgold had devised a machine for determining the flexure of a centrally-loaded beam whose output was shown using a pointer on an angularly-graduated scale (Fig. 32).

During the nineteenth century, a number of books were published surveying what was known about the mechanical strength of materials under quasistatic loading: Tredgold (cast iron and other materials) [111-113], Barlow (timber) [114], Navier [115, 116], von Gerstner (German studies on mechanics) [117], Rankine (engineering mechanics) [118, 119], Kirkaldy (results of his commercial materials tests) [120, 121], Tresca [122], Anderson (American research on materials and structures) [123], Kent (strength of materials) [124], Jeans (steel) [125], Abbott (testing machines) [126], Todhunter and Pearson (history of the strength of materials) [127], Unwin (testing construction materials) [128, 129], Ewing (strength of materials) [130]. In that century, the main countries where these studies took place were the UK, France, the US and the German lands. Of particular note were the studies by Kirkaldy in London who set up the first commercial 'testing and experimental works' in London in the 1860s under the motto "Facts not opinions" (Fig. 33). 
Fig. 27 a Compression and $\mathbf{b}$ flexure testing devices devised by Pieter van Musschenbroek. From [107]

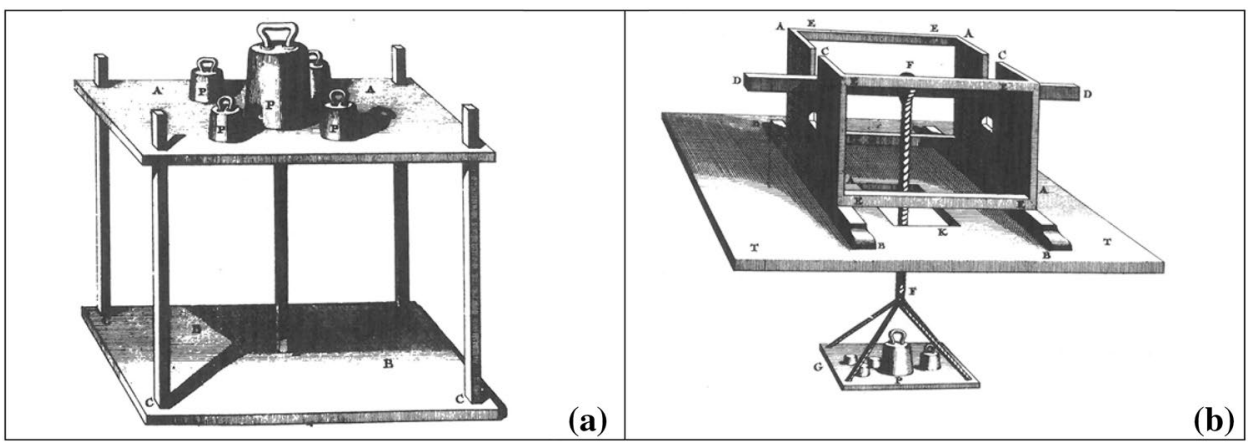

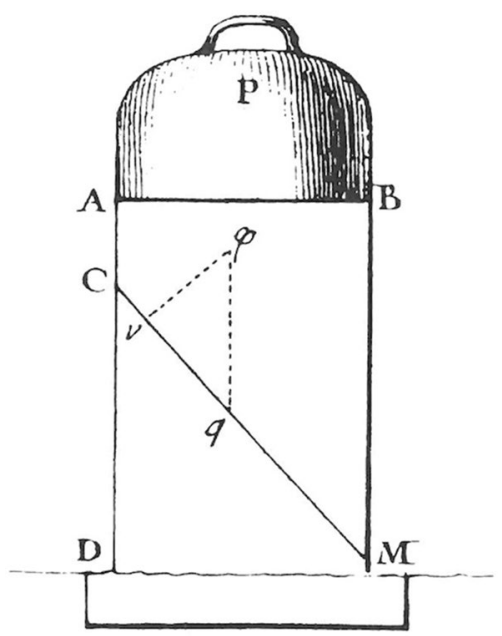

Fig. 28 Coulomb's 1773 diagram of the shear forces in a vertically loaded masonry pier. From [108]

His universal testing machine still exists in the premises where it was installed in 1874 (99 Southwark Street, London). A mechanical testing machine affordable by manufacturers of chain cables was described by Dunn in 1857 [131]. He also said it could be used for assessing timber.

Studies on the dynamic fracture of metals were largely concerned with the explosion of cannons [25, 132] and steam boilers $[133,134]$. These issues were recognised at the time as being related [135].

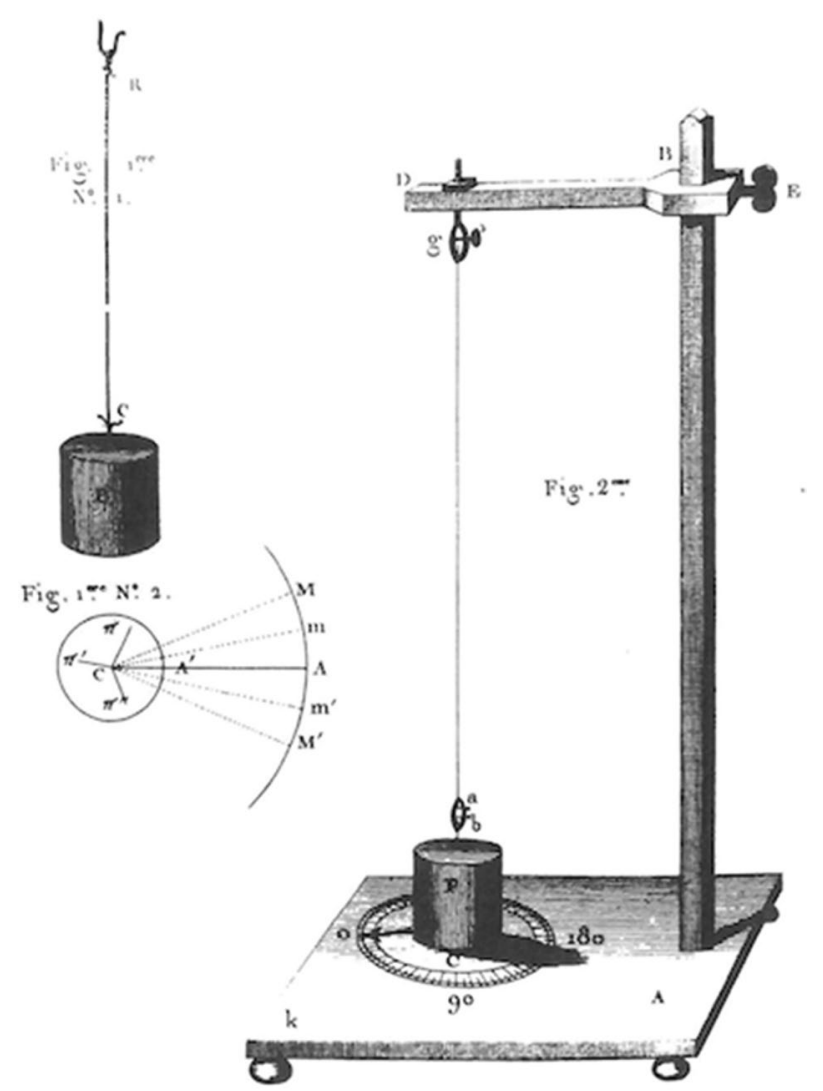

Fig. 30 Coulomb's 1784 experiments on the torsion of metal wires. From [109]
Fig. 29 Coulomb's 1773 experiments comparing the tensile and shear strengths of stone. From [108]

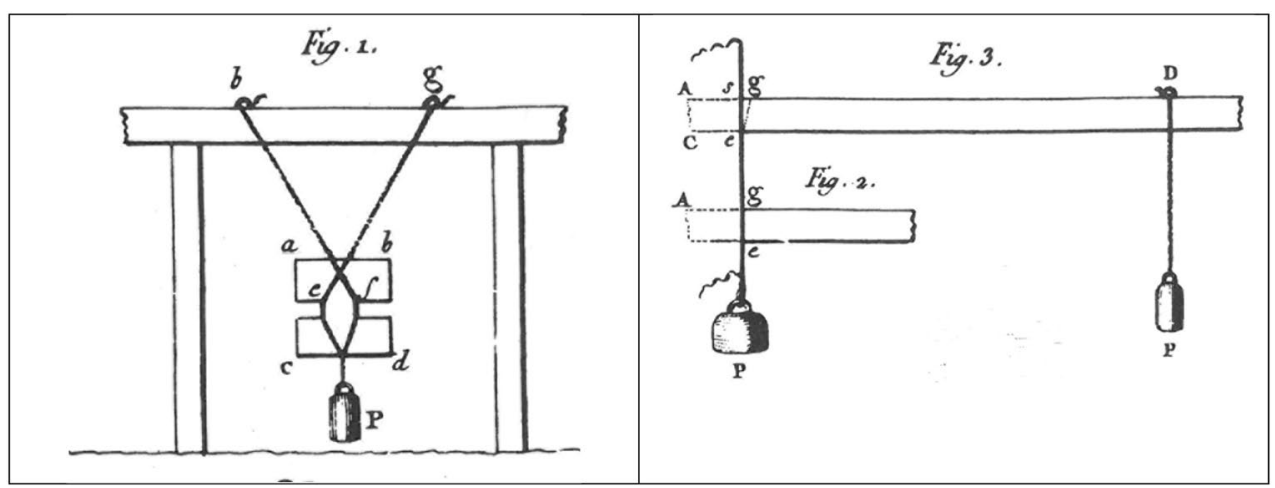


Fig. 31 Coulomb's analysis of the tensile and compressive forces in an end-loaded beam. From [108]

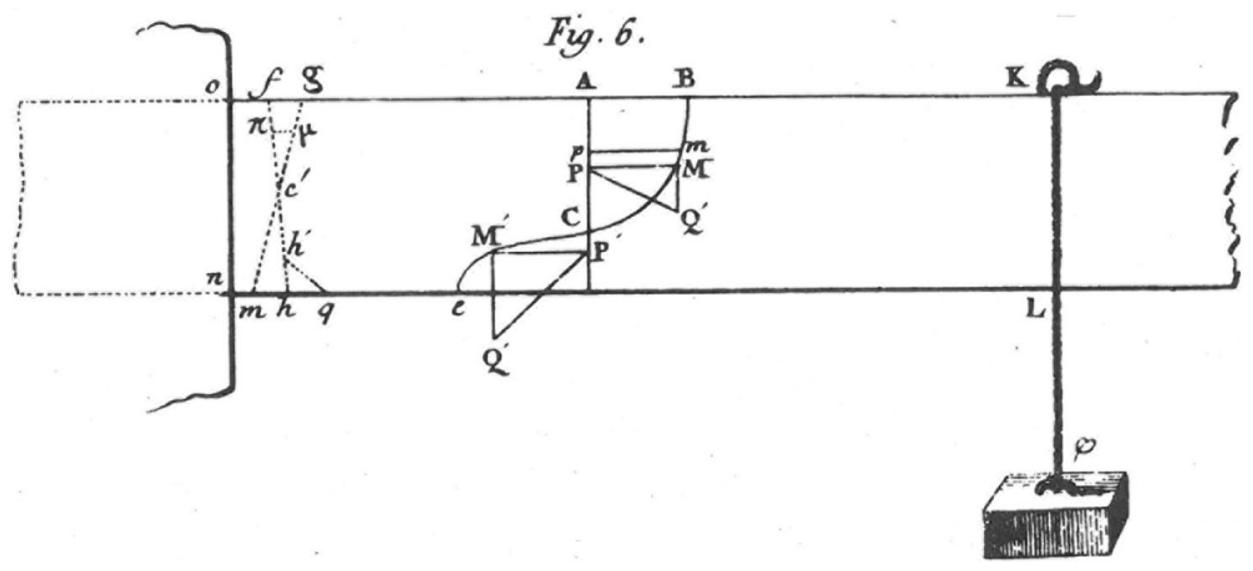

In the preface to his 1817 book, Peter Barlow reviewed the state of knowledge of the strength of materials:

A correct knowledge of the Strength and Stress of Timber, and other materials, is admitted to be of the highest value to every one concerned in mechanical and architectural constructions: and yet it is generally allowed to be a part of those arts less understood than any other; and in which, therefore, the greatest errors are frequently committed.

\section{TREDGOLD ( 1824 )}

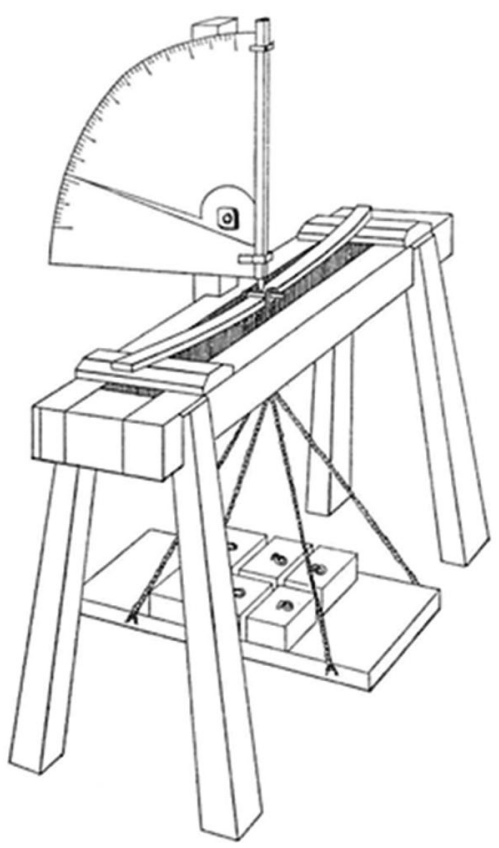

Fig. 32 Early (1824) instrumented mechanical testing machine for measuring and displaying flexure under dead-loading. From [110]
After quoting from Robison's article on 'Strength' in the Encyclopaedia Britannica in support of this assertion, Barlow went on to say:

It would be too much for me to presume that I have fully accomplished what [Robison] considers so great a desideratum; but I may, perhaps, be allowed to say, that I have made some considerable advances towards it, and put the practical engineer in possession of certain facts which have not before been generally known, and several rules for computation that he will in vain look for in any other work: for it is not only our country that has to complain of this paucity of information, there being no treatise, at least that I am acquainted with, in the French or any other language, from which such practical knowledge is to be obtained.

Barlow's main critique of the best book previously written on this topic (in French in 1798) by Pierre-Simon Girard (Traité Analytique de la Résistance des Solides) [136] was that Girard employed "a calculus much too refined for the nature of the subject" and as a result Girard arrived "at the same erroneous conclusions [as Mariotte and Leibnitz]; making the strength of a beam, under certain circumstances, three times what it is in others...". Barlow also criticised Galileo and Leibnitz for the error of assuming that materials are incompressible. This assumption of incompressibility "makes the strength of a triangular beam supported at each end with its edge upwards, double that of the same, or of an equal beam, with its base upwards.... whereas experiment shews it to be strongest in the latter position..."

However, as discussed earlier, Barlow was one of those who quoted the numbers in strength formulae to an absurd level of accuracy. For example, he wrote that the load $P$ at which an oak beam begins to bend was given by:

$\frac{P f^{2}}{3 b}=\frac{11,784,451(f+0.03) a h^{2}}{1.3}$, 


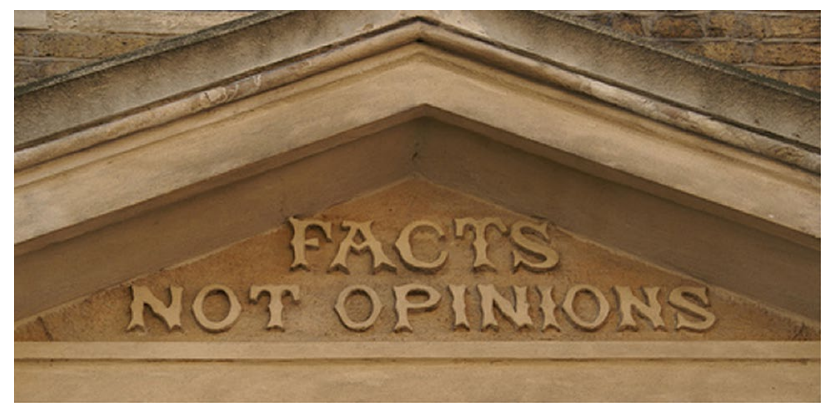

Fig. 33 Kirkaldy's motto inscribed in stone over the entrance to his business premises in London

where $a$ is the beam thickness, $h$ the beam width, $f$ is half the beam length, and $b$ is the 'versed sine' of the deflection [137].

As far as I have been able to discover, the first people to raise the issue of the lack of knowledge of the dynamic mechanical properties of materials (in 1849) were Cox [138] and 'The Commissioners Appointed to Inquire into the Application of Iron to Railway Structures' [139]. It is clear from what he wrote in his introduction to the paper that Cox believed it was a new problem:

The dynamical strength of beams, or their capability of sustaining weights moving rapidly over them, has never been satisfactorily discussed. There does not appear to be extant a single theoretical investigation of this subject - and the deficiency is due to two causes: it occurs partly because the subject has but comparatively recently grown into importance; partly because of its excessive and insuperable difficulties when investigated by the exact methods of theoretical mechanics.

The reason the problem had not arisen before in the history of the world was that bridges constructed from iron had not existed before 1781 for any purpose [140-142] let alone been designed to carry railway trains. This is made clear by the following quote from the introduction to the report of the Railway Structures Commissioners [139]:

From the information supplied to us, it appears that the proportions and forms at present employed for iron structures, have been generally derived from numerous and careful experiments, made by subjecting bars of wrought or cast iron of different forms to the action of weights, and thence determining by theory and calculation such principles and rules as would enable these results to be extended and applied to such larger structures and loads as are required in practice. But the experiments were made by dead pressure, and only apply therefore to the actions of weights at rest:- On the contrary, from the nature of the railway system the structures employed therein are necessarily exposed to concussions, vibrations,torsions, and momentary pressures of enormous magnitude, produced by the rapid and repeated passage of heavy trains.

Cox stated that there was much uncertainty about the different effects of dynamic as opposed to static loading [138]:

There seems to exist great discrepancy of opinion as to the effect of the velocity of transit. Some have imagined that it may become a source of safety, by causing the railway trains to pass over before the girder has had time to yield. Others, again, have estimated the effect of the moving load as highly as six or seven times that of the same load at rest. In the following investigation, both these opinions will be shown to be incorrect: they are here cited merely as indications of the extreme uncertainty prevalent on the subject.

Around this time (1847) Bélanger wrote a book based on the lecture courses that he had given in France to the students at that country's Central School for Arts and Manufactures. It was mostly about static mechanics but it also contained some observations of elastic collisions as the following quote concerning the effect of the shape and orientation of colliding materials makes clear ([143], p. 209):

Mais il importe de remarquer que la figure des corps qui se choquent a une influence considérable sur le phénomène. Si l'on fait tomber une boulle de caoutchouc sur une table de marbre, elle rejaillit à peu près aux $\frac{2}{3}$ de la hauteur de la chute; mais si l'on fait la même expérience avec un disque de la même matière, que l'on fasse tomber à plat, le rejaillissement est presque nul. (But it is important to notice that the

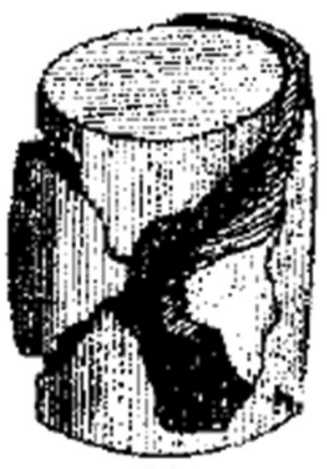

(a)

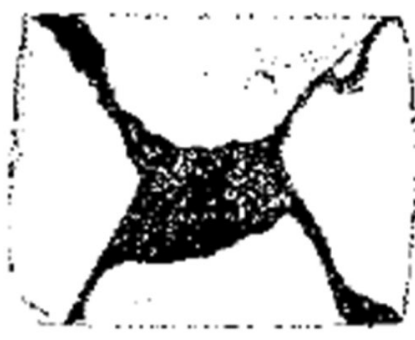

(b)
Fig. 34 Engraved drawings from what is believed to be the first published report (in 1839) of the cracking produced by the quasistatic compression of solid cylinders. The material tested was cast iron. From [148] 
shape and orientation of bodies that undergo impact has a considerable influence on the outcome. If a rubber ball is dropped onto a marble table, it bounces back about $\frac{2}{3}$ of the height it was dropped from. But if you do the same experiment with a disc of the same material, made to fall flat, the rebound is almost zero.)

An Englishman with a professional interest in iron bridges was Hodgkinson [144]. He was the first person to publish articles (during the 1830s) on experimental investigations into the dynamic properties of materials [145-149]. He was also the first person to publish drawings of the X-shaped fracture produced by the compression of metal cylinders (Fig. 34) [147, 148].

Another important factor giving people cause for concern in the use of iron in bridges in the early nineteenth century was its embrittlement at low temperature. The earliest mention I have so far come across to the phenomenon of the ductile-brittle transition is due to Pope in 1811 in a discussion of designing bridges suspended using iron chains ([140], p. 190) (thanks to Kanji Ono and Ron Armstrong for bringing this reference to my attention):

[Another important defect may be added], attendant on this kind of Bridge, namely, the natural and certain tendency that frost produces upon all iron, to make it brittle, and consequently to lessen its strength, derived by cohesion. If this be a fact, we may naturally infer that, were the chains for a Bridge made strong enough to carry all the weight required, in Summer, yet they are liable to break down with half that weight in Winter, and as it is also a fact that we have a right to calculate on double the weight being on such a Bridge in Winter, more than in Summer, through rain, ice, and snow; then, quere [sic], whether a Bridge of this kind, if it even possessed four times the strength it required in Summer, could in any wise be depended upon in Winter, while it was subject to the unfriendly embraces of an enemy so capable of effecting its destruction and as the breaking of one link would not only endanger the whole fabric, but, very probably, utterly destroy it, how easy is it to prove that a structure so easily affected cannot be of long duration, and that, at the best, they are but mere temporary expedients.

A beautiful early example of an iron-chain suspension bridge may still be seen in North Wales (Fig. 35). Although all the material of which the bridge is made (apart from the stone arches at either end) has been replaced since it was first built in the years 1819-1826, it still follows the

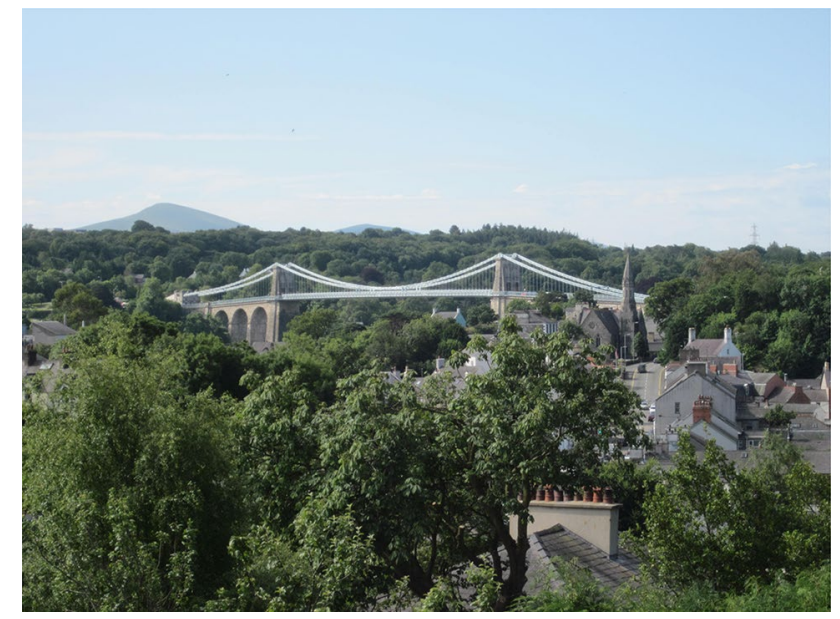

Fig. 35 One of the first iron chain suspension bridges in the world, built 1819-1826 at Porthaethwy (now also known in the English tongue as Menai Bridge), Anglesey (known in the Welsh tongue as Ynys Môn), North Wales. Photograph taken by the author in July 2015. Note that although the existing structure is the original design, the decking was replaced in 1893 and the cables and chains were replaced in 1938

original design. Note that another iron chain bridge (the Union Chain Bridge over the River Tweed) linking England and Scotland was opened in 1820 [150].

A book outlining the lecture course that had been given at the School of Bridges and Roads in France about the experience of building railways in Britain and France was written by Minard in 1834 [151]. In terms of material properties, the two that Minard highlighted were fracture of the rails and friction between the wheels and the rails. In terms of fracture, 'malleable iron' was found to be superior to cast or rolled iron (see p. 7 of his book).

A major difference in the attitudes to technical education between France and England may be seen in the following quote that Bashforth gave in 1881 from a letter that and unnamed but "very distinguished Fellow of the Royal Society" had written to The Times (of London) on February 11, 1870 about the uselessness of giving military officers technical training ([152], p. 91):

It is high time that the guardians of the public purse should set their faces against such vicious reproduction of fresh nuclei of misapplied prodigality, surely designed to eventuate (if I may apply the words of an eloquent member of the deputation of which I formed a part) in endowed and decorated idleness.

In 1842, Weertheim published a list of studies [153] into the elasticity of a number of metals (lead, zinc, silver, platinum, copper, iron and steel) by Coulomb, Tredgold, Barlow, 


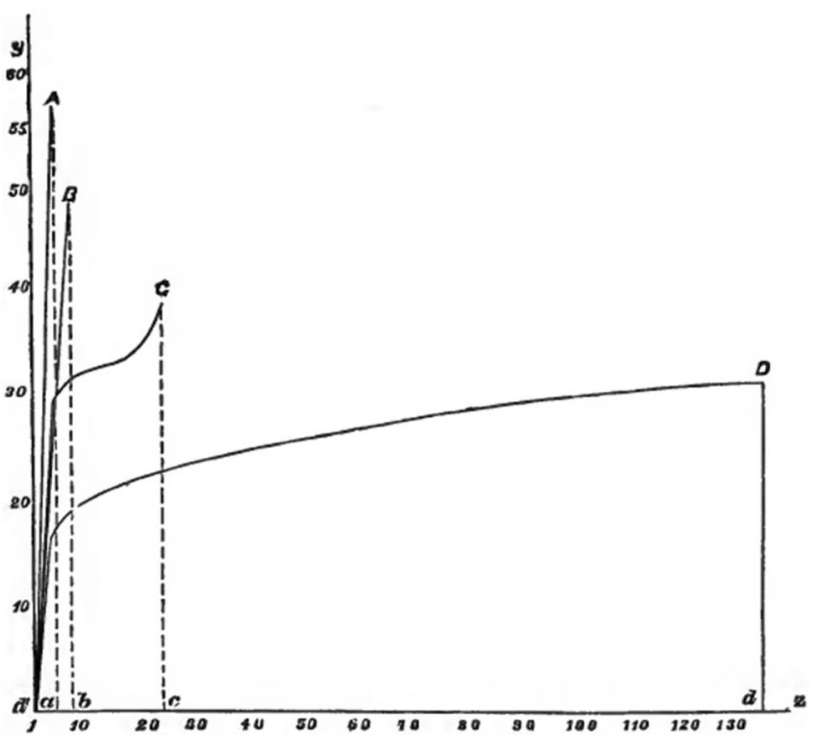

Fig. 36 Plots of the ductility of various irons and steels. Experiments reported in 1865. Curve A was for cast steel. Curve B for 'harsh, strong wrought iron'. Curve C was for 'soft strong iron'. Curve D was for 'extremely ductile but not very strong iron'. From ([25], p. 305)
Young, Rennie, Duleau, Navier, Lagerhjelm, Leslie, Gerstner, Séguin, Martin, Savart, Weber. He also reported that the speed of sound in iron, copper, silver and tin had been measured by Chladni and those for zinc and lead by Masson [153].

\section{Nineteenth Century Terminal Ballistics Experiments}

Totten reported in 1857 that many experiments had been carried out at West Point, New York between 1852 and 1855 involving the firing of heavy ordnance against fixed targets made from granite, concrete and brick [154]. The effect of armouring the targets using wrought- and cast-iron plates had also been investigated. Cast iron was found to be useless (for the reason shown in Fig. 36), but wrought iron was found to offer some protection. Totten also reported that unarmoured granite walls shattered cannonballs fired at them.

Wrought iron's superiority to cast iron was also demonstrated by some tests performed at Portsmouth, UK in 1858 that were witnessed by a certain Captain Hewlett ([155], p.

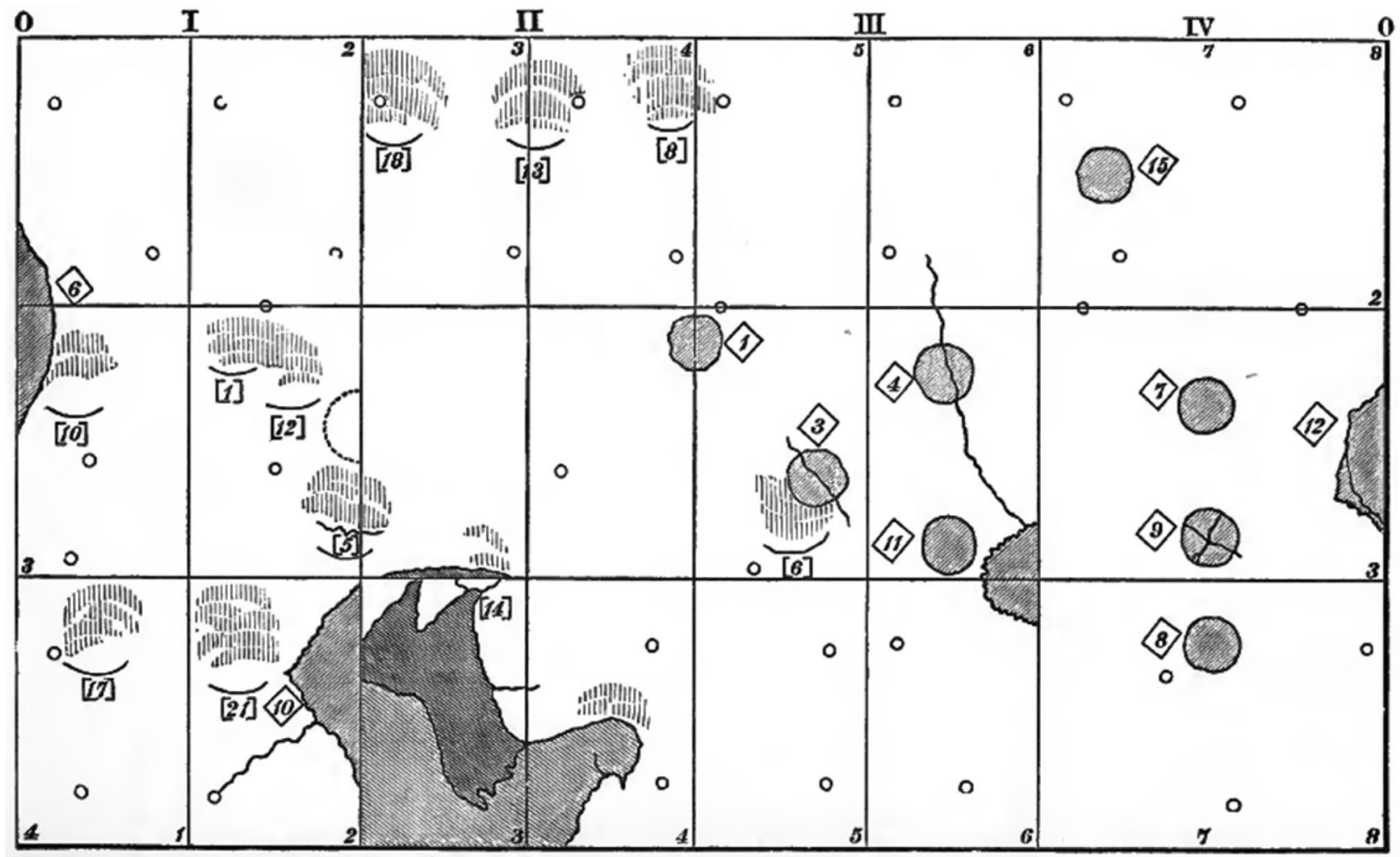

Fig. 37 Drawing of results of impacts of elongated solid cast iron shot against a $7 \mathrm{ft}$. long, $3 \mathrm{ft}$. wide timber-backed wrought-iron plate 4.5 in. thick inclined at $51^{\circ}$ to the vertical. These experiments were performed in 1861. From ([25], p. 641) 
124). Wide variability in the ballistic resistance of wrought iron "made by the same manufacturers under apparently similar circumstances" was a problem, but Hewlett hoped that continued experiments might explain why this was so. According to Baxter, the effects of rifled ordnance against armour were first studied by British researchers in 1858 ([155], pp. 125-127).

In 1861, the effect of impact angle on penetration of timber-backed targets was investigated. It was found that the depth of penetration of cast iron shot into wrought-iron plates inclined at $51^{\circ}$ to the vertical was found to be about half that for the same plates mounted normal to the gun (Fig. 37). However, no effect of impact angle on penetration depth was found for unbacked plates ([25], pp. 665-666). At the time that he wrote (1865), Holley had no explanation for the different outcomes of these experiments.

Around the same time that these studies by Holley were being performed in the US, a 'Special Committee on Iron' was appointed by the British Secretary of State for War to investigate the application of iron to defence purposes. The main findings of their final report (published in 1864) were as follows [156]:

(i) wrought iron of the softest and toughest quality is the best material for armour plates;

(ii) the static properties of iron are no sure guide to its response to impact by shot;

(iii) steel shells are "by far the most damaging projectiles for use against armour-plated vessels";

(iv) the great number of splinters of wood shows how untenable wooden ships must be when penetrated by heavy artillery, without the protection afforded by an iron skin;

(v) for plates of equal quality, a large area is an advantage as the plates are decidedly weaker towards the edges than in the middle;

(vi) a literature review performed at the start of their work (1861) showed "that although sufficient trials had been made to lead to a belief that iron was capable of forming a good protection against artillery, still very little practical knowledge had been acquired either as to the quality of material most efficient for the purpose, or the most advantageous mode in which the material should be applied";

(vii) rolling as opposed to hammering was found to be the best way of manufacturing armour plates as it produces a softer, more uniform product;

(viii) inviting the ironmasters to witness the experiments had led to a "great improvement in the manufacture of heavy iron plates";

(ix) after investigating more than 400 designs of various structures suggested by "certain eminent engineers and ship-builders... we have arrived at the simple result, that the best application of the material is a single plate of uniform thickness, with the surface perfectly plane";

(x) the ballistic resistance of plates was found to be approximately proportional to the square of the thickness;

(xi) experiments performed to see if wood backing could be dispensed with led to the conclusion that wood "appears to have important functions for which no ... substitute has yet been found".

In 1866 Watts et al. gave a description of the effect of armour on cast iron shot and the effect of shot on armour plate [157]. They quoted quantitative estimates of the impact energy lost during the impact of brittle and ductile shot that had been made by Sir W. G. Armstrong and the Iron Plate Committee who reckoned that about half the impact energy of brittle cast-iron shot was 'wasted' by fragmentation on impact whereas only one fifth of the impact energy of ductile wrought iron or soft steel shot was 'wasted' in producing plastic deformation of the shot.

Watts et al. were clear-sighted about the lack of knowledge of the dynamic strength of materials at the time:

Besides the quality of the iron, the dynamic resistance of a plate of a given thickness depends on the volume of metal put into a strained condition by the blow of the shot, and on the distribution of the stress in that metal. Owing to the imperfect state of our experimental knowledge, there does not yet exist any complete and exact theory of the laws of the dynamic resistance of plates to shot; but from such investigations as are possible in the current state of knowledge, it is clear, that for a plate of a given thickness there is a certain diameter of indentation for which the dynamic resistance is a minimum; becoming greater for a larger indentation, because of the increased volume throughout which the stress acts; and greater also for a smaller indentation, because of the way the stress is distributed.

They also reported that the backing of armour plate by wood was being actively investigated:

Backing composed wholly of timber (as when armourplates are simply bolted upon a wooden ship) adds little to the power of an armour-plate to resist penetration, its principal use being to stop shot and shell after they have passed through the armour-plate, and to diminish the vibration communicated to the hull of a ship by a blow; and for that purpose it should be made as thick as possible, by filling in the spaces between the frames with solid wood. It is otherwise when the wooden backing has a rigidly framed iron skin behind 


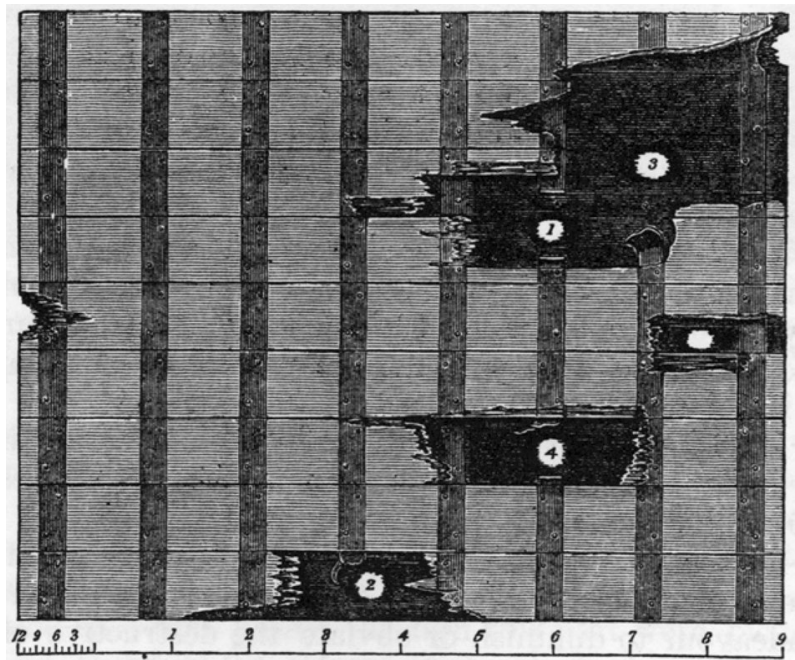

Fig. 38 Results of firing various types of shot against a wood and iron specimen representing a section of HMS Simoom. Scale bar below the drawing is in feet. The construction and dimensions of the specimen were as follows: ribs of $\frac{5}{8}$ in. iron, 4.5 in. wide, $11.5 \mathrm{in}$. apart, covered with 5 in. teak planking on the outside and 2 in. on the inside. The breadth of the 5 in. planking was 10.5 in. and the breadth of the 2 in. planking was $9 \frac{2}{3}$ in. The whole specimen was $10 \mathrm{ft}$. long by 8 in. in depth. From ([158], p. 140)

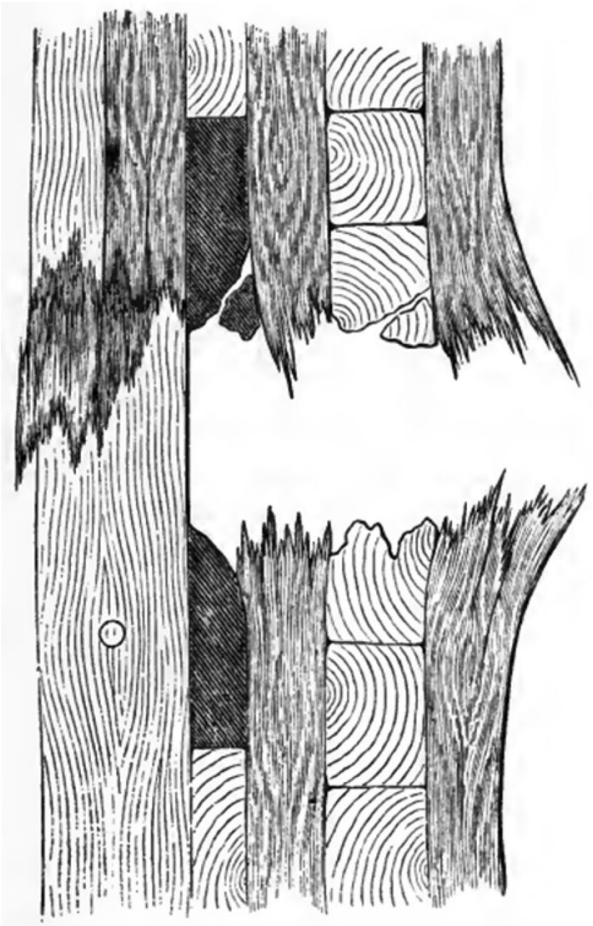

Fig. 39 Cross-section of wood from a target consisting of a 4.5 in. thick iron plate faced with $12 \mathrm{in}$. oak and backed by 20 in. of oak after the impact of one 11 in. shot. From ([25], p. 755) it; for then the compression of the wood between the armour-plate and the iron skin takes up a considerable part of the energy of the blow; so that the backing not only serves to stop shot that may penetrate through the armour-plate, and to deaden vibration, but adds to be dynamic resistance that must be overcome before the plate can be penetrated.

Two drawings of the results of ballistic experiments performed in the 1850s and 1860s on specimens made of wood and iron are presented in Figs. 38 and 39. More such drawings may be found in [23].

The effect of backings made from materials such as cast iron, granite, and various types of wood on the penetration mechanics of wrought iron was also studied in the 1860s. Rigid backings were found to be better than elastic ones ([25], p. 668). Rubber facings were also investigated ([25], p. 744).

Despite the thousands of terminal ballistics experiments that were performed in mid nineteenth century in various countries (UK, France, Italy, Belgium, France, US, Russia), men were aware of their lack of understanding as can be seen from the following quote from Holley in 1865 ([25], pp. 133-134):

The great problem remains unsolved. Indeed, engineers are looking for its solution in diverse or opposite directions. Seeing that the results of experiments, and especially of warfare, in testing guns against armor are developing new features of strength and weakness every day; that these results are still somewhat uncertain, and that time enough has not elapsed to enable the profession at large to collect and digest what facts there are, few if any first principles are universally recognized. This is still more the case since, from motives of gain, pride, or official conservatism, many persons have taken advantage of the limited knowledge on the subject to establish their own schemes, by arranging experiments to show their favorable side and to conceal the other, or by publishing one class of facts and ignoring those of a conflicting character. Or sometimes reticence and a show of mystery are maintained, ostensibly to withhold information from foreign governments, when it is very well known that governments find means of acquainting themselves with each other's practice. The real loser is the government that, in concealing the truth, withholds it from its own people - from the great mass of ingenious and skilful men in civil life who would turn it to good account.

In the context of trying to understand the differences between low and high velocity impact on plates, Holley made the first mention that I know of concerning elastic/ shock wave effects ([25], pp. 280-281): 


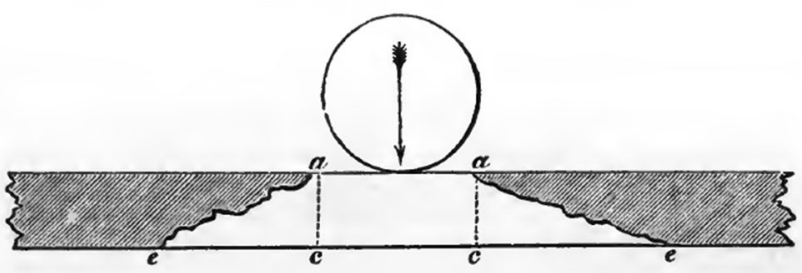

Fig. 40 An early example of the report of what later came to be known as a Hertzian cone crack in solid plate. From ([25], p. 158)

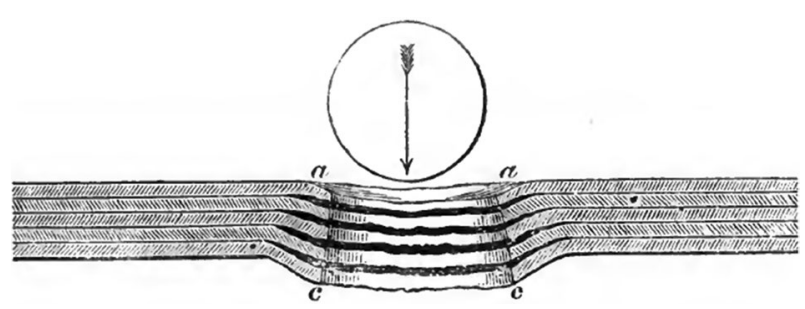

Fig. 41 Mechanism of damage produced in a laminated armour. From ([25], p. 158)

...if the plate is 100 times heavier than the shot, and the shot has a velocity of 1000 feet per second, the plate will be moved bodily at the rate of 10 feet per second. But before this occurs, the whole force of the shot will have been communicated through the mass from one layer to the other, by a wave moving at about the velocity of sound.

Holley also gave a possible explanation of the observation that a $66 \mathrm{lb}$ shot travelling at $1422 \mathrm{ft} . / \mathrm{s}$ had far greater penetrating power than a $200 \mathrm{lb}$ shot travelling at $780 \mathrm{ft} . / \mathrm{s}$, despite the calculated work done on impact being almost the same ([25], p. 136), namely that the faster, lighter shot "does its work in much less time than the other. This explains the whole matter." He had previously pointed out in a footnote on p. 135 of his book [25] that rate/velocity effects were well-known in the slate industry:

The punching of clean, small holes in roofing-slate, by a rapid stroke, when a lighter and slower stroke would smash the whole mass; and many other everyday experiments and processes illustrate the fact, that the element of time essentially modifies the effects of moving forces.

Holley also gave an explanation for the effect of duration of impact as follows:

In the case of the high velocity, the effect was wholly local, because the surrounding material had not time to propagate the vibrations throughout the mass. In other words, the cohesion of the material was not sufficient, in the time allowed, to overcome the inertia of the sur-

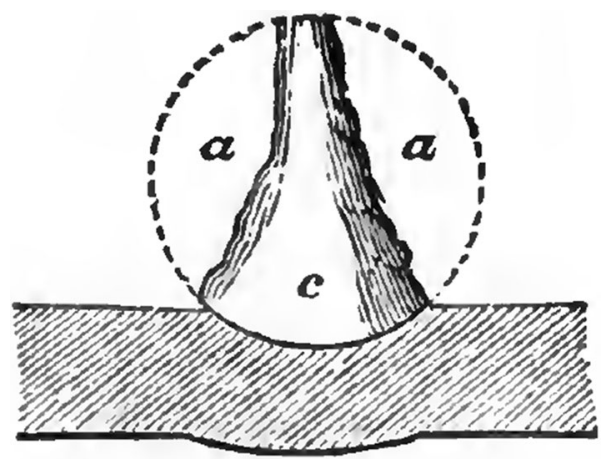

Fig. 42 Fracture of a spherical shot caused by impacting armour. From ([25], p. 198)

rounding mass. The distribution of the effect, in the other case, was due to the low velocity. In both cases, the work done might have been the same.

In a discussion of laminated and solid armour plate for wooden ships ([25], pp. 156-157), Holley compared the action of a shot with a punch in a workshop. He pointed out that in a workshop a plate rests upon a die containing a hole whose diameter is shown schematically as $a c$ in Fig. 40. No such hole exists when a shot impacts an armour plate. So the diameter of the rear of the hole produced by the impact of a sphere is much greater $(a e)$ meaning that the load is distributed over a much larger area. Lamination substantially reduces the area within the fracture zone (see Fig. 41) meaning that laminated armour is more easily pierced than solid armour.

I believe that Fig. 40 may be the first published drawing of what later became known as 'Hertzian fracture' after the German scientist who first analysed the elastic stress field under an indenter and showed qualitatively that the lines of maximum shear stress form a cone [159-162]. The idea that the cone produced by Hertzian fracture spreads the load in hard-faced body armour (and thus reduces injury to the wearer) was proposed in 1989 by Field et al. [163].

One disadvantage of spherical shot that Holley identified is shear fracture (Fig. 42). He comments that when a sphere strikes a plate "the mass $c$ is directly arrested and supported; but the overhanging mass $a a$, having no support, often breaks away, and having failed to impart its momentum to $c$, strikes a large area of the plate, in a salvo of small pieces, with greatly diminished velocity and effect" ([25], pp. 198-199). For this and a number of other reasons Whitworth and others developed cylindrical shot around this time [20].

These were the sort of experiments that were being performed in the years around the time (1859-1860) that the decision was taken in France, Britain and the US to start building ironclad wooden warships. No fast-response 


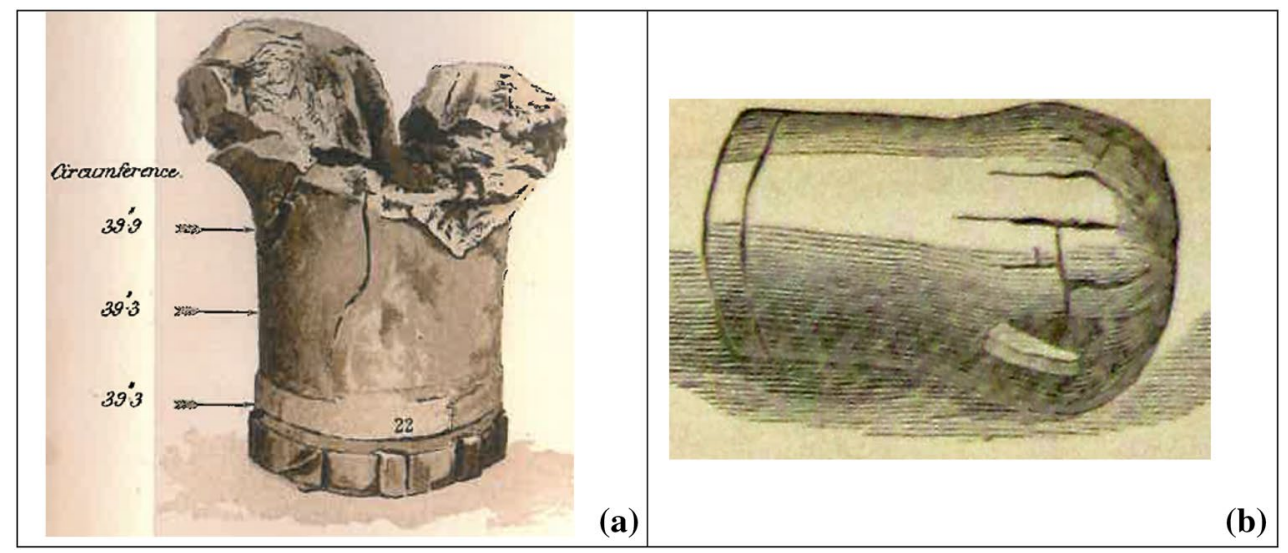

Fig. 43 a Body of a recovered 38 ton shell (12.5 in. diameter) after striking an $11 \mathrm{in}$. thick compound plate ( $7 \mathrm{in}$. of iron faced by $4 \mathrm{in}$. of steel that had been welded together) of lateral dimensions $10 \mathrm{ft}$. by $5.5 \mathrm{ft}$. at $1425 \mathrm{ft} . / \mathrm{s}$. From [165]. b Recovered Whitworth shell that was fired at $1538 \mathrm{ft} . / \mathrm{s}$ against a 19 in. thick steel plate made by $\mathrm{M}$.

optical diagnostics or electrical stress or strain gauges were then available. In the absence of such diagnostics, all the investigators of the time could do was to construct targets representing sections of proposed armour systems, fire at them, and then describe, draw (and later photograph) the resulting damage ([25], p. 143 and following) (see, for example, Figs. 37, 38, 39). This was expensive, but still cheaper than firing at complete ships or fortifications. However, there were issues around about how large to make the targets as Hewlett noted that projectiles that struck near the edge of a plate produced more damage ([155], p. 124). There were many thousands of such descriptions in the military research literature of the second half of the nineteenth century.

All this was known at the time to be very unsatisfactory, so that, for example, in 1873, Bashforth lamented the way that terminal ballistics experiments had been performed up to that date [58] (p. xix):

The very numerous and costly experiments on the penetration of iron plates throw little light upon the subject, because they have been made on no system, by the use of shot which generally broke up in penetrating. Much valuable information might be derived from experiments carefully conducted on a small scale, by the help of a reliable chronograph, with shot made of the Whitworth metal, or some other metal which did not break up on penetrating.

No doubt many qualitative phenomenological observations were made during all the thousands of ballistic tests that were performed during the years from the 1850s up to the First World War, but only a small fraction were reported in visual form, probably due to the skill needed
Schneider of dimensions $10 \mathrm{ft} .10 \mathrm{in}$. by $8 \mathrm{ft}$. $7 \mathrm{in}$. The mass of the shell was not given, but Browne reckoned the 'stored-up work' was 34,080 foot-tons [a foot-ton is the amount of energy expended in raising one ton $(2240 \mathrm{lbs})$ a distance of $1 \mathrm{ft}$.]. From [166]

(and hence the high cost) of producing engravings from photographs. Some of the most detailed were published in the plates accompanying the articles by Browne [164] and O'Callaghan [165] in 1884. Examples are given in Fig. 43.

It is likely that observations of the deformation produced by impact such as those shown in Fig. 43 led to the remarkable rod-on-anvil experiments (Fig. 44) reported by Alphonse, Comte de Maupeou d'Ableiges (Directeur du Génie Maritime, France) in 1902 some four decades before the famous papers on this topic by G. I. Taylor and co-workers reporting studies they had performed during the Second World War [167-170]. de Maupeou's paper is a wide-ranging overview of research that was being carried out in France at the beginning of the twentieth century on topics of relevance to the French navy. de Maupeou did not he say why these rod-on-anvil tests were performed or by whom or whether any useful information was obtained from them. Although de Maupeou did not give the dimensions of the cylinders shown in Fig. 44, he did include a graduated

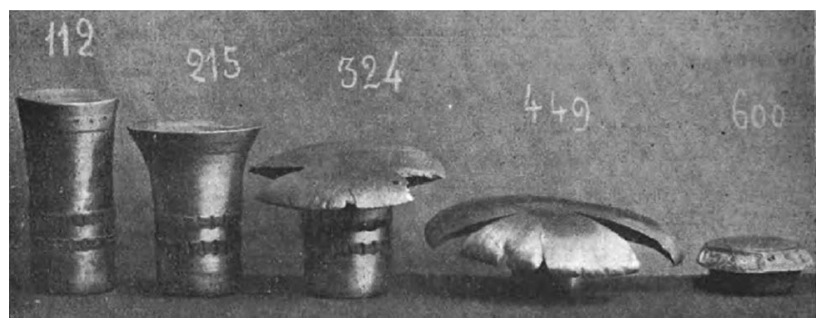

Fig. 44 First reported rod-on-anvil experiments (1902) for steel. This test later became known as Taylor impact. The velocity of impact in $\mathrm{m} / \mathrm{s}$ is written above each deformed cylinder. The dimensions of the cylinders were not given but may be deduced from the scale bar in Fig. 45. From $[171,172]$ 


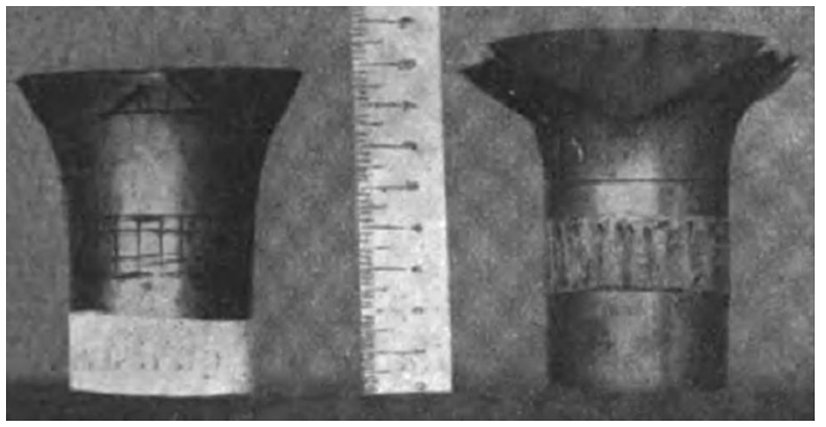

Fig. 45 Photographs of two rod-on-anvil specimens that fractured during impact (velocities of impact not given). Assuming the rear of the cylinders did deform, the scale bar included indicates that the original diameter of the cylinders was about $43 \mathrm{~mm}$. From [171]

scale in a photograph of other cylinders that had undergone fracture during impact (Fig. 45) from which we can see that their diameter was about $43 \mathrm{~mm}$.

The parallel scratch marks on the surface of the lower half of the cylinders indicate that the gun used to fire them was rifled. The only observations he reported was that a minimum impact velocity of $30 \mathrm{~m} / \mathrm{s}$ was required to deform the steel cylinders and that the front of the cylinder could get hot enough to glow while the rear remained cold ("la partie avant du cylindre deviant brûlante, tandis que la partie arrière ne change pas de température"). Intriguingly Régnauld reproduced Fig. 44 in a paper he wrote in 1927 in the Revue de Métallurgie [172]. The University Library in Cambridge had a subscription to this journal. So it is possible that G. I. Taylor may have seen this photograph. Anyway, the rod-on-anvil test is well-named the 'Taylor impact test' as Taylor, unlike de Maupeou or Régnauld, performed a mathematical analysis of the plastic deformation allowing him to estimate the high rate compressive strengths of the metals he was studying.

Although de Maupeou did not report any formal mathematical analysis of the deformation of the cylinders shown in Fig. 44, he (or one of his researchers) was clearly thinking about the wave processes that take place within the cylinders that lead to them slowing down and eventually stopping as the following quote shows:

Pendant que la face avant du cylindre s'écrase, la face arrière subit une série de ralentissements, qui se succedent à des intervals de temps très rapprochés. Le partie arrière du cylindre se ralentit donc progressivement, ce qui explique qu'elle ne se déforme pas comme l'avant. On voit d'ailleurs que la vitesse avec laquelle l'écrasement se propage, ou la velocité de l'écrasement, est bien inférieure à la vélocité de la pression. It serait intéressant de savoir si la première vélocité est constant comme la seconde et, sinon,

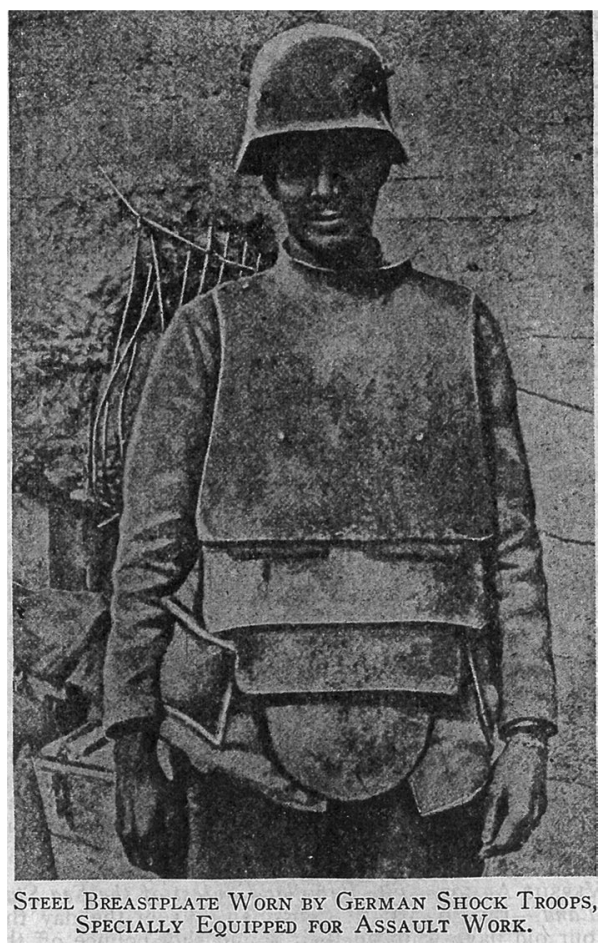

Fig. 46 Steel breastplate worn by German shock troops during World War 1. From [174]

comment elle varie avec la pression. (While the front face of the cylinder is undergoing impact, the rear face undergoes a succession of decelerations, which follow one other at very short time intervals. The rear part of the cylinder thus gradually slows down, which explains why it does not deform. We also see that the speed with which the strain propagates is much lower than the velocity of the stress. It would be interesting to know if plasticity propagates at some constant velocity like the stress does and, if not, how the speed of propagation of plasticity varies with pressure.)

These issues are still being investigated.

Studies of steel armour between the 1850s and the First World War was on heavy armour for naval ships. However, the German army did make some attempt to provide body armour, particularly for their shock troops (Fig. 46). But as can be seen from the following quote (from an English translation published in 1922), it wasn't very well-designed and in addition some accused the suppliers of war-profiteering [173]:

Why were, in 1915, movable firing screens supplied by thousands and in 1918 breast plates by the hundred thousand? The home people were astonished by seeing pictures of 'knights without fear and without reproach' in armor. The procurement of breast plates involved an enormous useless expense and waste of 




Fig. 47 Engraving of a photograph reported by Fuller [184] as having been taken in 1858 of a cannonball (top right) shortly after having been fired from a gun. The method by which photographs like this were taken was described by Thomas J. Skaife in three letters to The Times (of London) in 1858 and also in a book he published in 1860 [181]

material, because they were worn only when the superior officer was in sight, or possibly by a Landswehrsman who had left wife and children and home and was oppressed with anxiety on their account; one could neither shoot not go about while wearing this thing. The front reported at once that they were impractical: we were supplied with new ones. Again we reported for the second and third time, but they continued to arrive. We had the impression that war material contractors had a good piece of business.

In the last decade of the nineteenth century, Garrison reviewed the progress that had been made in iron and steel armour during that century $[175,176]$. He wrote the following about cast iron: "Chilled cast iron is one of the hardest substances known in the arts, but what iron gains in hardness when in this form it loses in other qualities such as elasticity, ductility, etc. In order to possess a maximum of ballistic resistance an armor-plate must be not only very hard, but also elastic and ductile; these fundamental conditions have been thoroughly demonstrated by several trials of chilled cast-iron armor."

\section{The Beginnings of High-Speed Photography}

Although it was about 70 years after the invention of photography in the 1820s $[177,178]$ before it became possible to trigger a camera accurately enough to capture the moment of impact [179], people early on understood the potential of photography to obtain information about ballistic events [180]. Even as early as 1858 it proved possible to



Fig. 48 Diagram of the spinning disc technique for photographing cannonballs emerging from guns. From [182]

capture images ofcannonballs emerging from guns (Fig. 47) [181-183].

Skaife made his original report in a letter to The Times (of London) published on p. 12 of the May 29, 1858 issue:

\section{A FEAT IN PHOTOGRAPHY \\ TO THE EDITOR OF THE TIMES}

Sir, Permit me, through your world-wide journal, to inform your numerous photographic readers, that, on the third and last firing of the 13-inch shell from the mortar battery at Woolwich Common, a few minutes before 12 o'clock this day, I succeeded (with permission of the authorities) in photographing stereoscopically, from behind the battery, the descending shell at the instant of its explosion, when in the air, within a few yards of the flagstaff target together with the target and the Artillery Engineers who fired the shell, which (I believe) unprecedented feat in photography was witnessed by Colonel Burrows, Acting Commandant of the battery, and several other military gentlemen who were present at the time.

I am, Sir, yours obediently, THOMAS SKAIFE

Vanbrugh-house, Blackheath, May 27

Skaife wrote two more letters of increasing length on this topic to The Times in the following months (July 14, 1858, p. 12; August 5, 1858, p. 9). In the third and last of these letters he reported that a 'gentleman' to whom he had shown the pictures exclaimed "What stopped the ball!". He also said he had sent photographic evidence to the editor of The Times to back up his claims, but in 1858 The Times did not publish 


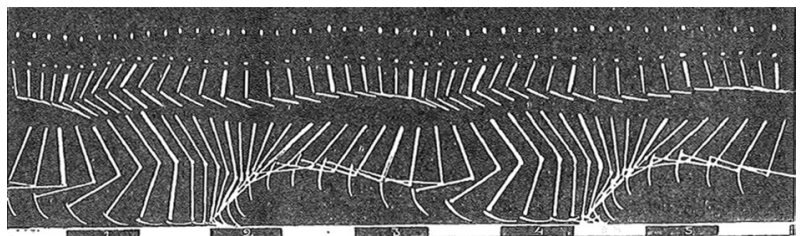

Fig. 49 Photographic sequence of running man. Frequency of images: about 60/s. From [189]

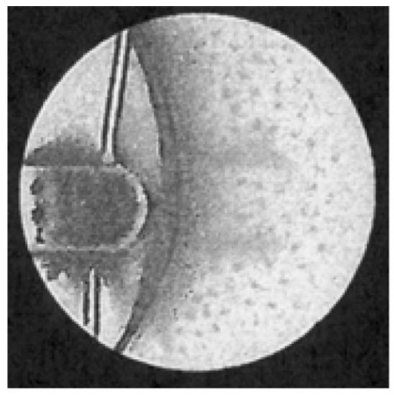

(a)

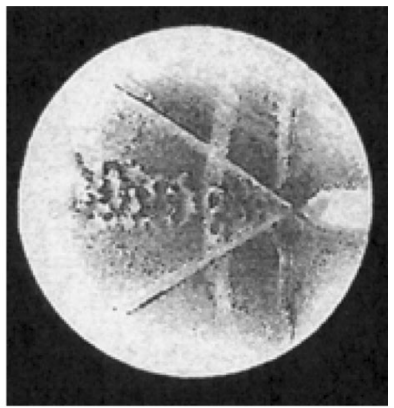

(b)
Fig. 50 Photographs of bullets in flight taken by Mach and Salcher in 1887 revealing the associated air shock waves. a Shock wave ahead of an infantry rifle bullet that was travelling at $438 \mathrm{~m} / \mathrm{s}$ and b shock wave behind an infantry rifle bullet that was travelling at $530 \mathrm{~m} / \mathrm{s}$. From [190]

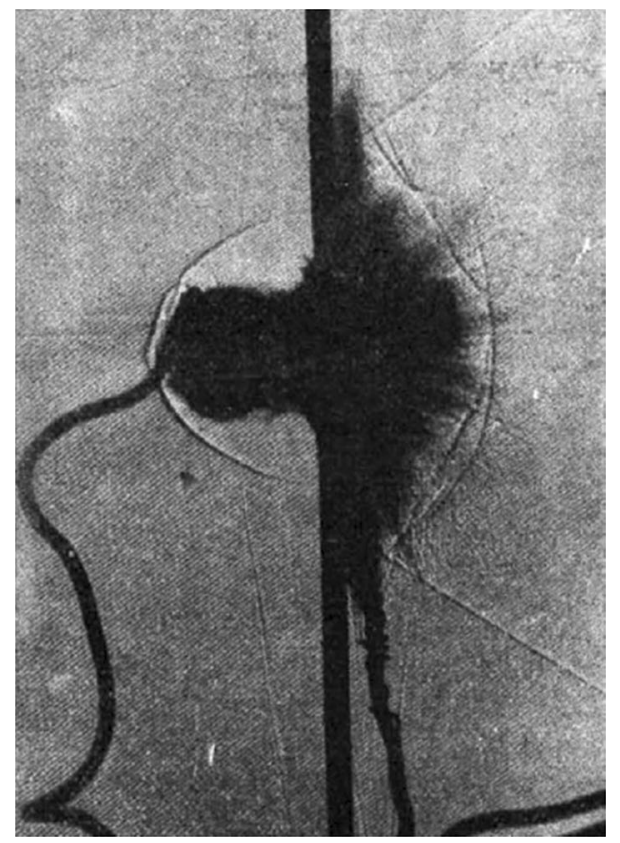

Fig. 51 Shadow photograph published in 1893 of a rifle bullet about half way through penetrating a sheet of glass. Neither the velocity of the bullet nor the thickness of the glass were given, but the bullet velocity can be calculated from the angle to the direction of travel of the conical shock wave in the air on the right hand side of the photograph. From [192]

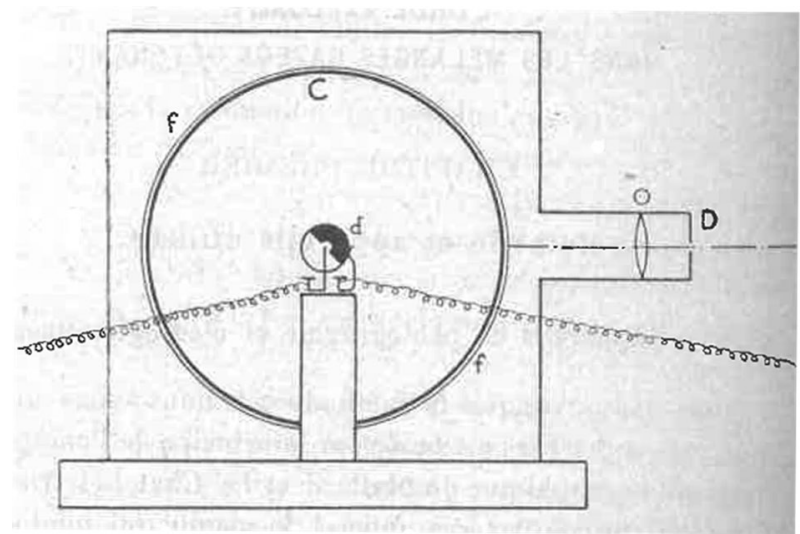

Fig. 52 Early streak photography apparatus (1925) to record shock waves produced by the detonation of gases or explosives. Key: C, horizontal cylinder to which was attached a piece photosensitive paper, f, $6 \mathrm{~cm}$ in width and $75 \mathrm{~cm}$ long. From [193]

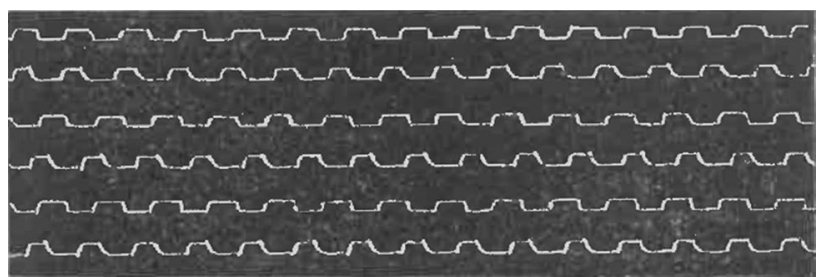

Fig. 53 Alternating traces of the tuning-fork timing signal and the rotation of cylinder $\mathrm{C}$ (with photographic paper attached) shown in Fig. 48. From [193]

engravings of photographs. So it is not clear from where Fuller obtained the engraving shown in Fig. 46.

After Skaife, a spinning disc method was developed at Woolwich, England, to 'freeze' cannonball motion (Fig. 48). Sadly the author of this report did not arrange for engravings to be made of the photographic images, and I have not been able to find out whether the photographic plates still exist.

By the 1880 s, it became possible to study photographically the motion of running men (Fig. 49), how horses gallop $[185,186]$, the splashes produced by the impact of liquids on solid and liquid surfaces [187, 188], and the shock waves produced by bullets in flight (Fig. 50).

Not long after (1893), Boys photographed the moment of penetration of a glass sheet by a rifle bullet (Fig. 51) [179]. Although Boys did not give the velocity of the bullet, this information can be calculated from the angle of the conical shock wave in the air on the right hand (impact) side of the photograph. The technology that made photographs like this possible were short-duration flash bulbs. Histories of highspeed photography relevant to ballistics have been written by Dalton [191], Field [177], Fuller and Rendell [178] and Fuller [184]. 
Fig. 54 Two examples of streak photographs from Laffitte's paper published in 1925. a Effect of coarse sand (3 mm particle size) on the detonation of a mixture of $\mathrm{CS}_{2}$ and oxygen in a $23 \mathrm{~mm}$ diameter glass tube. The sand shortened the distance needed for the deflagration to detonation transition from 58 to $45 \mathrm{~cm}$. b Detonation of $6 \mathrm{~g}$ of dynamite in a glass tube $3.7 \mathrm{~mm}$ diameter, $50 \mathrm{~mm}$ length. The detonation velocity was measured as being about $1700 \mathrm{~m} / \mathrm{s}$

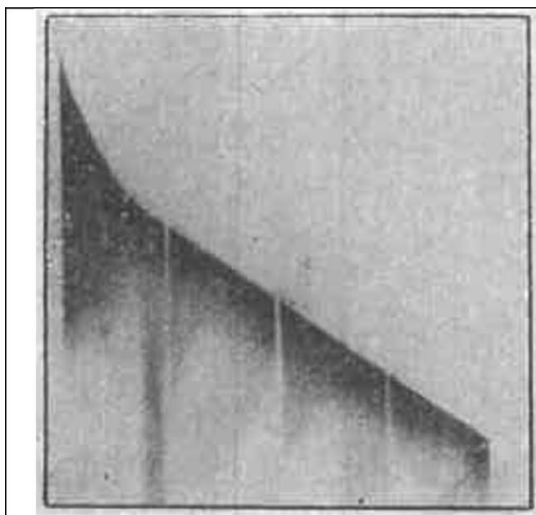

(a)

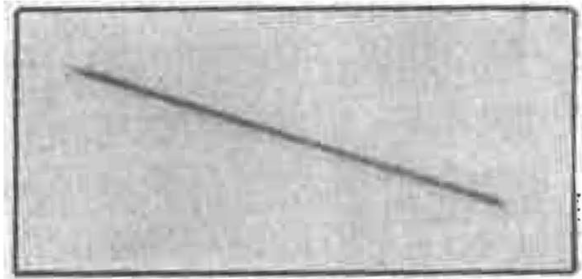

(b)

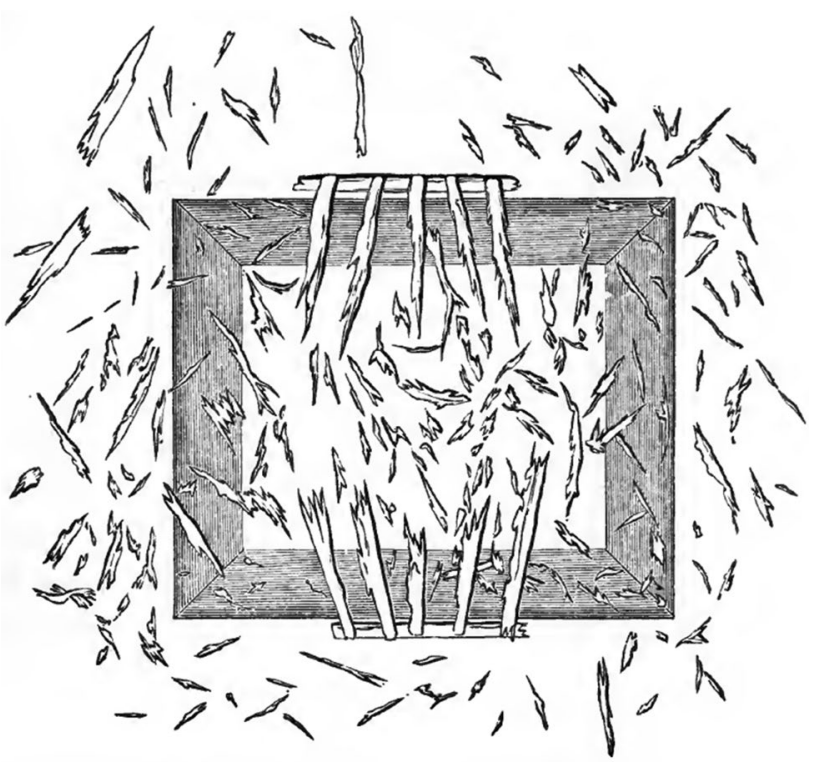

Bridge of oak, shattered to atoms by a box of 25 lbs. of gun-cotton.

Fig. 55 Effect of 25 lbs on guncotton on an oak bridge. From ([25], p. 795)

The cylindrical apparatus shown in Fig. 52 (dating from the mid-1920s) allowed streak photographs to be taken of shock waves produced by the detonation of gases or explosives [193]. The cylinder could be spun using an electric motor at a rate between 55 and 60 rps (any faster and the photographic paper was found to tear apart). Figure 53 shows alternating traces of the timing signal (provided by a tuning fork vibrating at $100 \mathrm{~Hz}$ ) and the rotation of the cylinder $C$ shown in Fig. 52.

Laffitte's paper contains a number of streak photographs of shock waves propagating within glass tubes. Two examples are given in Fig. 54.

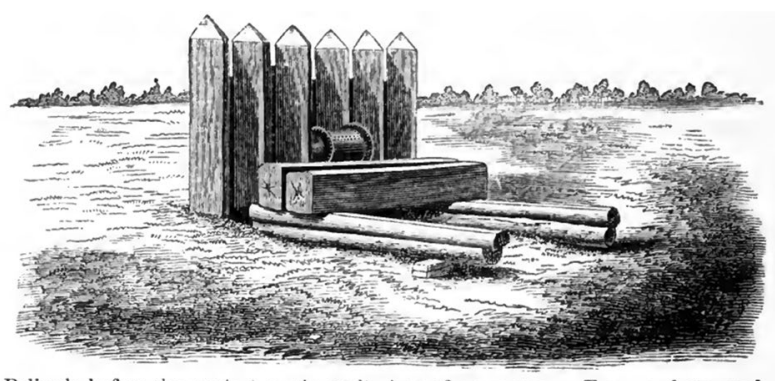

Palisade before the expiusion of a $2 j-1 b$. box of gut-cotton. From a photograph.

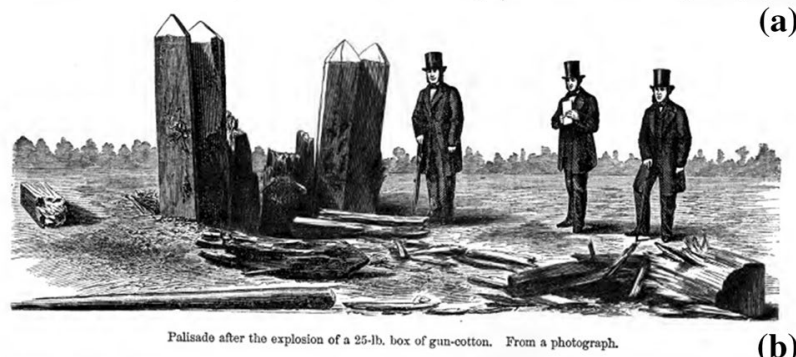

(b)

Fig. 56 Engravings of photographs of the effect of $25 \mathrm{lbs}$ on guncotton on a wooden palisade. a Before explosion. b After explosion. From ([25], pp. 830-831)

\section{Blast}

Then as now armour and fortifications are subject to attack by blast as well as impact. Although guncotton, a detonating explosive, was invented in the 1840s [194], it was not until the 1860s that it was introduced into service after ways of making and handling it safely had been developed [195-197]. Its effect on wooden structures such as bridges (Fig. 55) and palisades (Fig. 56) was found to be devastating.

The combination of ballistic impact and blast was first studied in the US in 1887. Figure 57 shows the result of the sequential impact of three $122 \mathrm{lb}$ shells (each filled with 2.3 lbs of dynamite) on a target consisting of a doublethickness 14 in. wrought-iron wall on top of which was a 3 in. thick iron roof. The conclusion of this study was that a 


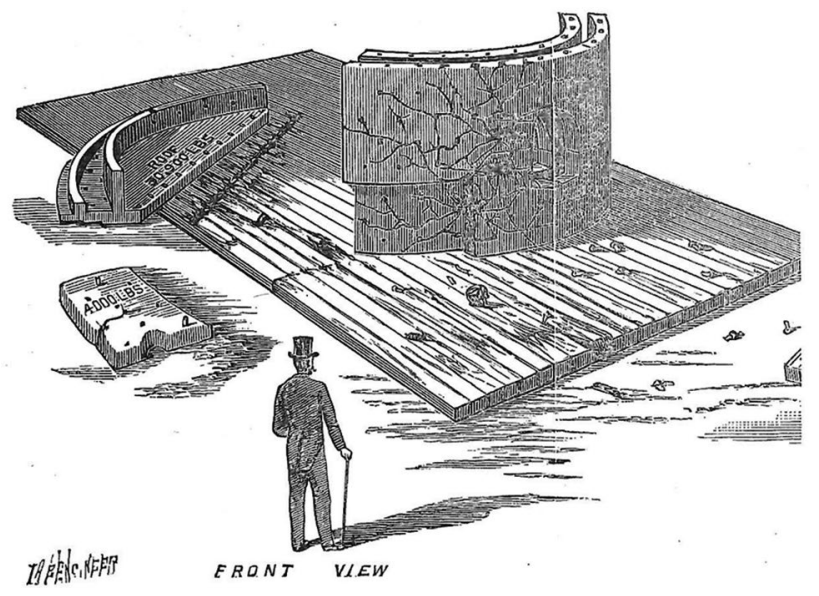

Fig. 57 Result of an American experiment on the combined effect of blast and impact due to the explosion after impact of a dynamitefilled shell on wrought-iron armour. From [198]

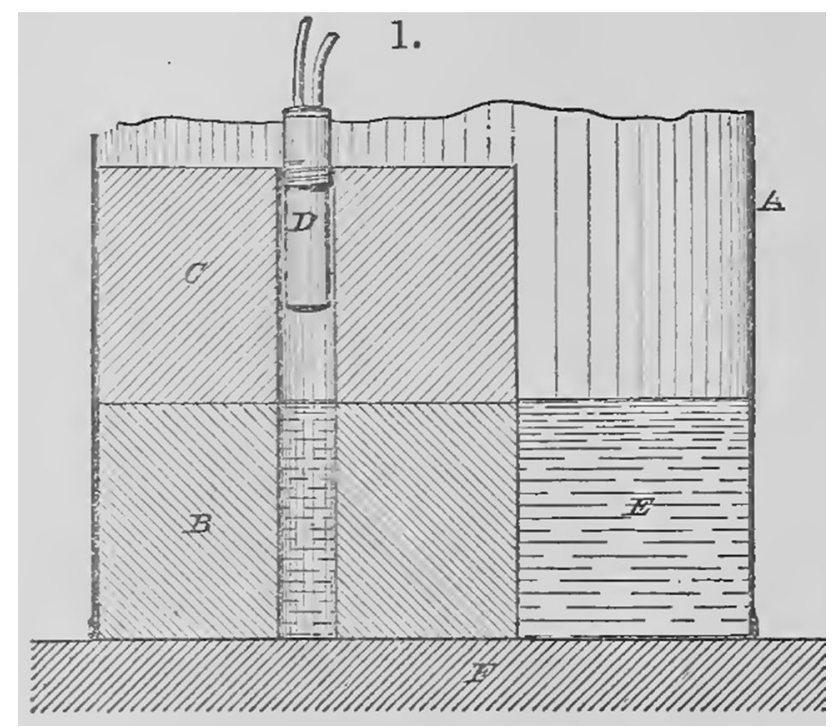

Fig. 58 Diagram of Munroe shock experiment. Key: A, 5.5 in. diameter tin can; B, 3.5 in. diameter disc of wet guncotton; C, 3.5 in. diameter disc of dry guncotton; D, detonator; E, water; F, iron beam. From [199]

combination of ballistic impact and blast could overcome an armoured fort that was able to indefinitely withstand ballistic impact on its own.

In 1888 Munroe reported that the shocking of an iron beam by a $5.5 \mathrm{in}$. diameter cylinder made up of both dry and wet guncotton in mechanical proximity with water (Fig. 58) produced ripples with a wavelength of about $1.5 \mathrm{~mm}$ around the circumference of the circle of shocked iron (Fig. 59). He advanced no explanation for the ripple effect in the paper, saying [199]: “...the objects for which this station [the Torpedo Station, Newport, RI, USA] does not embrace the

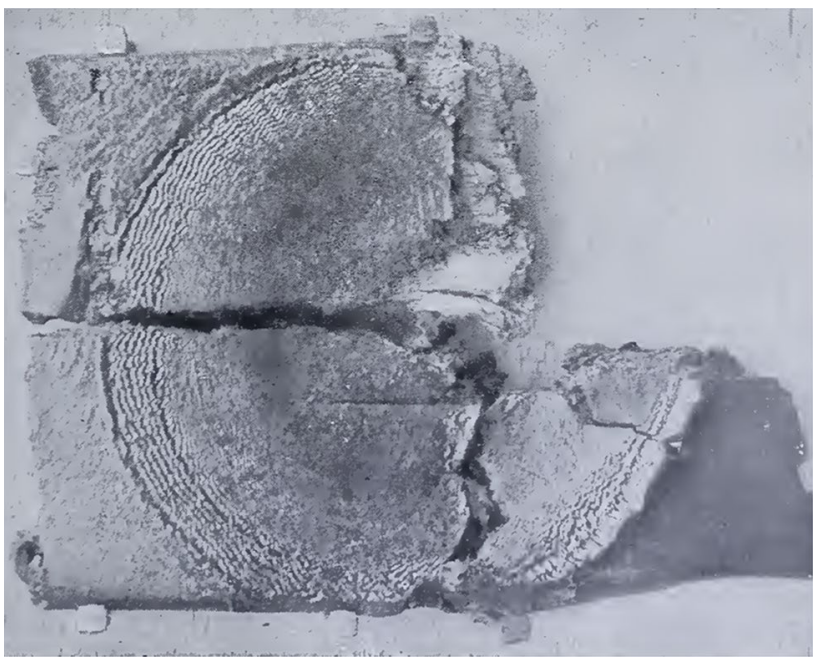

Fig. 59 Wave-like effects on the iron beam labelled as ' $F$ ' in Fig. 58 produced by the experiment shown in the same figure. From [199]

carrying on of researches for purely theoretical purposes..." It appears that this wave effect was not investigated (or if it was, the studies were not well known [200]) as in 1954 Allen et al. reported such an effect on the end of a steel cylinder fired obliquely at a thin target [201] saying that "the mechanism responsible for production of these waves is somewhat obscure". However, after explosive welding was developed in the early 1960s [202-206], an explanation for this strikingly regular wave phenomenon was eventually given as a consequence of the rapid flow of material across a solid surface [207-212].

\section{The Beginnings of Serious High Strain Rate Testing}

As far as I have been able to discover, the first time anyone reported a quantitative difference between the dynamic and static tensile strengths of any material was Holley in 1860, for in 1865 Holley quoted from a report he wrote in 1860 to the effect that "the dynamic tensile strength of an iron cannon burst using gunpowder was 75,684 lbs per square inch whereas its strength measured using a 'testing machine' was only $26,866 \mathrm{lbs}$ per square inch" [25] (p. 300). Certainly no comparable measurement was known to Cox who wrote in 1849 [138]: "The dynamical strength of beams, or their capability of sustaining weights moving rapidly over them, has never been satisfactorily discussed." He said this was for two reasons. The first was that "the subject has but comparatively recently grown into importance." The second reason was "because of its excessive and insuperable difficulties when investigated by the exact methods of theoretical 

century tuning-fork/lamp-black method of recording a timing dynamic mechanical experiment. From [219]
Fig. 60 Classic nineteenth signal of known frequency in a

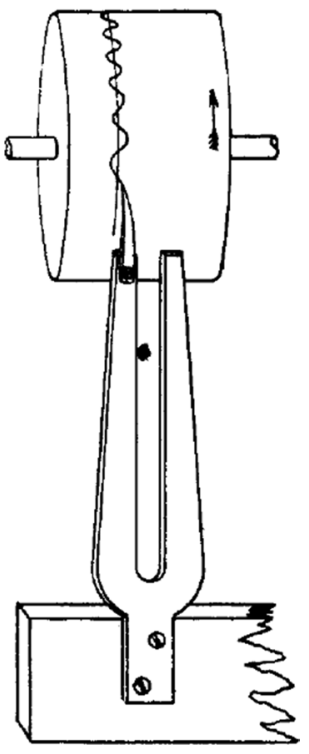

mechanics." Cox's own interest in the topic was due to "its influence on the security of railway traffic."

John Hopkinson is usually credited with demonstrating (in 1872) that iron wires break in a different manner when loaded dynamically by a falling weight as compared to statically [213, 214]. What John Hopkinson thought he had shown was "...two blows were equivalent when...the velocities or heights of fall are equal" [213] rather than their 'vis viva' (kinetic energy) or momenta. However, Bell was later very critical of John Hopkinson's study saying that his "...results were inadequate for any firm conclusion" [215]. When John Hopkinson's son Bertram repeated his father's experiment in 1905 [216], his main conclusion was that in dynamic loading iron and copper wires remained elastic to strains greater than the static elastic limit.

In 1891, Dunn (who worked for the Ordnance Department of the US Army) was wondering whether the recently developed metal crusher gauges (whose shortening was used to determine the maximum pressure produced by the explosion of gunpowder within guns [217, 218]) were giving accurate results. The problem was that military engineers were using the static strengths of the metal from which the gauge was made. In one of the papers he wrote in 1897 about his studies, he wrote [219]:

It is a mistake to assume that a piece of metal, or other material, will show the same effect when subjected, on the one hand, to a given force applied slowly (as in a static testing machine) and, on the other, to the same force applied and withdrawn within thousandths or tens of thousandths of a second.

He described in his 1897 papers the problems he had had to overcome [219-221]. The first was that the classic tuning-fork method [63] of measuring time on millisecond

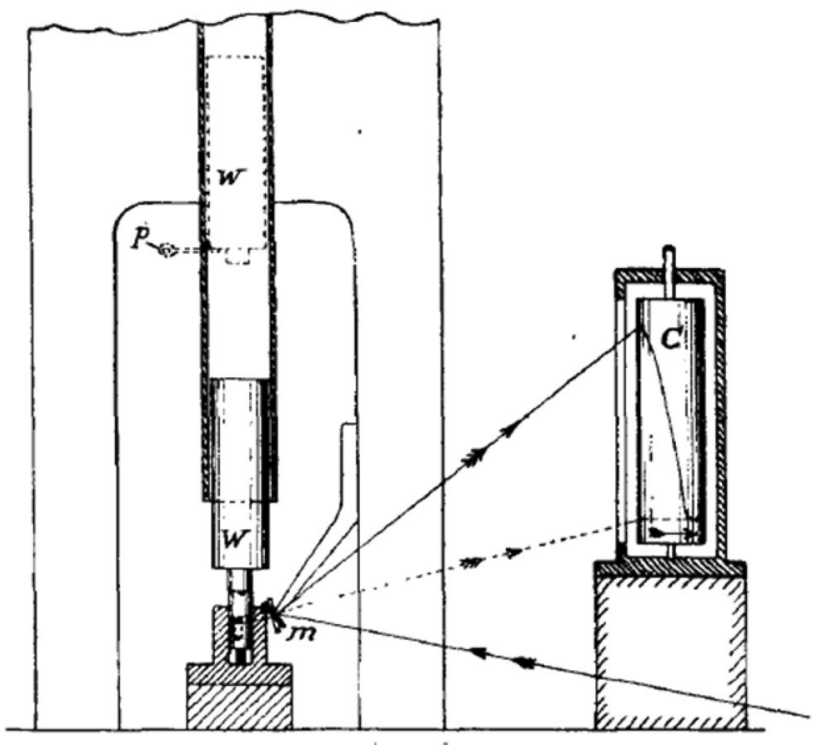

Fig. 61 Schematic diagram of Dunn's dropweight apparatus with photographic method of recording displacement during impact. Key: $\mathrm{W}$, dropweight; $\mathrm{C}$, rotating glass cylinder coated in photosensitive chemicals; m, mirror; P, hardened steel plug. From [219]

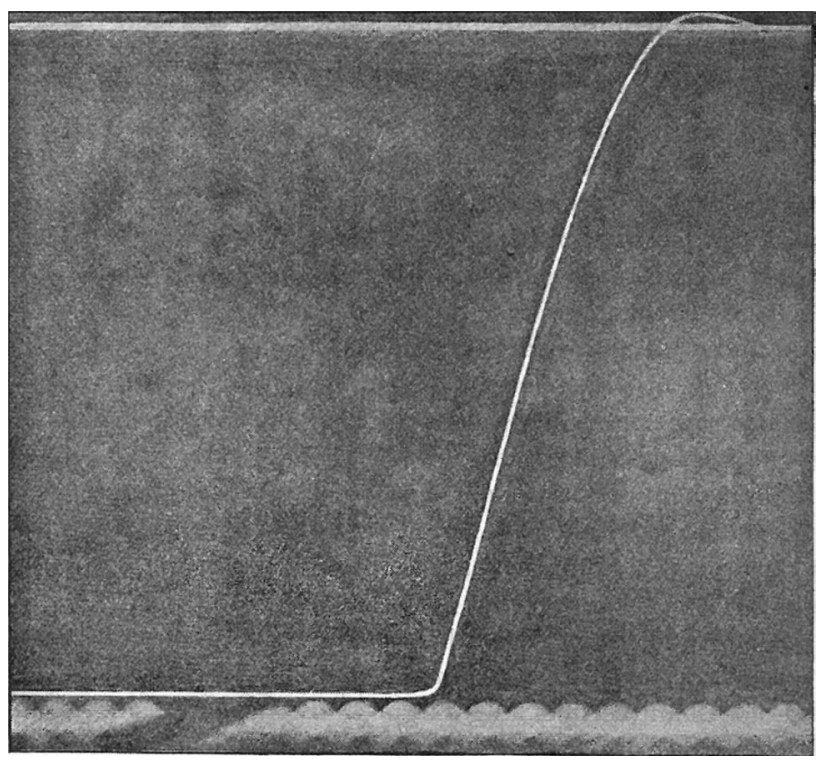

Fig. 62 The top line is the displacement trace produced during a dropweight test by the rotation of mirror ' $m$ ' in Fig. 61. The oscillating trace along the bottom of the photograph is an optical recording of the timing signal produced by a tuning-fork. From [219]

timescales using a lamp-blackened metal surface (Fig. 60) became less and less accurate as the frequency of the tuning fork was increased due to the angle the sinusoidal trace made with a straight line along the middle line of the sinusoid becoming shallower. Dunn also used a tuning-fork to measure time but replaced the mechanical method shown 


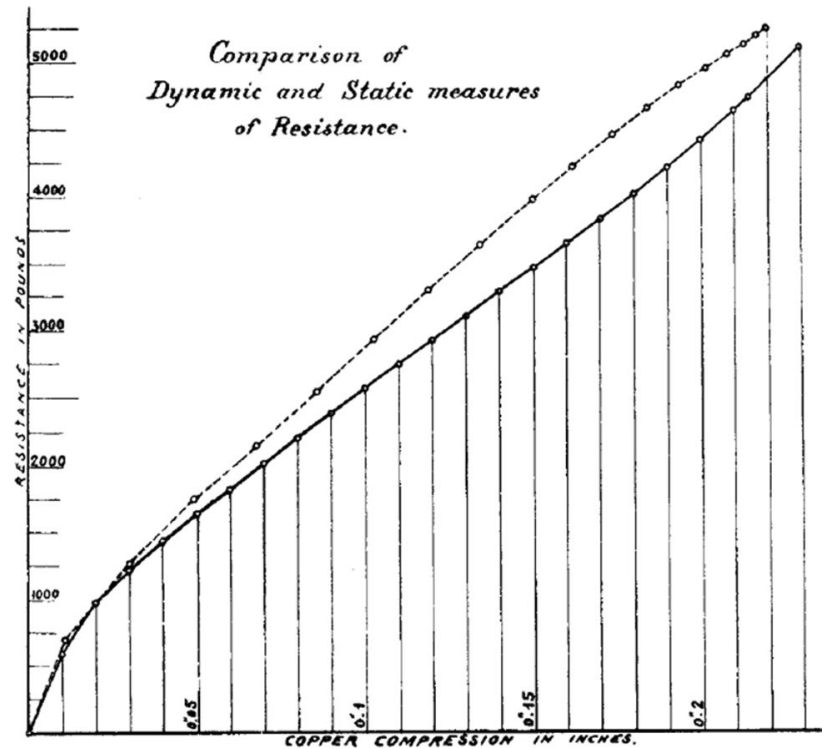

Fig. 63 First known graph of the difference between the quasistatic (solid line) and dynamic (dotted line) compressive strength of a metal (copper). The dynamic data obtained using the dropweight machine shown in Fig. 61. From [219]

in Fig. 60 with a photographic technique (he used the Sun as the light-source), which meant the experiments had to be performed in a blacked-out room. He claimed the time accuracy was thereby improved from 2 to $0.25 \mathrm{~ms}$. He thought that the shortest time interval his optical technique could distinguish was $0.1 \mu \mathrm{s}$. To achieve this he calculated that it would require the diameter of cylinder $C$ to be increased to $12 \mathrm{in}$. and spun at 10,000 rpm He also used an optical method to record the displacement of the dropweight during impact (Fig. 61). An exampleof the optical traces recorded using this apparatus is shown in Fig. 62. More details of the development of his experimental method may be found in [220, 221]. A discussion with other researchers of his technique and results was published the following year [222]. A comparison of the quasistatic and dynamic stress-strain curves that Dunn obtained for copper is given in Fig. 63. The dynamic strength can be seen to be greater than the quasistatic strength (note that when Bell discussed these results in 1973 [215] he wrongly labelled the upper curve as the quasistatic one). Dunn did not give a figure for the strain rates in his experiments.

Some experiments performed by Sears in the Engineering Laboratory in Cambridge, England in the early twentieth century $[223,224]$ laid the foundations of what later became known as the Hopkinson pressure bar [225, 226]. Sears was interested in checking whether the velocity of elastic waves in rods could be calculated from static measurements of the elastic modulus. He performed the check by devising an apparatus to measure the contact times of the impact of two



Fig. 64 Pendulum bar device for measuring the contact times of round-ended rods. From [223]

round-ended rods suspended by wires (Fig. 64). He used round-ended rods so that "...the nature of the impact should not be materially affected by slight deviations from axial collinearity". The contact times were measured electrically by means of a steady current from a battery and a ballistic galvanometer (current only flowed when the rods were in contact so the angular deflection of the galvanometer was proportional to the contact time).

Sears investigated steel, copper and aluminium. He found that the elastic wave velocity measured dynamically agreed with that calculated using the statically-measured elastic modulus to within $0.3 \%$ i.e. "well within the limits of experimental error" and so "we may therefore assume that Young's modulus has the same value whether the loading is slow or sudden". Sears concluded his second paper [224] with the following expression of thanks to Bertram Hopkinson:

I have to express my thanks to Prof. Hopkinson, of the Engineering Laboratory, Cambridge, where the work was carried out, for his unfailing interest and kind advice. When he first suggested that I should undertake experiments on the velocity of wave-propagation in metal rods, the developments he had in view were, I believe, of a far more practical character than those here described. I happened, however, to be interested 


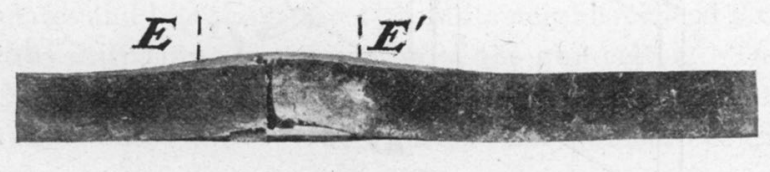

Fig. 65 Incipient spall produced in a 1.25 in. thick mild steel plate by the detonation of a slab of guncotton on the underside. From [227]

in the abstract problem of impact, and he has always shewn himself perfectly willing that I should follow up the work on these lines.

An understanding of why explosive loading of iron plates produces spall fracture was first provided in 1912 in the published version of a lecture by the same Bertram Hopkinson that he gave to the North-East Coast Institute of Engineers and Shipbuilders [227]. He used elastic wave theory to explain why scabs of metal are thrown off one side of a metal plate at high speed by the detonation of an explosive charge on the other side (Fig. 65), a phenomenon later called 'Hopkinson fracture' by Kolsky [228]. These experiments performed in Cambridge, England, had almost immediate implications for battleships and tanks in the Great War. Tragically Bertram Hopkinson died while flying his own plane on August 26 1918, but the significance of his work for the Allied war effort was described in a number of obituaries [229-233], the introduction to his collected papers [234], summaries of his wartime experiments on explosives and explosive devices [225, $235,236]$, and in a radio tribute which was broadcast on the BBC on March 5, 1937 (a transcription of this broadcast may be found as an Appendix to [237]).

From 1912 onwards, therefore, researchers had both the theoretical and experimental tools to understand, measure and explain the phenomena that their predecessors had observed but struggled to explain. No longer would it be adequate simply to fire a gun at a target and describe what happened.

The first symposium on the impact testing of materials was held in 1922 in Atlantic City, NJ as part of the annual meeting of the American Society for Testing Materials [238]. Nine research papers (mostly on the dynamic fracture of materials) were published as a result of this symposium along with a very helpful survey and bibliography of published articles about the impact testing of materials up to 1922 [239]. Another symposium on impact testing was held by the American Society for Testing Materials was held in 1938 [240]. However, it was not until 1957 that the first conference entirely dedicated to "The Properties of Materials at High Rates of Strain" was held, hosted by the Institution of Mechanical Engineers in London [241]. There were no papers in this conference on the

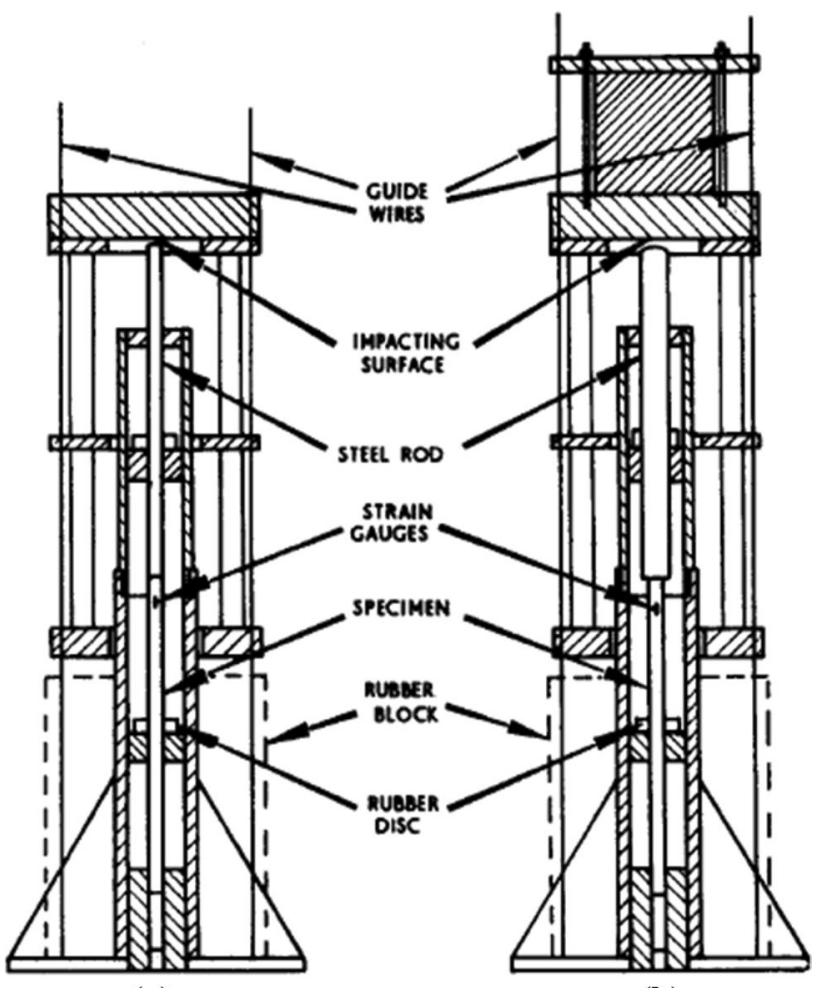

(a)

(b)

Fig. 66 Schematic diagrams of the hybrid dropweight-Hopkinson bar high rate mechanical testing machines developed in the Engineering Department of Oxford University in the early 1950s. From [247, 248]

split Hopkinson pressure bar technique, but there were three papers that reported results obtained using hybrid dropweight-Hopkinson bar machines (Fig. 66) [242-244]. The 1957 conference appears to have been a one-off. It was not until 1974 that the first in a series of conferences on the "Mechanical Properties at High Rates of Strain" was held in Oxford, UK [245]. This conference was held in Oxford every 5 years until 1994 when it joined with the International Conference series of the DYMAT Association that



Fig. 67 Photograph of a 2 in. Berry strain gauge in use in 1913. From [264] 


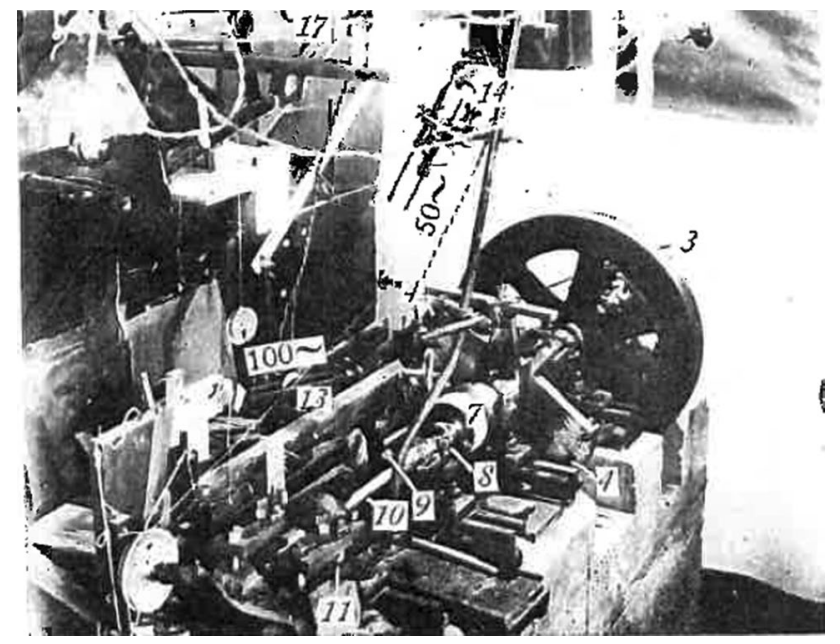

Fig. 68 Photograph of high-rate torsion testing machine developed in Japan in the 1930s. From [263]

had begun in 1985 [246], and which has been held since then every 3 years up to the present day.

Although the first known paper on the effect of strain (along with temperature) on the resistance of metal wires was published in 1856 [249], and the phenomenon was studied from time to time in the decades that followed [250-255], it took until the early 1930s for it to become common [256, 257]. In the late 1930s, the aircraft industry seems to have been the driving force for the use of electric strain gauges for dynamic strain measurements in connection with the vibration and fatigue of propellers [258] and



Fig. 69 Schematic diagram of the optical technique used by Itihara for measuring strain in his dynamic torsion test. From [263]

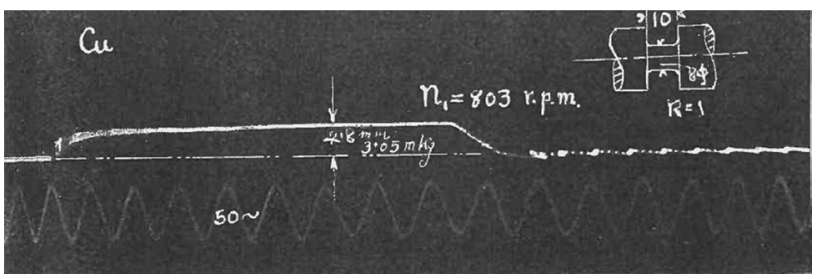

Fig. 70 Example of a dynamic torsion result obtained for copper in 1935. From [263]

the dynamic loading of landing gear $[259,260])$, presumably because outputting the signal electrically was easier and more convenient than using the optical methods that were the only alternative at the time [261-263] (early twentieth century strain gauges were basically calipers with a dial gauge output (Fig. 67) [264] and therefore completely unsuitable for making dynamic measurements).

Between the First and Second World Wars, there seem to have been very few studies of the effect of high strain rates on the stress-strain response of materials with the exception of a study performed in Japan in the mid 1930s of the dynamic torsional response of various steels (Figs. 68, 69, 70) $[263,265-270]$. Note that Itihara, like Dunn 38 years before him, used an optical method of recording the data from his machine (Figs. 67, 68).

During these years, with the exception of these Japanese studies, the term 'impact test' nearly always referred to dynamic fracture experiments such as those famously developed by Russell [271], Charpy [272, 273] and Izod [274].

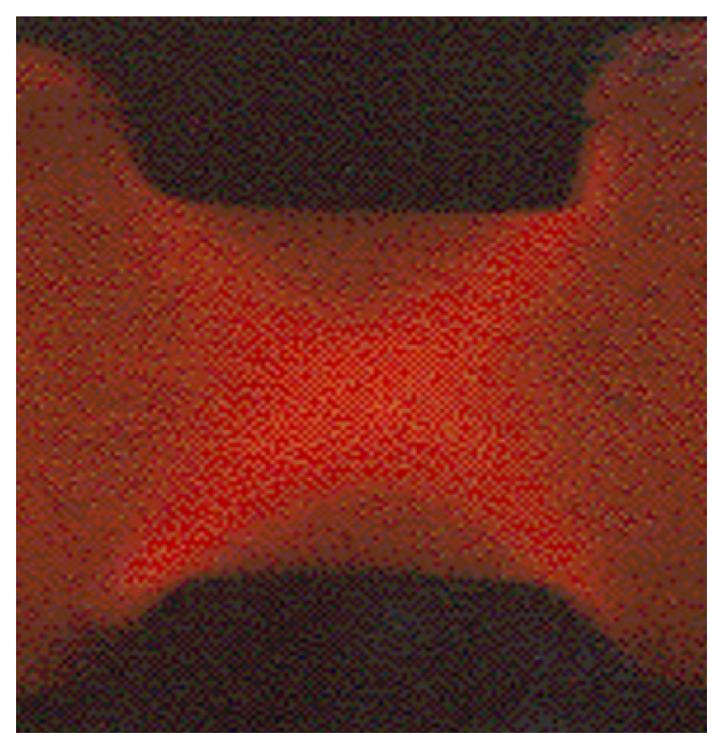

Fig. 71 Photograph of the diffuse heat cross in mild steel produced by punch forging. This study was performed by Johnson and co-workers in the same forging shop as Massey used in 1921 to study this phenomenon [289]. From [290] 

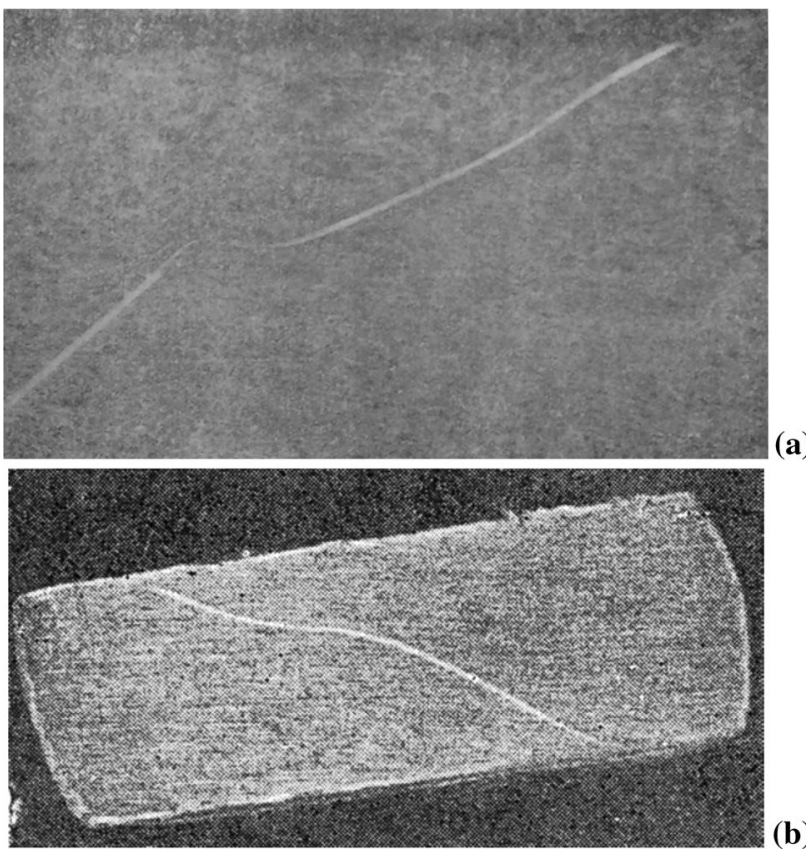

(b)

Fig. 72 a Adiabatic shear band in a steel reported by the Russian investigator Kravz-Tarnavskii in 1928 [291]. b Adiabatic shear band reported by Davidenkov in 1935 in a sectioned and etched steel specimen that had been impacted by a $50 \mathrm{~kg}$ weight dropped from a height of $2.55 \mathrm{~m} \mathrm{[292]}$

Again Japanese researchers also appear to have been in the vanguard of those seeking to make dynamic fracture tests more quantitative [275-280].

One important precursor to dynamic fracture in ductile materials is adiabatic shear banding, ASB [281, 282].
Diffuse heat crosses (a phenomenon similar to ASBs) were first reported by Tresca [283-288] and by Massey in repeats of Tresca's experiments [289]. The first photograph of this phenomenon was obtained by Johnson et al. in 1964 who repeated Massey's experiment (Fig. 71) [290]. But the first true ASBs were reported by Kravz-Tarnavskii in a Russian language journal in 1928 (Fig. 72a) [291]. Although this author's studies were remembered inside the Soviet Union (Fig. 72b) [292, 293], his work does not appear to have been known outside Russia [294]. The record has recently been set right by Dodd et al. [295]. Translations into English of Kravz-Tarnavskii's 1928 Russian paper and Davidenkov's 1935 paper (written in German) may be found on arXiv [296].

Apart from Kravz-Tarnavskii, Davidenkov appears to have been the only Russian researcher to have performed studies on the high rate properties of properties of metals up until the Second World War [297-299]. As some of his work was published in American journals [300, 301], his studies were known to American researchers during that conflict [302].

Bertram Hopkinson's pressure bar was neglected until the Second World War [303] when Enrico Volterra and G. I. Taylor devised a two-bar system suspended from wires (Fig. 73) [167, 304] (similar to Sears' design 35 or so years before $[223,224]$ ) in order to obtain the dynamic stress-strain curves of soft materials such as polyethylene (Fig. 74). It should be noted here that in the 1930s there was an interest in the tyre industry in the high rate properties of vulcanized rubber [305-310]. The testing machines used in these studies were either modified Charpy pendulum impact testers or drop-weight machines.
Fig. 73 Enrico Volterra's design of a split Hopkinson pressure bar [304]. This was designed and used during the Second World War [167]



Fig. 4. 


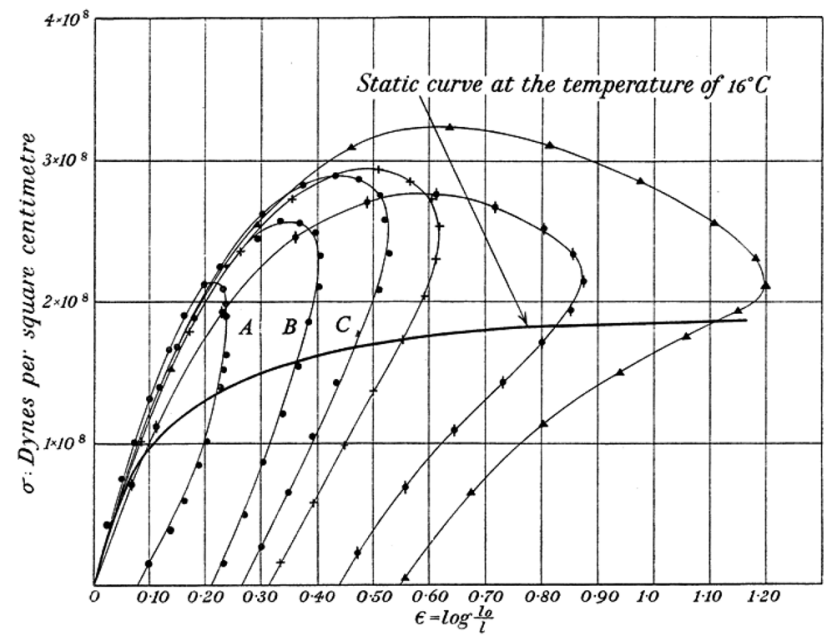

Fig. 74 First published compressive high-rate stress-strain curves (for polyethylene) obtained using a split Hopkinson pressure bar (Volterra's design). From [167]

G. I. Taylor and R. M. Davies also devised and built a direct-impact Hopkinson pressure bar (Fig. 75) in 1942 in order to measure the dynamic strengths of explosives such as cordite (Fig. 76). For reasons of secrecy this work was not published until 1958 [311].

As already mentioned, the suspended bar system developed by Davies, Taylor and Volterra was limited to obtaining the strengths of very weak materials. Herbert Kolsky's innovation in 1949 [312] was to load one end of a two-bar system using a detonator (Fig. 77). This produced a stress pulse of sufficient amplitude to deform metals (Fig. 78). Note that Kolsky used condenser microphones rather than strain gauges to record the stress pulses half-way along and at the end of the output bar (Fig. 77), despite strain gauges having already been used by several authors in the late 1930s to record stress pulses travelling along rods (Fig. 79).

Why did Kolsky use condenser microphones rather than strain gauges to record the strain pulses in the bars? One reason might be that commercial strain gauges (Fig. 80) had only recently become commercially available [260, 316-318]. But the main reason was given by Davies in a paper he published in 1948 [226]: unlike a strain gauge that can only be attached to one point on a surface, condenser microphones respond to the motion of a surface and therefore an accurate measurement can be made even if the distribution of stress across the bar diameter is non-uniform.

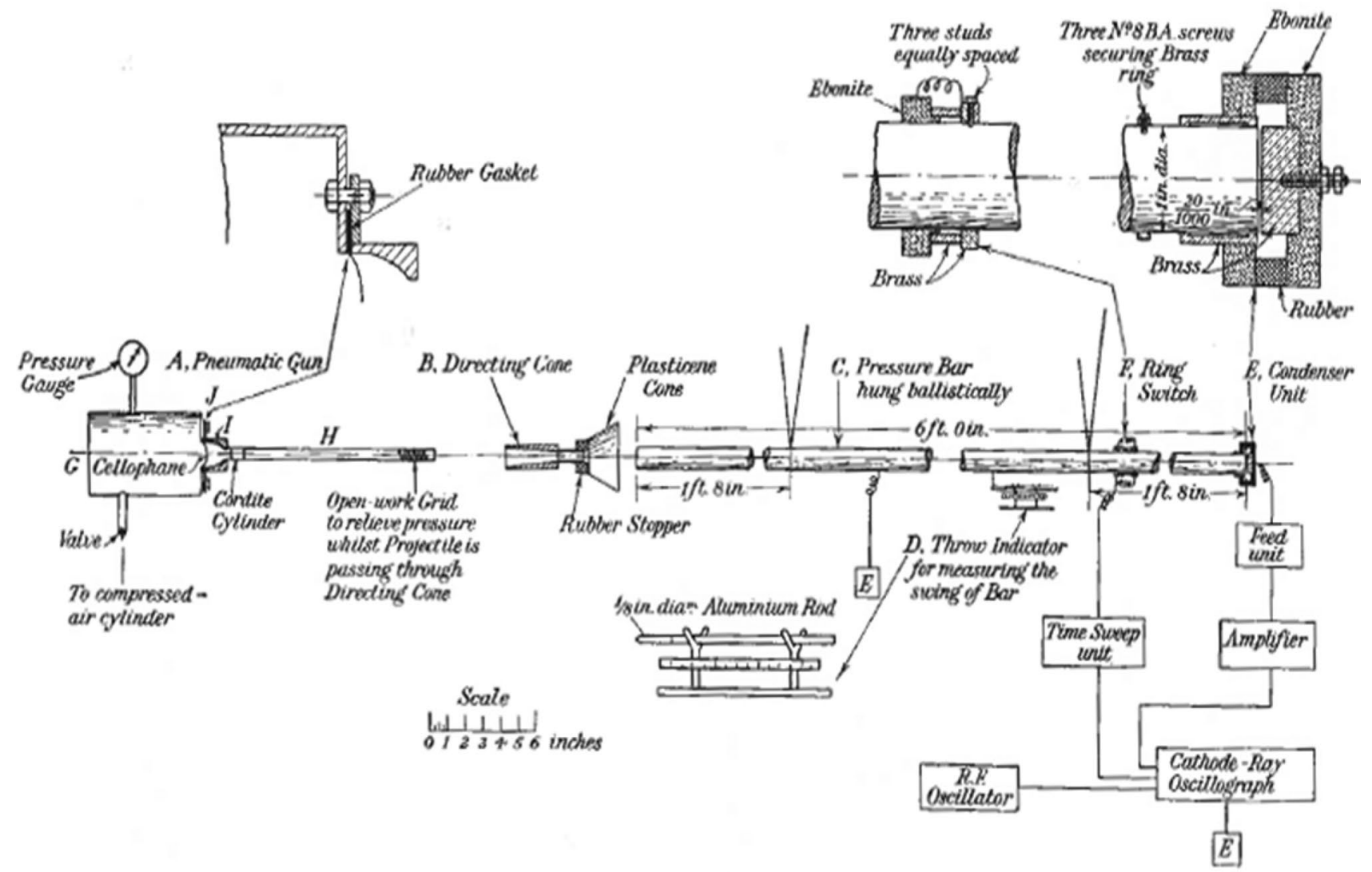

Fig. 75 G. I. Taylor's direct impact Hopkinson pressure bar for measuring the dynamic mechanical properties of explosives. This device was built and used during World War 2, but information about it was not published until 1958 [311] 


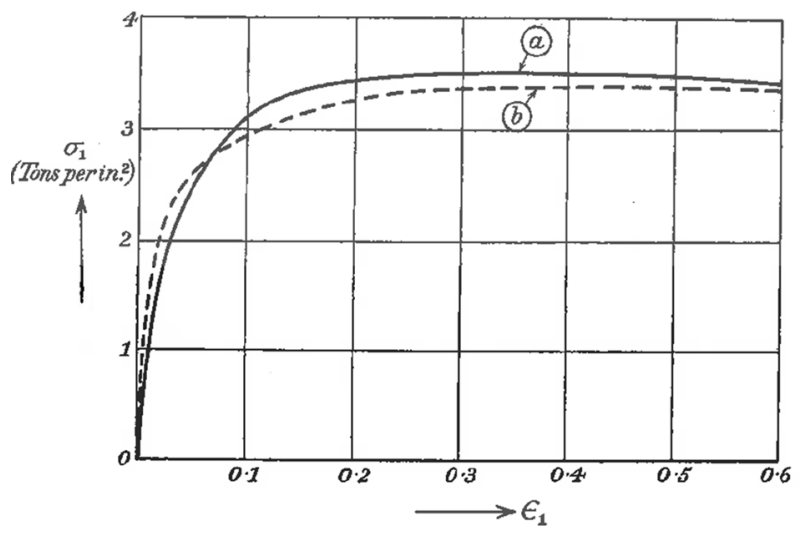

Fig. 76 First known dynamic compression stress-strain curve (for cordite) obtained using the Hopkinson pressure bar shown in Fig. 75. Data obtained in 1942 but not published until 1958. From [311]

Davies also gave much more information about the design of the condenser microphones used by both him and Kolsky to record strain pulses in rods.

The first split Hopkinson pressure bar of modern design (i.e. one that used a light gas gun to accelerate a striker bar against the end of the input bar) was developed by Krafft and co-workers at the Naval Research Laboratory, Washington, DC in the early 1950s (Fig. 81) [319]. For a recent account of the history of the split Hopkinson (or Kolsky) pressure bar, see [237].

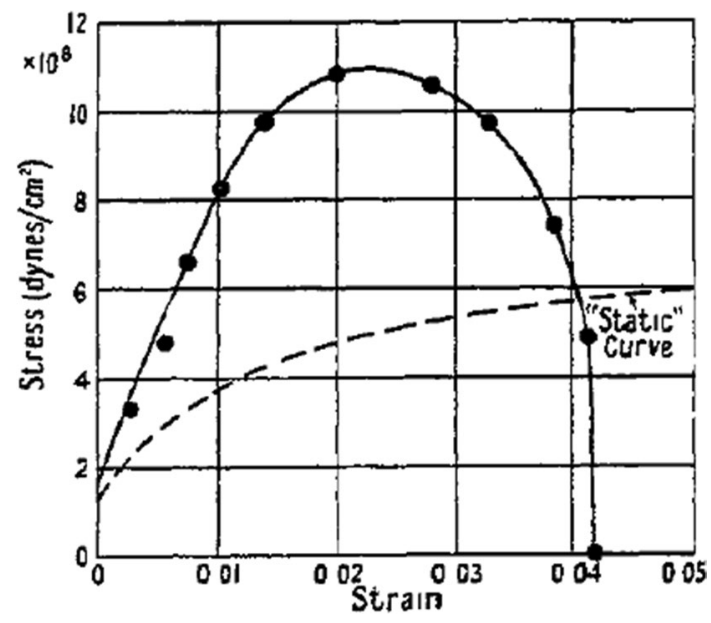

Fig. 78 Comparison of dynamic and static stress-strain curves for copper. High rate data obtained using the device shown in Fig. 77. From [312]

\section{Summary and Conclusions}

Up until the Industrial Revolution, the only people who had to worry about the response of materials to high rates of loading were makers of armour and makers of cannon. Doubtless many empirical studies were conducted in the workshops dedicated to these arts (people's lives and the fate of kingdoms depended on it), but no record of the results of their experiments appears to have survived. The invention of the steam engine, the building of railways, and the armouring of ships led people to realise by the

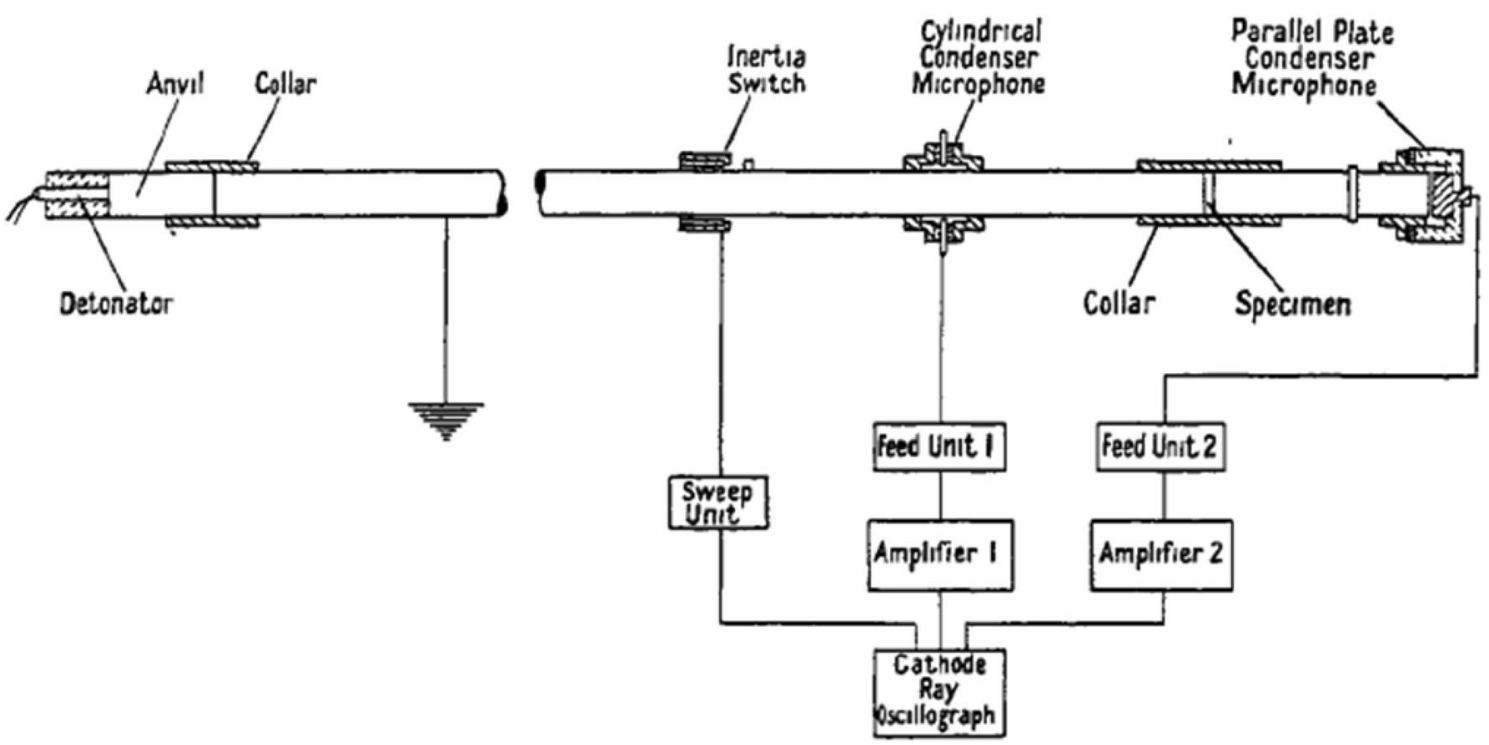

Fig. 77 Kolsky's design of high amplitude stress pulse split Hopkinson pressure bar for obtaining high rate compressive data for metals. From [312] 
Fig. 79 First known studies (1939 and 1940) of the use of strain gauges to record elastic waves in rods. a From [313]. b From [314]. See also the discussion of this study by Bernhard et al. [315]

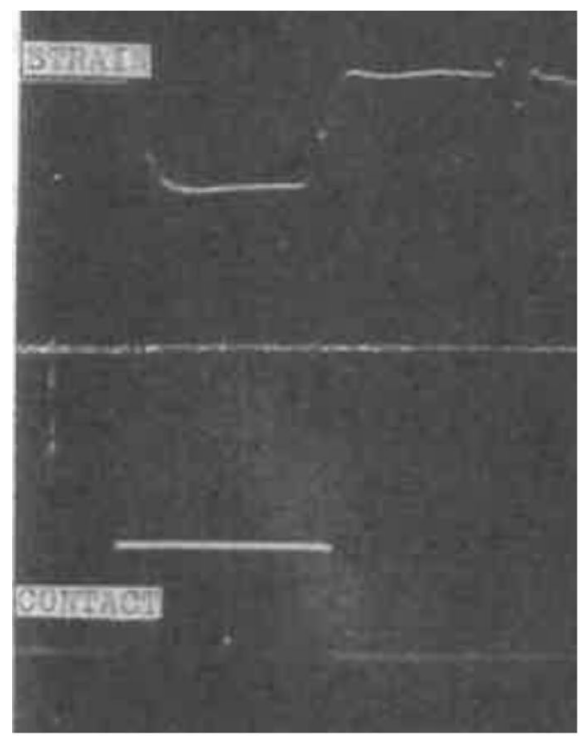

(a)

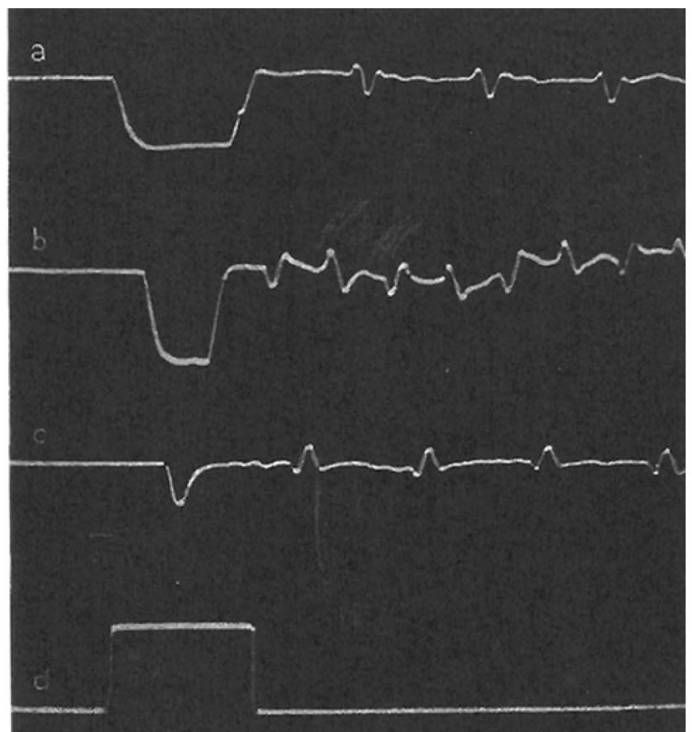

(b)

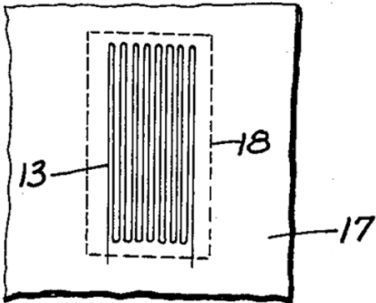

(a)

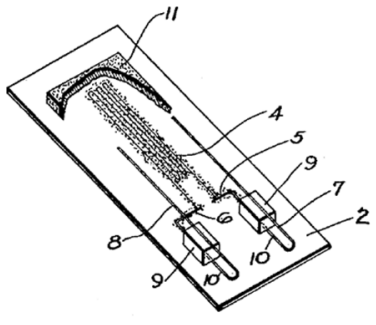

(b)
Fig. 80 Schematic diagrams of two different designs of strain gauge patented in 1944. a From [318]. b From [317]

middle of the nineteenth century that they needed to be able to measure the dynamic mechanical properties of materials, especially iron and steel $[138,139]$. Despite the perceived need and the likely financial and military benefits, the technology to do this was not invented until the end of that century [219]. Although valid theories of the plasticity and fracture of materials did not exist in the nineteenth century $[128,320]$ (these only arrived during the twentieth century with fracture mechanics [321] and dislocation theory [322-324]), steady improvements to steam boilers were made during the second half of the nineteenth century that made them less prone to explode [134]. In the absence of a proper theory of strength, this would have to have been done by a process of trial, error and empirical testing.

A number of things have impressed me while compiling this review. The first is the ingenuity of people in the nineteenth century in devising ways of recording dynamic force and strain information despite their lack of electronic technology. The main nineteenth century methods involved tuning forks (for the time-base), electromechanical, pneumatic, hydraulic and (later on) optical techniques. The second is rather paradoxical: sometimes I have sometimes been amazed how early in history some measurements were made but on the other hand how recently some other observations
Fig. 81 First split Hopkinson bar of modern design that used a light gas gun to accelerate a striker bar against the input bar. Dimensions given in inches. From [319]




Table 1 Developments in the study of the dynamic properties of matter (excluding shock wave studies)

\begin{tabular}{|c|c|}
\hline Date & Major developments \\
\hline 1726 & $\begin{array}{l}\text { Isaac Newton and colleagues study the velocity and shape dependence of the resistance of fluids to projectile motion ([4], pp. } \\
339-340,351-356)\end{array}$ \\
\hline 1742 & Benjamin Robins invents the ballistic pendulum for indirectly measuring the muzzle velocity of guns [43] \\
\hline 1803 & First direct method developed for measuring projectile velocity $[52,53]$ \\
\hline $1810 \mathrm{~s}-1830 \mathrm{~s}$ & First systematic study of the velocity dependence of penetration of solids such as wood, earth and masonry [70-72] \\
\hline 1834 & Eaton Hodgkinson reports studies on the inelastic collision of solid spheres [145] \\
\hline 1840 s & Electrical method devised for measuring the velocity of a projectile inside a gun [63] \\
\hline $1840 \mathrm{~s}$ & $\begin{array}{l}\text { The development of the railways leads to the realization that the dynamic properties of materials might be different to their static } \\
\text { properties }[138,139]\end{array}$ \\
\hline $1850 \mathrm{~s}$ & First quantitative measurements of the blast produced by the firing of guns [79] \\
\hline 1865 & $\begin{array}{l}\text { First quantitative report of the difference between static and dynamic fracture strength of any material (the iron used to make can- } \\
\text { non [25], p. 300) }\end{array}$ \\
\hline 1865 & $\begin{array}{l}\text { Explanation given in terms of ductility and brittleness as to why different types of iron and steel respond differently to ballistic } \\
\text { impact ([25], p. 305) }\end{array}$ \\
\hline $1860 \mathrm{~s}$ & Mechanical method invented for recording impulses $[67,68]$ \\
\hline $1860 \mathrm{~s}$ & Electrical method of measuring projectile velocity in flight [55] \\
\hline $1860 \mathrm{~s}$ & Photographic technique developed for imaging a cannonball in flight $[181,182]$ \\
\hline $1870 \mathrm{~s}-1880 \mathrm{~s}$ & Mathematical analysis of dispersion of elastic waves in rods [325-328] \\
\hline 1887 & Images obtained of shock waves in air produced by rifle bullets [190] \\
\hline 1888 & Wave phenomena reported on the surface of explosively shocked steel [199] \\
\hline 1893 & First photographic image of terminal ballistic impact [179] \\
\hline 1897 & First high strain-rate mechanical testing machine built for measuring dynamic strength of metals [219-222] \\
\hline 1902 & $\begin{array}{l}\text { First report of rod-on-anvil experiments, later known as Taylor impact after the researcher who mathematically analyzed the } \\
\text { problem [171] }\end{array}$ \\
\hline 1907-1908 & $\begin{array}{l}\text { Sears develops a rod impact technique in Bertram Hopkinson's Laboratory in Cambridge to determine whether dynamic and } \\
\text { static elastic moduli are different }[223,224]\end{array}$ \\
\hline 1914 & Bertram Hopkinson experimentally analyses the pulse shapes due to bullet impact and explosions [227, 329] \\
\hline 1928 & Kravz-Tarnavskii in Russia reports the first observation of adiabatic shear bands in metals [291] \\
\hline 1935 & Japanese researchers develop an optical technique for obtaining the dynamic torsional strength of metals [263] \\
\hline $1939-1940$ & First use of strain gauges to record elastic pulses travelling in metal rods [313-315] \\
\hline 1940 s & $\begin{array}{l}\text { Taylor, Volterra and Davies develop the Sears-Hopkinson bar technique so as to obtain the stress-strain curves of explosives and } \\
\text { very soft polymers }[167,304,311]\end{array}$ \\
\hline 1949 & $\begin{array}{l}\text { Kolsky uses detonators to increase the strength of the loading pulse so that the dynamic stress-strain curves of metals can be } \\
\text { measured using Hopkinson bars [312] }\end{array}$ \\
\hline $1940 \mathrm{~s}$ & Taylor mathematically analyses the rod-on-anvil test [168] \\
\hline
\end{tabular}

became possible. Table 1 below is a summary of when key developments that have been discussed in this paper took place.

In writing this review, I have sought to break out of the Anglophone world, and give due credit to those who wrote in other languages. I believe I have fairly addressed the literature written in the French tongue, but am conscious that I may well not know about important papers written in German.

I finish with the heartfelt wish expressed by Walter Rosenhain in An Introduction to Physical Metallurgy which he wrote in 1914 ([330], pp. 8-9), and which was still included in the third edition of his book published in 1935 ([331], p. 9):

What railway engineer would not be glad to have before him today, when called upon to draw up a specification for a fresh supply of rails or tyres, the data of chemical analyses, full mechanical tests, the microstructure, macrostructure and thermal data covering several hundreds of rails or tyres whose subsequent service behaviour was also recorded? At present only a few comparatively isolated data of this kind are available, and it may easily happen that the tests which have been made under various specifications did not really test just that property or combina- 
tion of properties which is of primary importance for these very articles.

\begin{abstract}
Acknowledgements I wish to record my thanks for the existence of and access to the Cambridge University Library and the British Library. Google was also invaluable in making so many out of print books so easily accessible online and Gallica made online access to eighteenth and nineteenth century French journals possible. I also acknowledge my debt of gratitude to the following authors: J. F. Bell for his monumental and thorough survey of The Experimental Foundations of Solid Mechanics (1973), P. Krehl for his History of Shock Waves, Explosions and Impact (2009), C. Truesdell for his Essays in the History of Mechanics (1968), J. Heyman for his translation of and commentary on Coulomb's Memoir on Statics (1972), and A. Becchi for his Essays on the History of Mechanics in Memory of Clifford Ambrose Truesdell and Edoardo Benvenuto (2012).
\end{abstract}

Open Access This article is licensed under a Creative Commons Attribution 4.0 International License, which permits use, sharing, adaptation, distribution and reproduction in any medium or format, as long as you give appropriate credit to the original author(s) and the source, provide a link to the Creative Commons licence, and indicate if changes were made. The images or other third party material in this article are included in the article's Creative Commons licence, unless indicated otherwise in a credit line to the material. If material is not included in the article's Creative Commons licence and your intended use is not permitted by statutory regulation or exceeds the permitted use, you will need to obtain permission directly from the copyright holder. To view a copy of this licence, visit http://creativecommons.org/licenses/by/4.0/.

\section{References}

1. Pearson K (1886) Preface. In: Todhumter I, Pearson K (eds) A history of the strength of materials from Galilei to the present time 1: Galilei to Saint-Venant. Cambridge University Press, Cambridge, $\mathrm{p}$ xi

2. Hauksbee F (1710) Experiments concerning the time required in the descent of different bodies, of different magnitudes and weights in common air, from a certain height. Philos Trans R Soc Lond 27:196-198

3. Desaguliers JT (1720) An account of some experiments made on the 27th day of April, 1719. to find how much the resistance of the air retards falling bodies. Philos Trans R Soc Lond 30:1071-1078

4. Newton I (1726) Philosophiae Naturalis Principia Mathematica, 3rd edn. The Royal Society, London

5. Koyré A, Cohen IB, Whitman A (eds) (1972) Isaac Newton's Philosophiae Naturalis Principia Mathematica. Cambridge University Press, Cambridge

6. Cohen IB, Whitman A (eds) (1999) Isaac Newton's Principia: mathematical principles of natural philosophy (a new translation). University of California Press, Berkeley

7. Brougham H, Routh EJ (1855) Analytical view of Sir Isaac Newton's Principia. Longman, Brown, Green, and Longmans, London

8. Loomis E (1854) On the resistance experienced by bodies falling through the atmosphere. Am J Sci Arts (Ser 2) 18:67-70

9. Cohen IB (1999) The motion of pendulums and the resistance of fluids to the motions of pendulums and projectiles: a general scholium (experiments on resistance to motion). In: Cohen IB, Whitman A (eds) Principia: mathematical principles of natural philosophy (a new translation). University of California Press, Berkeley, pp 180-184

10. Smith GE (1999) Another way of considering Book 2: some achievements of Book 2. In: Cohen IB, Whitman A (eds) Principia: mathematical principles of natural philosophy (a new translation). University of California Press, Berkeley, pp 188-194

11. Brougham H, Routh EJ (1855) Analytical view of Sir Isaac Newton's Principia. Longman, Brown, Green, and Longmans, London, pp 183-239

12. Cajori F (1980) A history of mathematics, 3rd edn. Chelsea Publishing Company, New York

13. Newton I (1960) Letter from Newton to Oldenburg, 13 June 1676. In: Turnbull HW (ed) The correspondence of Isaac Newton volume 2 (1676-1687). Cambridge University Press, Cambridge, pp 20-47

14. Cohen IB, Smith GE (eds) (2002) The Cambridge companion to Newton. Cambridge University Press, Cambridge

15. Montucla J-E (1758) Histoire des Mathématiques. 2. Jombert, Paris

16. Wallis $\mathrm{J}$ (1687) A discourse concerning the measure of the airs resistance to bodies moved in it. Philos Trans R Soc Lond 16:269-280

17. Saslow WM, Lu H (2008) Newton on objects moving in a fluid: the penetration length. Eur J Phys 29:689-696

18. Gaite J (2017) Penetration of fast projectiles into resistant media: from macroscopic to subatomic projectiles. Ann Phys 384:235-253

19. Cohen IB (1999) The solid of least resistance; the design of ships; the effect of water. In: Cohen IB, Whitman A (eds) Principia: mathematical principles of natural philosophy (a new translation). University of California Press, Berkeley, pp 181-184

20. Whitworth J (1870) On the penetration of armour plates with long shells of large capacity fired obliquely. Rep Br Assoc Adv Sci 39:430-434

21. Whitworth J (1873) Miscellaneous papers on mechanical subjects: guns and steel. Longman, Green, Reader and Dyer, London

22. Anon (1912) Evolution of the projectile in exterior form. J US Artill 38:photographic plate opposite 127

23. Walley SM (2018) The beginnings of the use of iron and steel in heavy armour. In: Kaufman B, Briant CL (eds) Metallurgical design and industry: prehistory to the space age. Springer, New York, pp 71-153

24. Scoffern J (1858) Projectile weapons of war and explosive compounds, 3rd edn. Longman, Brown, Green and Longmans, London

25. Holley AL (1865) A treatise on ordnance and armor. van Nostrand, New York

26. Davis C (1897) On the perforation of face-hardened armor. Proc US Nav Inst 23:283-309

27. Curtis CW (1946) Terminal ballistics of armor. In: Bush V, Conant JB, Adams LH (eds) Effects of impact and explosions. National Defense Research Committee, Washington, DC, pp $160-190$

28. Gamow G (1962) Biography of physics. Hutchinson, London

29. Bush V, Conant JB, Adams LH (eds) (1946) Hypervelocity guns and the control of gun erosion. National Defense Research Committee, Washington, DC

30. Burchard JE (ed) (1948) Rockets, guns and targets: rockets, target information, erosion information, and hypervelocity guns developed during World War II by the Office of Scientific Research and Development. Little, Brown and Company, Boston

31. Whipple FL (1958) The meteoric risk to space vehicles. In: Alperin M, Stern M, Wooster H (eds) Vistas in astronautics. Pergamon, London, pp 115-124 
32. Whipple FL (1963) On meteoroids and penetration. J Geophys Res 68:4929-4939

33. Wilson MPW (1967) The deformation of metals by hypervelocity impact: the kinetics of twinning. PhD Thesis, University of Cambridge

34. Brunton JH, Field JE, Thomas GP, Wilson MPW (1965) The deformation of metals by high-velocity impact. In: Benesovsky F (ed) Plansee proceedings 1964: metals for the Space Age. Metallwerk Plansee AG, Reutte, Tyrol, pp 137-148

35. Groetsch CW, Yost SA (2014) Vertical projection in a resisting medium: reflections on observations of Mersenne. Am Math Mon 121:499-505

36. Henninger-Voss MJ (2002) How the 'new science' of cannons shook up the Aristotelian cosmos. J Hist Ideas 63:371-397

37. Yavetz I (2015) Bodies and media: on the motion of inanimate objects in Aristotle's 'Physics' and 'On the Heavens'. Springer, New York

38. Walley SM (2018) Aristotle, projectiles and guns. http://arxiv .org/abs/1804.00716

39. Aquinas T (1989) There is a God. In: McDermott T (ed) Summa Theologiae: a concise translation. Methuen, London, pp 12-14

40. Shields D (2018) Everything in motion is put in motion by another: a principle in Aquinas's first way. Am Cathol Philos Q 92:535-561

41. Varignon P (1690) Nouvelles Conjectures sur la Pesanteur. Jean Bondot, Paris

42. Hutton C (1790) Abstract of experiments made to determine the true resistance of the air to the surfaces of bodies, of various figures, and moved through it with different degrees of velocity. Trans R Soc Edinb 2(2):29-36

43. Robins B (1742) New principles of gunnery: containing, the determination of the force of gunpowder, and an investigation of the difference in the resisting power of the air to swift and slow motions. J. Nourse, London

44. Robins B (1805) Of the resistance of the air; together with the method of computing the motions of bodies projected in that medium Read the 19th of June, 1746. In: Hutton C (ed) New principles of gunnery: containing the determination of the force of gunpowder and an investigation of the difference in the resisting power of the air to swift and slow motions with several other tracts on the improvement of practical gunnery, 2nd edn. F. Wingrave, London, pp 179-199

45. Simmons R (1812) The sea-gunner's Vade Mecum. The Board of Admiralty, London

46. Carmody T, Kobus H (eds) (1968) Hydrodynamics by Daniel Bernoulli and hydraulics by Johann Bernoulli. Dover, New York

47. Bernoulli D (1729) De actione fluidorum in corpora solida et motu solidorum in fluidis. Comment Acad Sci Imp Petropolitanae 2:304-342

48. Bernoulli D (1738) Hydrodynamica. John Reinhold Dulsecker, Basel

49. Bernoulli D (1968) Concerning the force of compressed air and a blast of ignited gunpowder for projecting shots in the employment of pneumatic rifles and cannons. In: Carmody T, Kobus H (eds) Hydrodynamics by Daniel Bernoulli and hydraulics by Johann Bernoulli. Dover, New York, pp 264-274

50. Robins B (1743) An account of a book intituled, New Principles of Gunnery, containing the determination of the force of gunpowder and an investigation of the resisting power of the air to swift and slow motions as far as the same relates to the force of gunpowder. Philos Trans R Soc Lond 42:437-456

51. Johnson W (1990) The origin of the ballistic pendulum: the claims of Jacques Cassini (1677-1756) and Benjamin Robins (1707-1751). Int J Mech Sci 32:345-374
52. Prony M (1803) Sur un moyen de mesurer la vitesse initiale des projectiles lancés par les bouches à feu, dans des directions tant horizontales qu'inclinées. J Mines 16:117-136

53. Prony M (1805) Report of a method of measuring the initial velocity of projectiles discharged from firearms, both horizontally and with different elevations, made to the Physical and Mathematical Class of the National Institute. J Nat Philos Chem Arts 12:41-46

54. Didion I (1860) Traité de Balistique, 2nd edn. Dumaine, Paris

55. Bashforth F (1866) Description of a chronograph adapted for measuring the varying velocity of a body in motion through the air and for other purposes. Minutes Proc R Artill Inst 5:161-192

56. Bashforth $\mathrm{F}$ (1868) On the resistance of air to the motion of elongated projectiles having variously formed heads. Philos Trans $\mathrm{R}$ Soc Lond 158:417-441

57. Bashforth F (1870) Reports on experiments made with the Bashforth chronograph to determine the resistance of the air to the motion of projectiles (1865-1870). Eyre and Spottiswoode, London

58. Bashforth $\mathrm{F}$ (1873) A mathematical treatise of the motion of projectiles founded chiefly on the results of experiments made with the author's chronograph. Asher and Co., London

59. Bashforth $\mathrm{F}$ (1890) A revised account of the experiments made with the Bashforth chronograph to find the resistance of the air to the motion of projectiles with the application of the results to the calculation of trajectories according to J. Bernoulli's method. Cambridge University Press, Cambridge

60. Bashforth F (1895) A supplement to a revised account of the experiments made with the Bashforth chronograph to find the resistance of the air to the motion of projectiles with the application of the results to the calculation of trajectories and a historical sketch of the progress of ballistic experiments connected with the advanced class, Woolwich 1864-1890. Cambridge University Press, Cambridge

61. Bashforth F (1900) A second supplement to a revised account of the experiments made with the Bashforth chronograph to find the resistance of the air to the motion of projectiles with the application of the results to the calculation of trajectories. Cambridge University Press, Cambridge

62. Bashforth F (1873) On the resistance of the air. In: A mathematical treatise of the motion of projectiles founded chiefly on the results of experiments made with the author's chronograph. Asher and Co., London, pp 24-44

63. Pouillet CSMR (1844) Note sur un moyen de mesurer des intervalles de temps extrèmement courts, comme la durée du choc élastiques, celle de débandement des ressorts, de l'inflammation de la poudre, etc., et sur un moyen nouveau de comparer les intensités des courants électriques, soit permanents, soit instantanés. CR Acad Sci Paris 19:1384-1389

64. Schneebeli H (1872) Stossversuche mit Kugeln aus verschiedenem Metall (impact tests with balls of different metal). Ann Phys Chem 145:328-331

65. Hamburger M (1886) Untersuchungen über die Zeitdauer des Stosses von Cylindern und Kugeln (studies on the duration of impact of cylinders and balls). Ann Phys Chem 28:653-665

66. Bell JF (1973) Hausmaninger's use (1884) of the time of contact technique of Pouillet (1844) in the Boltzmann experiment, and the half century of similar experiments (1884-1936). Experimental foundations of solid mechanics. Springer, Berlin, pp 315-329

67. Marey EJ (1863) Physiologie Médicale de la Circulation du Sang Basée sur l'Etude Graphique des Mouvements du Coeur et du Pouls Artériel avec Application aux Maladies de l'Appareil Circulatoire. Adrien Delahaye, Paris

68. Donders FC (1867) Examen du cardiographe. Arch Néerl Sci Exactes Nat 2:230-246 
69. Griffith M (1897) On the testing of smokeless powders. J Mil Serv Inst US 20:180-191

70. Didion I (1848) Lois de la pénétration des projectiles. Traité de Balistique. Leneveu, Paris, pp 228-250

71. Moore W (1810) On the penetration of balls into uniform resisting substances. Philos Mag (Ser 1) 36:325-334

72. Piobert G (1836) Pénétration des obus. Traité d'Artillerie: Théorique et Pratique. Libraire pour l'Art Militaire, Paris, pp 180-187

73. Greaves $\mathbf{J}$ (1685) An account of some experiments for trying the force of great guns. Philos Trans R Soc Lond 15:1090-1092

74. Robins B (1747) A proposal for increasing the strength of the British Navy, by changing all the guns, from the eighteen pounders downwards, into others of equal weight but of a greater bore. J. Nourse, London

75. Laplace P-S (1814) Des milieux qu'il faut choisir entre les résultats d'un grand nombre d'observations. In: Théorie Analytique des Probabilités, 2nd edn. Courcier, Paris, pp lxxi-lxxv

76. Sampson RA (1918) The genesis of the law of error. Philos Mag (Ser 6) 36:347-351

77. Edgeworth FY (1921) The genesis of the law of error. Philos Mag (Ser 6) 41:148-158

78. Ihlseng MC (1879) Mode of measuring the velocity of sound in wood. Am J Sci Arts (Ser 3) 17:125-132

79. Woodbridge WE (1856) On the measurement of the pressure of fired gunpowder in its practical application. Am J Sci Arts 22:153-159

80. Ellis RL (1849) On the method of least squares. Trans Camb Philos Soc 8:204-219

81. Todhunter I (1865) A history of the mathematical theory of probability: from the time of Pascal to that of Laplace. Macmillan, London

82. Crofton MW (1870) On the proof of the law of errors of observations. Philos Trans R Soc Lond 160:175-187

83. Kohlrausch F (1886) An introduction to physical measurements. Appleton and Company, New York

84. Burton CV (1889) On a physical basis for the theory of errors. Proc Phys Soc Lond 10:276-287

85. Glaisher JWL (1889) Observations and statistics: an essay on the theory of errors of observation and the first principles of statistics. Trans Camb Philos Soc 14:138-169

86. Jirungnimitsakul S, Wattanakasiwich P (2017) Assessing student understanding of measurement and uncertainty. J Phys Conf Ser 901:012121

87. Denker J, Smith L (2018) Guard digits vs. roundoff error vs. overall uncertainty. Phys Teach 56:532-534

88. Huang H (2018) A unified theory of measurement errors and uncertainties. Meas Sci Technol 29:125003

89. Clagett M (1959) The application of two-dimensional geometry to kinematics. The science of mechanics in the Middle Ages. University of Wisconsin Press, Madison, pp 331-346

90. Funkhouser HG (1936) A note on a tenth century graph. Osiris 1:260-262

91. Tilling L (1975) Early experimental graphs. Br J Hist Sci 8:193-213

92. Tufte ER (2001) Graphical excellence. The visual display of quantitative information, 2nd edn. Graphics Press, Cheshire, pp $13-51$

93. Spence I, Wainer H (2005) Introduction to Playfair's commercial and political atlas and statistical breviary. In: Wainer H, Spence I (eds) The commercial and political atlas and statistical breviary. Cambridge University Press, Cambridge, pp 1-35

94. Playfair W (1801) The commercial and political atlas representing by means of stained copperplate charts the progress of the commerce, revenues, expenditure and debts of England during the whole of the eighteenth century, 3rd edn. J. Wallis, London
95. Prosser GW (1840) An essay on the past and present state of fortification in Europe. 5. United Serv J (3)75-84

96. Dahlgren JA (1856) Shot and shells compared. Shells and shellguns. King and Baird, Philadelphia, pp 205-258

97. Dahlgren JA (1856) Penetration. Shells and shell-guns. King and Baird, Philadelphia, pp 173-203

98. Henry $\mathbf{J}$ (1856) On the mode of testing building materials and an account of the marble used in the extension of the United States Capitol. Am J Sci Arts (Ser 2) 22:30-38

99. Bell JF (1973) The experimental foundations of solid mechanics. Springer, Berlin

100. Tóth L, Rossmanith H-P, Siewert TA (2002) Historical background and development of the Charpy test. In: François D, Pineau A (eds) From Charpy to present impact testing. Elsevier, Amsterdam, pp 3-19

101. Galilei G (1638) Discorsi e Dimostrazioni Matematiche, intorno à Due Nuoue Scienze. Elzevir, Leiden

102. Galilei G (1914) Second day: Proposition I. In: Crew H, de Salvio A (eds) Dialogues concerning two new sciences. Macmillan, London, pp 115-117

103. Galilei G (1954) Second day: Proposition I. In: Crew H, de Salvio A (eds) Dialogues concerning two new sciences. Dover, New York, pp 115-117

104. Bell JF (1973) Experiments before 1780. The experimental foundations of solid mechanics. Springer, Berlin, pp 160-168

105. Barlow P (1817) An essay on the strength and stress of timber, founded upon experiments performed at the Royal Military Academy, on specimens selected from the Royal Arsenal, and His Majesty's Dock-Yard, Woolwich: preceded by an historical review of former theories and experiments; with numerous tables and plates. Also an appendix on the strength of iron and other materials. J. Taylor, London

106. Barlow P, Barlow PW, Barlow WH (1867) A treatise on the strength of materials with rules for application in architecture, the construction of suspension bridges, railways etc. (new edition). Lockwood and Co., London

107. van Musschenbroek P (1729) Physicæ Experimentales. Samuel Luchtmans, Leyden

108. Coulomb CA (1773) Essai sur une application des règles de maximis \& minimis à quelques problèmes de statique, relatifs à l'architecture. In: Mémoires de Mathématique et de Physique. Academie des Sciences, Paris, pp 343-382

109. Coulomb CA (1784) Recherches théoriques et expérimentales sur la force de torsion et sur l'élasticité des fils de métal. Histoire de l'Académie Royale des Sciences, Paris, pp 229-269

110. Tredgold T (1824) Experiments on the elasticity and strength of hard and soft steel. Philos Trans R Soc Lond 114:354-359

111. Tredgold T (1822) Practical essay on the strength of cast iron, and other metals; intended for the assistance of engineers, iron masters, architects, Millwrights, founders, and others engaged in the construction of machines, buildings, \&c. containing practical rules, tables, and examples; founded on a series of new experiments, with an extensive table on the properties of materials. J. Taylor, London

112. Tredgold T (1824) Strength of cast iron. J. Taylor, London

113. Tredgold T, Hodgkinson E (1842) Practical essay on the strength of cast iron, and other metals; containing practical rules, tables, and examples; founded on a series of new experiments, with an extensive table on the properties of materials. The fourth edition to which are added experimental researches on the strength and other properties of cast iron with the development of new principles; calculations deduced from them; and inquiries applicable to rigid and tenacious bodies generally. John Weale, London

114. Barlow P (1826) An essay on the strength and stress of timber, founded upon experiments performed at the Royal Military Academy, on specimens selected from the Royal Arsenal, and 
His Majesty's Dock-Yard, Woolwich: preceded by an historical review of former theories and experiments; with numerous tables and plates. Also an appendix on the strength of iron and other materials, 3rd edn, corrected. J. Taylor, London

115. Navier C-L (1826) Résumé des Leçons Faites Données à l'Ecole des Ponts et Chaussées sur l'Applications de la Mécanique à l'Etablissement des Constructions et des Machines. Firmin Didot, Paris

116. Navier C-L (1839) Résumé des Leçons Faites Données à l'Ecole des Ponts et Chaussées sur l'Applications de la Mécanique à l'Etablissement des Constructions et des Machines (Second Edition). Société Belde de Librairie, Brussels

117. von Gerstner FJ (1831) Handbuch der Mechanik. Herbig, Leipzig

118. Rankine WJM (1858) A manual of applied mechanics. Richard Griffin and Company, London

119. Rankine WJM (1862) A manual of civil engineering. Griffin, Bohn and Company, London

120. Kirkaldy D (1862) Results of an experimental enquiry into the comparative tensile strength and other properties of various kinds of wrought iron and steel etc. Bell and Bain, Glasgow

121. Kirkaldy D (1866) Experiments on wrought-iron and steel, 2nd edn. D. Kirkaldy Publishing, London

122. Tresca H (1869) Mémoires sur l'Écoulement des Corps Solides. Imprimerie Impériale, Paris

123. Anderson J (1872) The strength of materials and structures. 1: The strength of materials, as depending on their quality, and as ascertained by testing-apparatus. 2: The strength of structures, as depending on the form and arrangement of their parts, and on the materials of which they are constructed. D. Appleton and Co., New York

124. Kent W (1879) The strength of materials. D. van Nostrand, New York

125. Jeans JS (1880) Steel: its history, manufacture, properties and uses. E. and F.N. Spon, London

126. Abbott AV (1884) Testing machines, their history, construction and use. van Nostrand, New York

127. Todhunter I, Pearson K (1886) A history of the strength of materials from Galilei to the present time. 1: Galilei to Saint-Venant. Cambridge University Press, Cambridge

128. Unwin WC (1888) Testing of materials of construction. Longmans, London

129. Unwin WC (1899) Testing of materials of construction: a textbook for the engineering laboratory and a collection of the results of experiment, 2nd edn. Longmans, London

130. Ewing JA (1899) The strength of materials. Cambridge University Press, Cambridge

131. Dunn T (1857) On chain cable and timber testing machines. Minutes Proc Inst Civ Eng 16:301-308

132. Rodman TJ (1861) Reports of experiments on the properties of metals for cannon, and the qualities of cannon powder, with an account of the fabrication and trial of a 15 inch gun etc. H.C. Baird, Philadelphia

133. Fairbairn W (1851) Two lectures on the construction of boilers and on boiler explosions with the means of prevention. Simpkin, Marshall and Co., London

134. Winship IR (1991) The decline in locomotive boiler explosions in Britain 1850-1900. Trans Newcom Soc 60:73-94

135. Longridge JA (1860) On the construction of artillery and other vessels to resist great internal pressure. Minutes Proc Inst Civ Eng 19:283-460

136. Girard PS (1798) Traité Analytique de la Résistance des Solides et des Solides d'Egale Résistance. Firmin Didot, Paris

137. Barlow P (1834) Report on the present state of knowledge respecting the strength of materials. Rep Br Assoc Adv Sci 3:93-103
138. Cox $H$ (1849) The dynamical deflection and strain of railway girders. J Frankl Inst 47(73-81):145-153

139. Wrottesley J, Willis R, James H, Rennie G, Cubitt W, Hodgkinson E, Galton D (1849) Report of the commissioners appointed to inquire into the application of iron to railway structures. Her Majesty's Stationery Office, London

140. Pope T (1811) A treatise on bridge architecture in which the superior advantages of the flying pendent lever bridge are fully proved. Alexander Niven, New York

141. Fletcher NJ (1976) The Iron bridge. Met Constr 8:252-253

142. Pekalski G, Rabiega J (2011) Grey cast iron as construction material of bridges from the 18th and 19th century. Arch Foundry Eng 11(Special issue 2):175-179

143. Bélanger J-B (1847) Cours de Mécanique ou Résumé de Leçons sur la Dynamique, la Statique, et leurs Applications à l'Art de l'Ingenieur. Carillan Goeury, Paris

144. Hodgkinson E (1831) On suspension bridges; containing an inquiry into the proper forms of their catenaries; with remarks on the Menai Bridge, and that at Broughton; as likewise some account of the failure of the latter. Manchester Literary and Philosophical Society, Manchester

145. Hodgkinson E (1834) On the collision of imperfectly elastic bodies. Rep Br Assoc Adv Sci 4:534-543

146. Hodgkinson E (1836) Impact upon beams. Rep Br Assoc Adv Sci 5:93-116

147. Hodgkinson E (1838) On the relative strength and other mechanical properties of cast iron obtained by hot and cold blast. Rep Br Assoc Adv Sci 6:337-376

148. Hodgkinson E (1839) On the relative strength and other mechanical properties of cast iron obtained by hot and cold blast. J Frankl Inst 28:184-195, plate XXIV

149. Rawson R (1865) Memoir of the late Eaton Hodgkinson. Mem Lit Philos Soc Manch 2:145-203

150. Miller G (2017) Samuel Brown and Union Chain Bridge. The Friends of the Union Chain Bridge, Berwick-upon-Tweed

151. Minard CJ (1834) Leçons Faites sur les Chemins de Fer à l'Ecole des Ponts et Chaussées en 1833-1834. CarillanCoeury, Paris

152. Bashforth F (1881) Supplement to a mathematical treatise of the motion of projectiles founded chiefly on the results of experiments made with the author's chronograph. Asher and Co., London

153. Wertheim G (1842) Recherches sur l'élasticité et la tenacité des métaux. CR Acad Sci Paris 15:110-117

154. Totten JG (1857) Report on the effects of firing with heavy ordnance from casemate embrasures and also the effects of firing against the same embrasures with various kinds of missiles in the Years 1853, 1853, 1854, and 1855 at West Point in the State of New York. Taylor and Maury, Washington, DC

155. Baxter JP (1933) The introduction of the ironclad warship. Harvard University Press, Cambridge

156. Hay JCD, Jervois WFD, Henderson W, Percy J, Fairbairn W, Pole W, Harrison A (1864) Transactions and Report of the Special Committee on Iron. The War Office, London

157. Watts I, Rankine WJM, Barnes FK, Napier JR (1866) Shipbuilding for purposes of war. Shipbuilding: theoretical and practical. William Mackenzie, London, pp 293-297

158. Douglas H (1855) A treatise on naval gunnery, 4th edn. John Murray, London

159. Hertz H (1896) On the contact of elastic solids. In: Jones DE, Schott GA (eds) Miscellaneous papers by Heinrich Hertz. Macmillan, London, pp 146-162

160. Hertz H (1896) On the contact of rigid elastic solids and on hardness. In: Jones DE, Schott GA (eds) Miscellaneous papers by Heinrich Hertz. Macmillan, London, pp 163-183 
161. Walley SM (2012) Historical origins of indentation hardness testing. Mater Sci Technol 28:1028-1044

162. Walley SM (2013) Addendum and correction to 'Historical origins of indentation hardness testing'. Mater Sci Technol 29:1148

163. Field JE, Sun Q, Townsend D (1989) Ballistic impact of ceramics. Inst Phys Conf Ser 102:387-393

164. Browne CO (1884) Present position of the armour question. J R United Serv Inst 28:107-126

165. O'Callaghan DDT (1884) Recent experiments with an 11 inch compound armour plate at Shoeburyness. Minutes Proc R Artill Inst 12:89-96

166. Browne CO (1884) Foreign armour experiments, and their bearing on our own armaments, and the bombardment of the Forts of Alexandria. Minutes Proc R Artill Inst 12:419-436

167. Taylor GI (1946) The testing of materials at high rates of loading. J Inst Civ Eng 26:486-519

168. Taylor GI (1948) The use of flat ended projectiles for determining yield stress. 1: Theoretical considerations. Proc R Soc Lond A 194:289-299

169. Whiffin AC (1948) The use of flat ended projectiles for determining yield stress. 2: Tests on various metallic materials. Proc $\mathrm{R}$ Soc Lond A 194:300-322

170. Carrington WE, Gayler MLV (1948) The use of flat ended projectilesfor determining yield stress. 3: Changes in microstructure caused by deformation at high striking velocities. Proc R Soc Lond A 194:323-331

171. de Maupeou A (1902) Action comparée des forces sur les solides: Invariables, élastiques, déformables. Bull Assoc Tech Marit 13:LVIII-LIX, 271-365

172. Régnauld P (1927) La fragilité de l'acier. Rev Métall Mém 24:509-515

173. Hesse K, Merz H, Ruhlen G (1922) Truths from the German front. J US Artill 56:346-356

174. Crossman EC (1918) Bullet versus armor: the familiar contest of the sea started anew upon the land. Proc US Nav Inst 44:1581-1587

175. Garrison FL (1892) The development of American armor-plate. J Frankl Inst 134:20-42

176. Garrison FL (1892) The development of American armor-plate. J Frankl Inst 133:337-356, 421-453

177. Field JE (1989) High-speed photography: its history and application. Proc R Inst 60:195-222

178. Fuller PWW, Rendell JT (1997) The development of high speed photography. In: Ray SF (ed) High speed photography and photonics. Focal Press, Oxford, pp 7-28

179. Boys CV (1893) On electric spark photographs or photography of flying bullets etc. by the light of the electric spark. 1. Nature $47: 415-421$

180. Skaife $\mathrm{T}$ (1860) The pistolgraph and its chromo-crystal productions. J. Hogarth, London

181. Skaife T (1860) Instantaneous photography. H.S. Richardson, Greenwich

182. Anon (1866) Photographing cannonballs. Br J Photogr 13:328-329

183. McKinley $P$ (1866) Method of obtaining the picture of a gun in the act of firing. Minutes Proc R Artill Inst 5:113-115

184. Fuller PWW (1997) High speed photography in ballistics. In: Ray SF (ed) High speed photography and photonics. Focal Press, Oxford, pp 205-232

185. Muybridge E (1887) Animal locomotion: an electro-photographic investigation of consecutive phases of animal movements. University of Pennsylvania, Philadelphia

186. Muybridge E (1979) Muybridge's complete human and animal locomotion: all 781 pictures from the 1887 animal locomotion. Dover, New York
187. Worthington AM (1882) On impact with a liquid surface. Proc R Soc Lond A 34:217-230

188. Worthington AM (1908) A study of splashes. Longman and Green, London

189. Marey M (1884) Analyse des mouvements par la photographie. J Phys Théor Appl (Sér 2) 3:199-203

190. Mach E, Salcher P (1887) Photographische Fixirung der durch Projectile in der Luft eingeleiteten Vorgänge (photographic capture of the processes produced by projectiles passing through the air). Ann Phys Chem 32:277-290, plate II

191. Dalton S (1983) Split second: the world of high-speed photography. Dent, London

192. Boys CV (1893) On electric spark photographs or photography of flying bullets etc. by the light of the electric spark. 2. Nature 47:440-446

193. Laffitte $P$ (1925) Recherches expérimentales sur l'onde explosive et l'onde de choc. Ann Phys Fr (Sér 10) 4:587-694

194. Ransome $\mathrm{T}$ (1847) On the composition and explosion of guncotton. Philos Mag (Ser 3) 30:1-4

195. Lenk W (1864) Improved guncotton. United States Patent US $43166 \mathrm{~A}$

196. Abel FA (1865) On the chemical history and application of gun cotton. J Frankl Inst 79:37-44

197. Abel FA (1865) On some phenomena exhibited by gun-cotton and gunpowder under special conditions of exposure to heat. Minutes Proc R Artill Inst 4:127-139

198. Browne CO (1893) Development of armour and its attack by ordnance: from 1887 to early in 1893 . Armour and its attack by artillery supplement dealing with development of armour from 1887 to 1893: Part 1. Dulau and Co., London, pp 159-206

199. Munroe CE (1888) Wavelike effects produced by the detonation of guncotton. Am J Sci (Ser 3) 36:48-50, plate IV

200. Carl LR (1944) Brass welds made by detonation impulse. Met Prog 46(1):102-103

201. Allen WA, Mapes JM, Wilson WG (1954) An effect produced by oblique impact of a cylinder on a thin target. J Appl Phys 25:675-676

202. Philipchuk V, Bois FLR (1962) Explosive welding. United States Patent 3,024,526

203. Bahrani AS, Crossland B (1964) Explosive welding and cladding: an introductory survey and preliminary results. Proc Inst Mech Eng 179:264-305

204. Crossland B, Bahrani AS (1968) Fundamentals of explosive welding. Contemp Phys 9:71-87

205. Hay DR (1979) Explosive welding: applications and techniques. In: Timmerhaus KD, Barber MS (eds) High-pressure science and technology 2: applications and mechanical properties. Plenum, New York, pp 781-804

206. Pearson J (1983) Introduction to high-energy-rate metal working. In: Blazynski TZ (ed) Explosive welding, forming and compaction. Applied Science Publishers, London, pp 1-15

207. Abrahamson GR (1961) Permanent periodic surfaces deformations due to a traveling jet.Trans ASME J Appl Mech 83:519-528

208. Bahrani AS, Black TJ, Crossland B (1967) The mechanics of wave formation in explosive welding. Proc R Soc Lond A 296:123-136

209. Deribas AA, Kudinov VM, Matveenkov FI (1967) Effect of the initial parameters on the process of wave-formation in explosive welding. Combust Explos Shock Waves 3:344-348

210. Onzawa T, Ishii Y (1975) Wave formation in explosive welding of metals. In: Proceedings of the 5th international conference on high energy rate fabrication. Paper 4.8. University of Denver, Denver

211. Robinson JL (1975) The mechanics of wave formation in impact welding. Philos Mag 31:587-597 
212. El-Sobky H (1983) Mechanics of explosive welding. In: Blazynski TZ (ed) Explosive welding, forming and compaction. Applied Science Publishers, London, pp 189-217

213. Hopkinson J (1872) On the rupture of iron wire by a blow. Proc Manch Lit Philos Soc 11:40-45

214. Hopkinson J (1872) Further experiments on the rupture of iron wire. Proc Manch Lit Philos Soc 11:119-121

215. Bell JF (1973) The impact experiments of J. Hopkinson (1872) and Dunn (1897). In: The experimental foundations of solid mechanics. Springer, Berlin, pp 579-586

216. Hopkinson B (1905) The effects of momentary stresses in metals. Proc R Soc Lond 74:498-506

217. Quinan WR (1892) Crusher and cutter gauges for explosives. Proc US Nav Inst 18:507-588

218. Kellner W, Deering WH (1894) On the measurement of pressures by the crusher-gauge. Proc R Soc Lond 57:404-410

219. Dunn BW (1897) A photographic impact testing machine for measuring the varying intensity of an impulsive force. J Frankl Inst 144:321-348

220. Dunn BW (1897) Report on development of a photo-retardograph and its application to the dynamic measurement of resistance to compression offered by copper cylinders used in crusher gauges. 1. J US Artill 7:29-41

221. Dunn BW (1897) Report on development of a photo-retardograph and its application to the dynamic measurement of resistance to compression offered by copper cylinders used in crusher gauges. 2. J US Artill 7:213-225

222. Dunn BW, Thurston RH, Johnson JB, Gibbs G, Church IP, Christie J (1898) Discussion of 'A photographic impact testing machine for measuring the varying intensity of an impulsive force'. J Frankl Inst 145:36-47

223. Sears JE (1907) On the longitudinal impact of metal rods with rounded ends. Proc Camb Philos Soc 14:257-286

224. Sears JE (1908) On the longitudinal impact of metal rods with rounded ends. 2. Trans Camb Philos Soc 21:49-105

225. Landon JW, Quinney H (1923) Experiments with the Hopkinson pressure bar. Proc R Soc Lond A 103:622-643

226. Davies RM (1948) A critical study of the Hopkinson pressure bar. Philos Trans R Soc Lond A 240:375-457

227. Hopkinson B (1914) The effects of the detonation of gun-cotton. Trans Northeast Coast Inst Eng Shipbuild 30:199-217

228. Kolsky H, Shi YY (1958) Fractures produced by stress pulses in glass-like solids. Proc Phys Soc Lond 72:447-453

229. Ewing JA (1919) Bertram Hopkinson, 1874-1918. Proc R Soc Lond A 95:xxvi-xxxvi

230. Hill AV (1920) Obituary of Bertram Hopkinson. Alp J 32:353-357

231. Anon (1921) Obituary of Bertram Hopkinson, 1874-1918. Minutes Proc Inst Civ Eng 212:425-426

232. Hilken TJN (1967) Bertram Hopkinson: Professor of Mechanism and Applied Mechanics, 1903-1918. Engineering at Cambridge University 1783-1965. Cambridge University Press, Cambridge, pp 129-144

233. Charlton TM (1974) Professor Bertram Hopkinson, C.M.G., M.A., B.Sc., F.R.S. (1874-1918). Notes Rec R Soc Lond 29:101-109

234. Ewing JA, Larmor J (eds) (1921) The scientific papers of Bertram Hopkinson. Cambridge University Press, Cambridge

235. Robertson R (1921) Some properties of explosives. J Chem Soc Trans 119:1-29

236. Robertson R (1921) Some war developments of explosives. Nature 107:524-527

237. Walley SM (2018) The origins of the Hopkinson bar technique. In: Othman R (ed) The Kolsky-Hopkinson bar machine. Springer, Berlin, pp 1-25
238. Anon (1922) Symposium on impact testing of materials. American Society for Testing Materials, Philadelphia

239. Whittemore HL (1922) Resumé of impact testing of materials, with bibliography. Proc Am Soc Test Mater 22(2):6-36

240. Anon (1938) Symposium on impact testing. Proc Am Soc Test Mater 38(2):21-156

241. Anon (ed) (1957) Proceedings of the conference on the properties of materials at high rates of strain. Institution of Mechanical Engineers, London

242. Campbell JD, Duby J (1957) Delayed yield and other dynamic loading phenomena in a medium-carbon steel. In: Proceedings of conference on the properties of materials at high rates of strain. Institution of Mechanical Engineers, London, pp 214-220

243. Cook PM (1957) True stress-strain curves for steel in compression at high temperatures and high strain rates, for application to the calculation of load and torque in hot rolling. In: Proceedings of the conference on the properties of materials at high rates of strain. Institution of Mechanical Engineers, London, pp 86-97

244. Krafft JM, Sullivan AM, Irwin GR (1957) Relationship between the fracture ductility transition and the strain hardening characteristics of a low carbon steel. J Appl Phys 28:379-380

245. Harding J (ed) (1974) Mechanical properties at high rates of strain. Institute of Physics, London

246. Philibert J (ed) (1985) International conference on mechanical and physical behaviour of materials under dynamic loading. Editions de Physique, Les Ulis

247. Campbell JD (1953) An investigation of the plastic behaviour of metal rods subjected to longitudinal impact. J Mech Phys Solids $1: 113-123$

248. Campbell JD (1954) The yield of mild steel under impact loading. J Mech Phys Solids 3:54-62

249. Thomson W (1856) On the electrodynamic qualities of metals. Philos Trans R Soc Lond 146:649-751

250. MacGregor JG (1875) On the electrical conductivity of stretched silver wires. Proc R Soc Edinb 9:79-85

251. Tomlinson $\mathrm{H}$ (1877) On the increase in resistance to the passage of an electric current produced on certain wires by stretching. Proc R Soc Lond 26:401-410

252. Gray $\mathrm{T}$ (1883) The effect of permanent elongation on the specific resistance of metallic wires. Trans R Soc Edinb 30:369-382

253. Tomlinson $H$ (1883) The influence of stress and strain on the action of physical forces. Philos Trans R Soc Lond 174:1-172

254. Tomlinson H (1884) The influence of stress and strain on the physical properties of matter. 2: Electrical conductivity (continued). The alteration of the electrical conductivity of cobalt, magnesium, steel, and platinum-iridium produced by longitudinal traction. Proc R Soc Lond 37:386-391

255. Witkowski A (1883) Effects of strain on electric conductivity. Trans R Soc Edinb 30:413-418

256. Eaton EC (1931) Resistance strain gauge measures stresses in concrete. Eng News Rec 107:615-616

257. Davis RE, Carlson RW (1932) The electric strain meter and its use in measuring internal strains. Proc Am Soc Test Mater 32(2):793-801

258. Kearns CM, Guerke RM (1937) Vibration stress measurements in strong centrifugal fields. Trans Am Soc Mech Eng 59:A156-A159

259. Dohrenwend CO, Mehaffey WR (1943) Measurement of dynamic strain. Trans ASME J Appl Mech 10:85-92

260. Griffis L, Meier JH, Roberts HC, de Forest AV, Ruge AC, Gadd CW, Dohrenwood CO, Mehaffey WR (1944) Discussion of 'Measurement of dynamic strain'. Trans ASME J Appl Mech 11:57-62

261. Tuckerman LB (1923) Optical strain gages and extensometers. Proc Am Soc Test Mater 23(2):602-610 
262. Marrison WA (1929) Oscillographs for recording transient phenomena. Bell Syst Tech J 8:368-390

263. Itihara M (1935) Impact torsion test. 1: I. Impact torsion testing machine; II. General consideration of the impact torsion test; III. Impact torsion diagrams of mild steel and copper as tested with ordinary and notched bar test pieces. Technol Rep Tohoku Univ 11:16-50

264. Slater WA, Moore HF (1913) Use of the strain gage in the testing of materials. Proc Am Soc Test Mater 13:1019-1044

265. Itihara M (1935) Impact torsion test. 2: I. $1700 \mathrm{rev} / \mathrm{min}$ impact torsion tester; II. Impact and static torsion diagrams of metals at room temperature; III. Consideration of the dynamic sliding resistance of metals. Technol Rep Tohoku Univ 11:489-511

266. Itihara M (1935) Impact torsion test. 3: I. Coefficients of viscosity of solid metals; II. Impact torsion tests of cold-worked metals. Technol Rep Tohoku Univ 11:512-527

267. Itihara $M$ (1935) Impact torsion test. 4: Impact and torsion diagrams of Armco iron, mild steel and $0.3 \% \mathrm{C}$ steel at low and high temperatures. Technol Rep Tohoku Univ 11:528-581

268. Itihara M (1936) Impact torsion test. 5: On the impact and static torsion diagrams of $0.6,0.8,1.0$ and $1.3 \% \mathrm{C}$ steels at low and high temperatures. Technol Rep Tohoku Univ 12:63-104

269. Itihara M (1936) Similarity between the stress-strain diagrams obtained from impact tensile and torsional tests. Technol Rep Tohoku Univ 12:105-118

270. Itihara M (1936) Impact- and static-torsion and bending diagrams of fatigued metals. Anniversary volume of the science reports of the Tohoku Imperial University dedicated to Professor Kotaro Honda. Tohoku Imperial University, Sendai, pp 1041-1049

271. Russell SB (1898) Experiments with a new machine for testing materials by impact. Trans Am Soc Civ Eng 39:237-272

272. Charpy G (1901) Note sur l'essai des métaux à la flexion par choc de barreaux entaillés. Mém CR Soc Ing Civ Fr 76:848-877

273. Charpy G (2000) Essay on the metals impact bend test of notched bars (translated and reprinted from 1901). In: Siewert TA, Manahan MP (eds) Pendulum impact testing: a century of progress. American Society for Testing and Materials, West Conshohocken, pp 46-69

274. Izod EG (1903) Pendulum apparatus for testing steel as regards brittleness. Engineering 76(1):418, 431-432

275. Honda K (1926) A comparison of static and dynamic tensile and notched-bar tests. J Inst Met 36:27-37

276. Honda K (1927) Theoretical considerations on static and dynamic tensile and notched bar tests. Sci Rep Tohoku Imp Univ (First Ser) 16:265-277

277. Yamada R (1928) On the relation between stress and strain in the impact test. Proc Jpn Soc Mech Eng 31:420

278. Kawai T (1930) A simple method of studying the stress-strain relation in the notched-bar impact test. Sci Rep Tohoku Imp Univ (First Ser) 19:727-743

279. Sutoki T (1930) On the stress-strain relation in the impact test. Sci Rep Tohoku Imp Univ (First Ser) 19:1-15

280. Sunaga S (1936) Drop-hammer tests on white metals. In: Anniversary volume of the science reports of the Tohoku Imperial University dedicated to Professor Kotaro Honda. Tohoku Imperial University, Sendai, pp 1088-1095

281. Bai YL, Dodd B (1992) Adiabatic shear localization: occurrence, theories and applications. Pergamon, Oxford

282. Dodd B, Bai YL (eds) (2012) Adiabatic shear localization: frontiers and advances. Elsevier, Amsterdam

283. Tresca H (1874) Sur la répartition de la chaleur développée par le choc. C R Acad Sci Paris 78:1607-1609

284. Tresca H (1874) On the distribution of the heat developed by collision. Nature 10:400-401

285. Tresca $\mathrm{H}$ (1874) On the distribution of the heat developed by collision. J Frankl Inst 98:295-297
286. Tresca H (1878) On further applications of the flow of solids. Proc Inst Mech Eng 30:301-345

287. Tresca H (1878) On further applications of the flow of solids. J Frankl Inst 106:396-404

288. Johnson W (1987) Henri Tresca as the originator of adiabatic heat lines. Int J Mech Sci 29:301-310

289. Massey HF (1921) The flow of metals during forging. In: Transactions of the Manchester Association of Engineers, pp 21-66

290. Johnson W, Baraya GL, Slater RAC (1964) On heat lines or lines of thermal discontinuity. Int J Mech Sci 6:409-414

291. Kravz-Tarnavskii WP (1928) A peculiar band discovered in steel. J Russ Metall Soc 3:162-167 (in Russian)

292. Davidenkov N, Mirolubov I (1935) Eine besondere Art derStauchdeformation von Stahl: Der Krawz-Tarnawskij Effekt. Tech Phys USSR 2:281-298

293. Rastegaev MV (1959) On a hypothesis about phase changes in 'Kravz-Tarnavskii' bands. Met Sci Heat Treat Met 1(12):21-26

294. Zener C, Hollomon JH (1944) Effect of strain rate upon plastic flow of steel. J Appl Phys 15:22-32

295. Dodd B, Walley SM, Yang R, Nesterenko VF (2015) Major steps in the discovery of adiabatic shear bands. Metall Mater Trans A 46:4454-4458

296. Dodd B, Walley SM, Yang R, Nesterenko VF (2014) Major steps in the discovery of adiabatic shear bands. http://arxiv.org/ abs $/ 1410.1353$

297. Davidenkov N (1936) Note on the torsion impact testing. Tech Phys USSR 3:577-580

298. Davidenkov NN (1936) Dynamic testing of materials. ONTI, Leningrad (in Russian)

299. Davidenkov N, Sakharov P (1938) On the influence of cold working upon the brittleness of steel. Tech Phys USSR 5:743-757

300. Davidenkov NN (1934) Allowable working stresses under impact. Trans Am Soc Mech Eng 56:97-107

301. Davidenkov N (1938) Some considerations on the impact testing problem. Proc Am Soc Test Mater 38(2):135-139

302. Hollomon JH, Zener C (1946) Problems in fracture of metals. J Appl Phys 17:82-90

303. Volterra E (1958) Obituary of Prof. R.M. Davies. Nature 181:879-880

304. Volterra E (1948) Alcuni risultati di prove dinamiche sui materiali (some results on the dynamic testing of materials). Riv Nuovo Cim 4:1-28

305. Williams I (1929) Transformation of energy by rubber. Ind Eng Chem 21:872-876

306. van Rossem A, Beverdam HB (1931) Tensile tests of vulcanized rubber at high speed. Rubber Chem Technol 4:147-155

307. Albertoni GJ (1937) Impact machine for rubber testing: determining the stress-strain diagram at high speed. Rubber Chem Technol 10:317-328

308. Church HF, Daynes HA (1938) The falling-weight impact test for ebonite. Rubber Chem Technol 11:224-233

309. Ariano R (1940) The resistance of rubber to dynamic forces. 1. Rubber Chem Technol 13:81-91

310. Roth FL, Holt WL (1940) Tensile properties of rubber compounds at high rates of stretch. Rubber Chem Technol $13: 348-360$

311. Taylor GI, Davies RM (1958) The mechanical properties of cordite during impact stressing (originally written for the Ministry of Supply of the UK Government in 1942). In: Batchelor GK (ed) The scientific papers of Sir Geoffrey Ingram Taylor, vol 1. Mechanics of solids. Cambridge University Press, Cambridge, pp 480-495

312. Kolsky H (1949) An investigation of the mechanical properties of materials at very high rates of loading. Proc Phys Soc Lond B 62:676-700 
313. Deforest AV (1939) The measurement of impact strains. In: den Hartog JP, Peters H (eds) Proceedings of the fifth international congress for applied mechanics. Wiley, New York, pp 673-676

314. Fanning R, Bassett WV (1940) Measurement of impact strains by a carbon-strip extensometer. Trans Am Soc Mech Eng 62:A24-A28

315. Bernhard RK, DeJuhasz KJ, Goodier JN, Fanning R, Bassett WV (1940) Discussion of 'Measurement of impact strains by a carbon-strip extensometer'. Trans Am Soc Mech Eng 62:A125-A127

316. Ruge AC (1943) The bonded wire gage torque meter. Proc Soc Exp Stress Anal 1(2):68-72

317. Ruge AC (1944) Strain gauge. United States Patent 2,340,146

318. Simmons EE (1944) Strain gauge and method for making same. United States Patent 2,350,073

319. Krafft JM, Sullivan AM, Tipper CF (1954) The effect of static and dynamic loading and temperature on the yield stress of iron and mild steel in compression. Proc R Soc Lond A 221:114-127

320. Barus C (1879) On the relation between the thermoelectric properties, the specific resistance, and the hardness of steel. Philos Mag (Ser 5) 8:341-368

321. Griffith AA (1921) The phenomena of rupture and flow in solids. Philos Trans R Soc Lond A 221:163-198

322. Taylor GI (1934) The mechanism of plastic deformation of crystals. Proc R Soc Lond A 145:362-404
323. Orowan E (1934) Zur Kristallplastizität. Z Phys 89:605-659

324. Polanyi M (1934) Über eine Art Gitterstörung, die einen Kristall plastisch machen könnte. Z Phys 89:660-664

325. Pochhammer L (1876) Über Fortpflanzungsgeschwindigkeiten kleiner Schwingungen in einem unbegrenzten isotropen Kreiszylinder. J reine angew Math 81:324-336

326. Chree C (1886) Longitudinal vibrations of a circular bar. Q J Pure Appl Math 21:287-298

327. Chree C (1890) On the longitudinal vibrations of aelotropic bars with one axis of material symmetry. Q J Pure Appl Math 24:340-359

328. Chree C (1899) Longitudinal vibrations in solid and hollow cylinders. Philos Mag (Ser 5) 47:333-349

329. Hopkinson B (1914) A method of measuring the pressure produced in the detonation of high explosives or by the impact of bullets. Philos Trans R Soc Lond A 213:437-456

330. Rosenhain W (1914) An introduction to physical metallurgy. Constable, London

331. Rosenhain W, Haughton JL (1935) An introduction to the study of physical metallurgy, 3rd edn. Constable, London

Publisher's Note Springer Nature remains neutral with regard to jurisdictional claims in published maps and institutional affiliations. 